\title{
Identificación de áreas prioritarias para la conservación de los recursos naturales de las subcuencas Trabunco-Quitrahue (Provincia Neuquén).
}

Tesis de Maestría presentada por Lic. DANIELA MUSCHONG ante la Facultad de Ciencias Naturales y Museo de la Universidad Nacional de La Plata para optar por el grado académico de MAGISTER EN ECOHIDROLOGIA

Director de tesis: Dr. Ramiro Sarandón

Codirector de tesis: Ing. Marcelo Gaviño

La Plata

Noviembre de 2010 
Este trabajo de tesis esta dedicado especialmente a mi familia: Juan, Catalina y Mercedes que me dieron la energía para poder finalizar esta etapa de formación. Y a mi madre que con su ayuda hizo posible que tuviera unas horas diarias para sentarme a escribir este trabajo. 


\section{Agradecimientos}

Quisiera agradecer a todas las personas que colaboraron en llevar a delante este proyecto.

A mis directores de tesis por guiarme en este camino; a mis compañeros de gabinete: Marta, Vero, Julio y Sara por sus aportes, charlas y principalmente por contribuir a un agradable ambiente de trabajo.

A mis profesores de la carrera de Ecohidrología1) y fundamentalmente a mis compañeros y amigos de promoción de la maestría, no solo por compartir durante dos años todos los viernes de sus vidas, sino también por seguir compartiendo esas interesantes charlas.

A la Secretaria de Ciencia y Técnica de la Universidad Nacional de la Plata por estos seis años de formación académica que posibilitaron concluir esta etapa. A la Municipalidad de la ciudad de San Martín de Los Andes y sus habitantes por la información brindada. 


\section{Resumen}

En muchas partes del mundo la explotación de los recursos naturales y la degradación de los recursos acuáticos, terrestres y atmosféricos, por parte de las actividades humanas causan una pérdida irreversible de la diversidad biológica. En las últimas décadas, el turismo se ha desarrollado rápidamente en las áreas de montaña en distintas partes del mundo. Este crecimiento ha dado lugar a cambios significativos tanto de tipo económico como social con consecuencias ambientales frecuentemente inesperadas. En la Argentina, este fenómeno se viene manifestando en las últimas décadas en la región patagónica. El siguiente trabajo aborda una problemática que se observa principalmente en localidades de la ecorregión de los Bosques Andino Patagónicos, y que presentan un patrón de uso del suelo que no incluye explícitamente al componente ambiental. De esta manera, el desarrollo económico, cuya actividad principal es el turismo (en la mayoría de los casos asociado a la naturaleza) y la explosión demográfica, entre otros factores antrópicos, repercute negativamente sobre los bienes y servicios que los ecosistemas aportan a esta región. Tal es así que en muchas de estas localidades comienzan a surgir importantes problemas ambientales relacionados con la degradación de los recursos naturales a nivel estructural, funcional y estético, iniciando un círculo vicioso que repercute en el estilo de vida de estas comunidades. Finalmente la falta de una política de gestión del territorio en base a pautas claras de ordenamiento territorial ocasiona la degradación de los ecosistemas, en muchos casos mediante el reemplazo de hábitats autóctonos por exóticos y a través de la contaminación de cuerpos de agua. Todos estos impactos interfieren directamente con el desarrollo de estas localidades, el cual se orienta principalmente al turismo ecológico, reflejado en sus propagandas de "villa turística ecológica" y "aldeas de montaña". Basado en este contexto regional, el trabajo desarrolla una estrategia metodológica con el fin de establecer medidas de mitigación y preventivas que sirvan como lineamientos para la gestión del uso del territorio. Específicamente se tomó como área de estudio para el desarrollo del trabajo las subcuencas de los arroyos Trabunco-Quitrahue (Neuquén). De esta manera se abordó el tema de degradación de los recursos naturales en localidades patagónicas, particularmente, a través del reconocimiento y selección de áreas sensibles y prioritarias para ser conservadas con el fin de reestabler los bienes y servicios ambientales que los ecosistemas proveen y prevenir mayores impactos sobre el ambiente. En este trabajo, la estrategia metodológica propuesta para la identificación de dichas áreas, consta de una evaluación ambiental en la cual se organiza la información y se identifican los principales conflictos del área de estudio, y posteriormente se realiza una combinación de análisis multicriterio (utilizado comúnmente en la toma de decisiones) integrado a un sistema de información geográfica, el cual le da un componente espacial, indispensable para trabajar en temas de zonificación. 
En cuanto a los resultados específicos de la evaluación ambiental se pudo establecer, que existe un riesgo de degradación de los recursos naturales concreto en las subcuencas, principalmente en los recursos agua, suelo y el bosque nativo. Esto es debido principalmente: al aumento de la densidad poblacional, el crecimiento urbano sin planificación, los episodios de deforestación, la erosión y el deslizamiento de laderas. Tales acciones traen aparejadas consecuencias específicas, como la pérdida de hábitat, como el suelo y el bosque y también la contaminación de los cursos de agua. A su vez, a través de este paso se logró definir los puntos sensibles de las subcuencas que fueron la base del modelo conceptual utilizado en el análisis multicriterio. Por otro lado se elaboraron una serie de mapas temáticos, entre ellos un mapa de tipos de coberturas de las subcuencas, un modelo digital de elevaciones, un mapa de pendientes, un mapa de suelo, un mapa de zonas geológicas críticas, entre otros, que fueron utilizados como insumos en el análisis multicriterio y forman parte del sistema de información geográfica constituido para las subcuencas. Finalmente, la herramienta metodológica clave en este trabajo fue el análisis multicriterio. Éste, constituye una de las maneras de modelizar los procesos de decisión, es decir, se ocupa de cómo combinar la información de varios criterios para formar un solo índice de evaluación. El procedimiento para un análisis multicriterio debe seguir los siguientes pasos; definir el objetivo (que en este caso es la identificar espacialmente las áreas sensibles, prioritarias para la protección de los recursos naturales de las subcuencas Trabunco-Quitrahue), elaborar un modelo conceptual del sitio óptimo (en función de características físicas, bióticas y socioeconómicas) y seleccionar los criterios y condicionantes que integrarán el análisis. Del modelo conceptual elaborado se desprendió, que las áreas de mayor sensibilidad fueron las ocupadas por coberturas boscosas, también aquellas que incentivaran la conservación del suelo y la calidad de las aguas y a su vez también deberían estar a la mayor distancia posible de caminos y centros urbanos. Estos conceptos posteriormente fueron transformados en variables y espacializados. Debido a las diferentes escalas sobre las cuales se miden las mismas, fue necesario estandarizarlos, de manera tal que todos los mapas se correlacionen positivamente para la agregación de los criterios. Posteriormente, se seleccionaron los pesos de importancia y de orden y se utilizó la formula WOWA para la combinación de los criterios. Como resultado del análisis multicriterio, concretamente, se obtuvieron seis escenarios que muestran distintas alternativas dentro del espacio de decisión, esto se traduce en áreas con diferente grado de sensibilidad o aptitud, producto del orden de agregación y peso de los criterios. A partir de los seis escenarios se analizaron las áreas de mayor sensibilidad y se vio que éstas difieren de un escenario a otro. Sin embargo, existen algunas zonas que son seleccionadas en todos los casos, o en la mayoría de los escenarios. Por lo tanto, para la generación del mapa final de áreas prioritarias de protección de los recursos naturales se realizó una combinación de los escenarios, utilizando la metodología de combinación lineal ponderada quedando un mapa con valores de sensibilidad de 0 a 100 . El mismo, se reclasificó en tres categorías, que agrupan los valores de sensibilidad de 65 a 100. Así, quedaron identificadas cuatro zonas $(A, B, C$ y $D)$ de alta 
sensibilidad para la cuenca y prioritarias para la conservación de los recursos naturales las cuales cubren una superficie de 879 hectáreas y representan el $18 \%$ de las subcuencas Trabunco-Quitrahue. La zona $A$, presenta los valores de mayor sensibilidad (entre 90 y 100) y es seleccionada en todos los escenarios, tiene una superficie de 384,4 hectáreas, esta ubicada en la subcuenca del arroyo Trabunco, aquí el índice de inestabilidad del suelo (IIS) tiene valores de medio a muy alto (de 120 hasta 250), representa pendientes muy pronunciadas, suelos poco profundos y el grado de fracturación y erosión es variable. Se encuentra a más de 3.000 metros de distancia de los caminos y zonas urbanas y la vegetación dominante esta representada por un bosque de Lenga maduro. Por estas características, este sitio es seleccionado como una de las zonas con mayor prioridad para su protección, lo que alentaría en este caso a la regeneración del bosque y el suelo, y de esta manera los servicios ecosistémicos que proveen. La zona $B$, presenta valores de sensibilidad entre 80 y 90 , es seleccionada por cuatro escenarios, tiene una superficie de 82 hectáreas, se ubica sobre la parte media de la subcuenca Trabunco. Los valores del IIS son medios a altos, se encuentra a más de 2.500 metros de los caminos y áreas residenciales, la pendiente promedio supera el $20 \%$, y el bosque comprende especies de Lenga y Ñire. En este sector, además de ser una área muy vulnerable, se encuentra contigua a la zona $A$, con lo cual se amplia la superficie total de protección de estos ecosistemas y con ello todos los beneficios que aportan para la zona de estudio. La zona $C$, presenta valores de sensibilidad de 70 a 80 . Esta ubicada en la cabecera de las subcuencas y ocupa 317 hectáreas. Presenta valores medios a altos del IIS, alejada de los barrios residenciales y caminos. La vegetación dominante es el bosque de Lenga achaparrado, propio de estas alturas. Aquí, es importante el hecho de que en esta zona se encuentran las nacientes de muchos cuerpos de aguas temporarios e intermitentes que en su posterior trayecto formaran los arroyos Trabunco y Quitrahue. La cabecera de una cuenca cumple una importante función reguladora, ya que influye en la cantidad, calidad y temporalidad del flujo de agua, protege a los suelos de ser erosionados y de la consiguiente sedimentación, previene la degradación de los arroyos y la afectación en general de los distintos ecosistemas. La zona $D$, presenta valores de sensibilidad entre 65 y 70 , es seleccionada por cuatro escenarios, y abarca dos áreas. La más pequeña ocupa 27 hectáreas, se encuentra en la parte baja de la subcuenca Trabunco, lindante al barrio Covisal. Este sector tiene el grado más alto de fracturación y erosión, pendientes pronunciadas, y por lo tanto valores elevados del IIS. La protección de este sector toma sentido por el hecho de su cercanía con el área urbana, advirtiendo un posible avance antrópico sobre esta zona tan frágil en cuanto al componente edáfico. La otra área tiene una superficie de apenas 68,5 hectáreas, esta ubicada en la subcuenca del arroyo Quitrahue entre los 1.000 y 1.300 metros s.n.m. También representa valores muy altos del IIS, con grandes pendientes, suelos con profundidad media a baja y un grado de erosión moderada. Si bien es un área alejada del área urbana, no ocurre lo mismo con los caminos ya que presenta valores cercanos a 60 metros de ellos. Aquí, la vegetación dominante es un bosque mixto. Esta zona sería interesante de proteger con el fin de evitar que futuros emprendimientos en el área aumenten la inestabilidad del suelo, que de 
por si es elevada. De esta manera, se podría implementar un plan de manejo con el fin mantener la fertilidad y estructura del suelo para permitir el buen funcionamiento del ecosistema en su conjunto. En conclusión, la estrategia metodológica utilizada permitió la selección de cuatro zonas de la cuenca que involucran diferentes ecosistemas, generando así una amplia gama de oportunidades para la mitigación y prevención de los recursos naturales. La zona $A$, contiene un bosque de Lenga maduro, con muchos individuos deteriorados y un pequeño mallín (humedal). La conservación de la zona ayudaría a la recuperación del bosque y la biota asociada, ya que una de las maneras más eficaces de controlar la dinámica de la biota es a través de la regulación de los procesos hidrológicos como por ejemplo, mediante el aumento de la retención de agua a través de la reforestación. También la protección y restauración del mallín contribuiría a mejorar el flujo de agua y nutrientes, amplificando los ciclos biogeoquímicos y a la disminución de exportación de sedimentos. La protección de la zona $D$, estaría enfocada en la recuperación del suelo y disminución de la erosión y la zona B sería complementaria a la zona $A$. Por último la zona $C$, como se mencionó anteriormente, constituye la cabecera de una cuenca boscosa y de montaña, por lo tanto, los beneficios de conservar este sector son mundialmente promovidos y reconocidos. A su vez, se propone de modo complementario, la conservación de las áreas de ecotonos y vegetación ribereña y también una serie medidas preventivas y mitigadoras que debieran de implementarse con el fin de mejorar el funcionamiento integral de las subcuencas. Alguna de ellas son: recuperar la cobertura vegetal arbórea nativa en los sectores de la cuenca alta, por medio de mecanismos que favorezcan el establecimiento de renovales de Lenga; implementar medidas para minimizar la erosión en sectores de esquí, en consenso con responsables del emprendimiento y establecer patrones de uso sustentable del suelo en aceptación con la comunidad mapuche; definir densidades urbanas en relación al grado de inestabilidad del suelo y cercanía a los cursos de agua, en consenso con las autoridades locales de SMA, empresarios inmobiliarios y autoridades del Parque Nacional Lanín; instaurar una asignación de caudales para los distintos usos en la cuenca y organizar una entidad (asociación de usuarios) de diálogo, destinado al manejo del recurso hídrico de la cuenca y efectuar un manejo adecuado en los diferentes rodales de bosque, con el fin de aumentar la producción de madera y leña para autoconsumo o para la venta, de manera de incrementar su cantidad y calidad. Finalmente, más allá del trabajo de tesis, sería importante la implementación de estas zonas prioritarias y su posterior monitoreo, de manera de evaluar si el ambiente responde positivamente a estos sitios de conservación, y poder aplicar esta metodología a otras pequeñas cuencas de la región. 


\section{Summary}

In many parts of the world natural resources exploitation and the degradation of aquatic, terrestrial and atmosphere resources, by human activities cause an irreversible loss of biological diversity. In the last decades, tourism has rapidly developed in mountainous areas in different parts of the world. This growth has given place to significant changes in the social as well as in the economical aspect with frequently unexpected environmental consequences. In Argentina, this phenomenon has been showing in the last decades in the Patagonian region. The following work addresses a problem observed mainly in the towns of the Patagonic Andes forest ecoregion, presenting a land use pattern that does not include explicitly the environmental component. So, it is like this that the economic development, with tourism as main activity (mostly related with nature) and the demographic explotion, among other antropic factors, has a negative effect over goods and services provided by the ecosystems to this region. Such is the case that in many towns many important environmental problems started to appear related with the degradation of natural resources at structural, functional and aesthetic level, initiating a vicious circle, with implications in the lifestyle of these communities. Finally, the lack of a land use policy based in clear code for spatial planning cause the degradation of the ecosystem, in many cases by means of the replacement of native habitats by exotic ones and through contamination of the water bodies. All these impacts interfere directly in the development of these towns, which orientates mainly towards ecological tourism, reflected in propaganda of "ecological tourist village" and "mountain villages". Based in this regional context, the work develops a methodological strategy with the aim of establishing mitigating and preventing measures, useful as guidelines for the land use management. Specifically the study area considered for the development of this work was the subbasins of the Trabunco-Quitrahue streams (Neuquen). By this means, degradation of the natural resources in patagonian towns is treated, mainly, through the recognition and selection of sensible and priority areas to be conserved with the aim of re-establishing environmental goods and services provided by ecosystems and to prevent major impacts over the environment. In this work, the methodological strategy proposed for the identification of such areas, implies an environmental impact assessment in which the information is organized and main conflicts are identified, lately a combination of muticriteria analysis is made (used commonly in decision making) integrated in a geographic information system, which gives the spatial component, necessary to work in zonification subjects.

Regarding the specific results of the environment assessment it was established that there is an actual risk of degradation of the natural resources in the subbasins, mainly in the water, soil and native forest resources. This is due mainly to: raise in the population density, urban growth without planification, deforestation episodes, erosion and landslides. These actions bring specific consequences, such as habitat loss as well as soil and forest loss and also the contamination of the streams. Meanwhile, through this step sensible points in the 
subbasins were defined as base of the conceptual model using the multicriteria analysis. Also a series of thematic maps were elaborated, among them a map of land cover types in the subbasins, a soil map, a geologic risk map, among others, that were used as inputs in the multicriteria analysis and are included in the geographic information system made for the subbasins. Finally the key methodological tool in this work was the multicriteria analysis. This analysis is one of the ways to model decision processes, that is, it combines the information of various criteria to form a unique evaluation index. The procedure for a multicriteria analysis must follow these steps; define the objective (in this case the spatial identification of sensible areas, priority for the protection of the natural resources of the Trabunco-Quitrahue subbasins), elaborate a conceptual model of the optimum site (according to the physical, biotic and socioeconomic characteristics) and selection of the criteria and conditionings integrating the analysis. Of the conceptual model elaborated it was concluded that the areas with the highest sensibility were occupied by forest covers, also those which achieved soil conservation and water quality as well as being as far away from roads and urban centres as possible. These concepts were later transformed in variables and specialized. Due to the different scales in which they were measured, standardization was necessary, in a way that all maps correlate positively for the aggregation of the criteria. Later the importance and order weights were selected and the WOWA formula was used for the combination of the criteria. As a result of the multicriteria analysis, six scenarios were obtained showing different alternatives within the decision space, translating in areas with different sensibility grade o product aptitude of the aggregation order and weight of the criteria. From the six scenarios areas with highest sensibility were analysed and it was observed that they varied from one scenario to the other. However some areas are selected in all the cases, or in most scenarios. Therefore, for the generation of the final map of priority areas of natural resources protection a combination of scenarios was made using the weighed lineal combination methodology giving as a result a map with sensibility values ranging from 0 to 100 , which were reclassified in three categories, grouping sensibility values from 65 to 100. Consequently four areas were identified $(A, B, C$ and $D)$ of high sensibility for the basin and priority for the conservation of natural resources, covering an area of 879 hectares and representing 18\% of the Trabunco-Quitrahue subbasins. In the area $A$, the highest values of sensibility are present (between 90 and 100), this area is selected in all the scenarios, and it has an area of 384.4 hectares, placed in the subbasin of the Trabunco stream. Here the soil instability index (SII) has values from medium to very high (from 120 up to 250), presenting very steep slopes, shallow soils and fracture and erosion grade variable. It is located at more than 3000 meters from roads and urban areas and the dominant vegetation is represented by a mature lenga forest. Because of these characteristics this site is selected as one of the areas with highest priority for conservation, promoting in this case forest regeneration and soil protection, and in this way protecting the ecosystem services they provide. The area $B$ presents values of sensibility between 80 an 90 , is selected in four scenarios, has an area of 82 
hectares, is placed in the medium part of the Trabunco subbasin. The SII values are medium to high, is places more than 2500 meters away from roads and residential areas, the mean slope is over $20 \%$ and the forest is composed of lenga and ñire species. In this sector, besides from being vulnerable, the area $A$ is contiguous, increasing the total area of protection of these ecosystems and with it the benefits provided by them to the study area. The area $C$ presents sensibility values between 70 and 80 . It is located in the headstreams of the subbasins and occupies an area of 317 hectares. It presents medium to high SII values, away from residential areas and roads. The dominant vegetation is the shrub-sized lenga forests, typical of these heights. Here the importance is given by the fact that in this area most temporary and intermittent water bodies are born giving place to the Trabunco and Quitrahue streams. The headstream of a basin plays an important role in the regulation, since it has influence on the quantity, quality and temporality of the water flow, it protects the soils from eroded and of the subsequent sedimentation, prevents the degradation of the streams and the affectation in general of the different ecosystems. The area $D$ presents sensibility values between 65 and 70 , is selected in four scenarios and includes two areas. The smaller one occupies 27 hectares, is located in the lower part of the Trabunco subbasin, next to the Covisal neighbourhood. This sector has the highest level of fracture and erosion, steep slopes, and therefore high values of SII. The protection of this sector is important since its closeness to the urban area, noticing a possible antropic advance over this fragile area regarding the soil component. The other area occupies barely 68.5 hectares, is located in the Quitrahue subbasin between 1000 and 1300 masl. It also presents very high values of SII, with steep slopes, soil with low to medium depth and a moderate level of erosion. Even though is away from urban areas, it is near from roads showing distances near 60 metres away from them. Here the dominant vegetation is the mixed forest. This area is interesting to preserve with the aim to avoid future enterprises in the area which would raise soil instability which is already high. Following this a management plan could be implemented with the aim to maintain the fertility and structure of the soil to allow the functioning of the ecosystem. In conclusion, the methodological strategy used allowed the selection of four areas in the basin involving different ecosystems creating a wide range of opportunities for the mitigation and prevention of the natural resources. The area $A$ has a mature forest of lenga, with many individuals deteriorated and a small wetland. The conservation of the area would help to recover the forest and the associated biota since one of the most effective ways to control the dynamics of the biota is by means of the regulation of the hydrological processes such as increasing water retention by reforestation. Also the protection and restoration of the wetland would contribute to improve the water and nutrient flow, amplifying the biogeochemical cycles and reducing sediment exportation. The protection of the $D$ area would be focused on soil recovery and reduction of the erosion and the $B$ area would complement the area $A$. Last, the area $C$, as mentioned before, constitutes the headstream of a woody and mountainous basin, therefore, the benefits of conserving this sector are world widely promoted and 
recognized. Moreover, as a complementary measure, the conservation of the ecotone areas and river vegetation is proposed as well as a series of preventive and mitigation measures that should be implemented to improve the integral functioning of the subbasins. Some of them are: recovery of the native forest cover in the headstream areas by means of mechanisms that favour the establishment of lenga seedlings; implantation of measures to minimize erosion in skiing areas with the consent of the enterprises responsible and establishing sustainable use patterns in agreement with the mapuche community; definition of urban densities in relation with the soil instability grade and proximity to water courses in consent with local authorities (SMA), real state managers and Lanin National Park authorities; establishment of a stream flow assignment for the different uses in the basin and organization of an entity (users association) of dialogue destined to the hydrological resources in the basin and make a proper management in the different stands of the forest with the aim to obtain more wood production for self consume or for selling, in a way that would increase quantity and quality. Finally, besides the work in this thesis, the implementation of priority areas and its subsequent monitoring would be important as to evaluate if the environment responds positively to this conservation sites and apply this methodology to other small basins in the region. 


\section{Indice general}

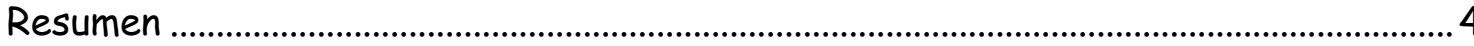

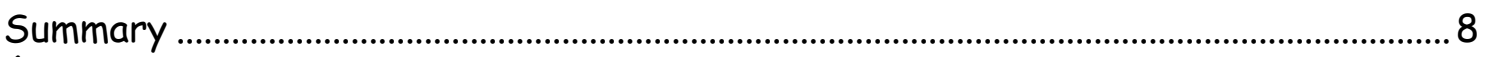

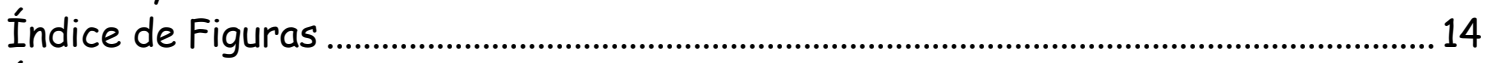

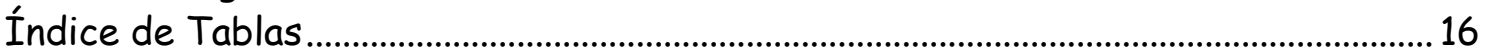

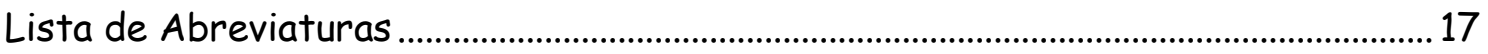

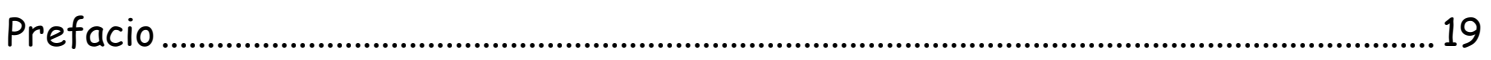

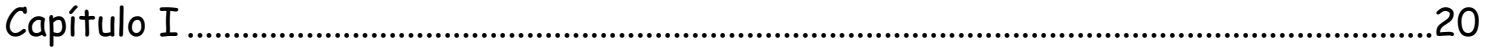

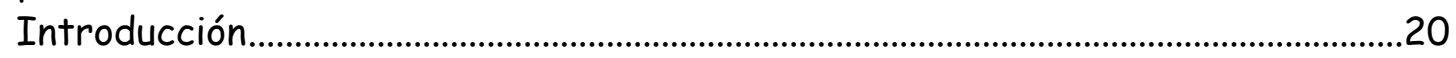

Exposición del Problema.............................................................................................20

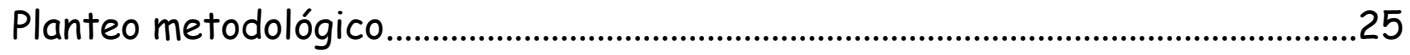

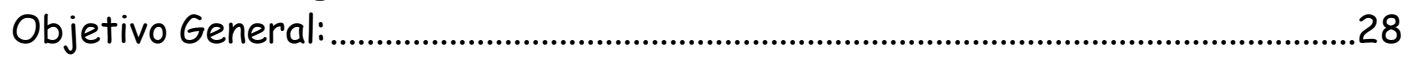

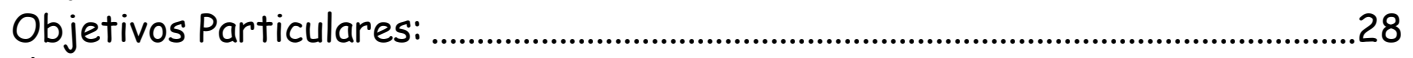

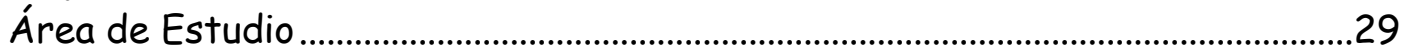

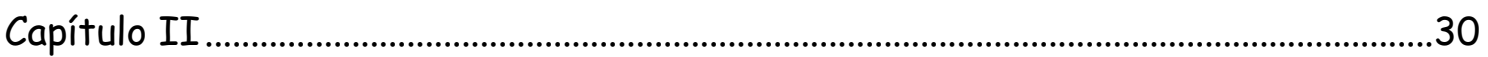

Evaluación Ambiental de las subcuencas de los arroyos Trabunco-Quitrahue.....30

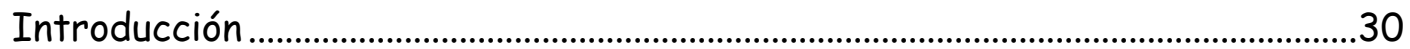

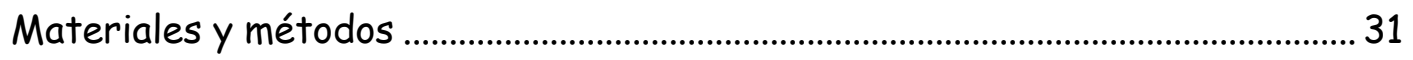

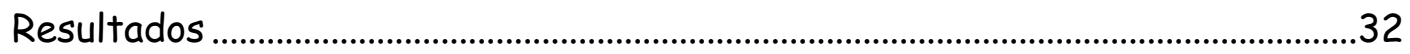

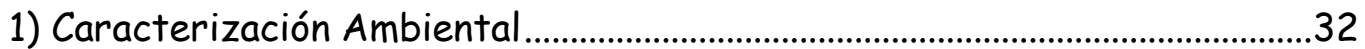

Área de estudio y primeros pobladores de la ciudad de San Martín de los

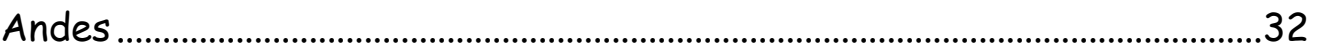

Escala Regional: la cuenca del río Hua Hum ....................................................33

Escala Local: las subcuencas de los arroyos Trabunco-Quitrahue ..............36

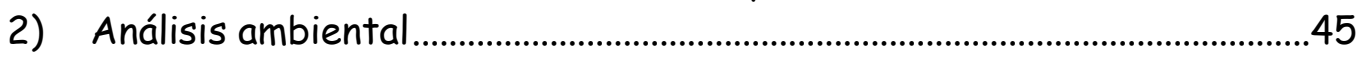

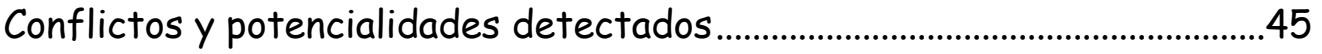

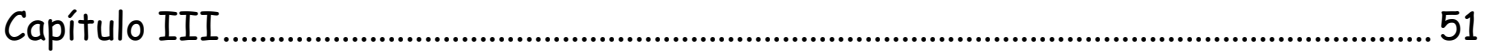

Sistema de Información Geográfica (SIG) de las subcuencas Trabunco-

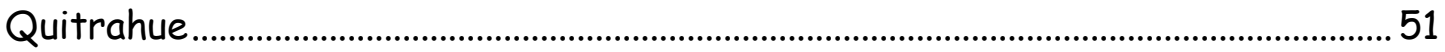

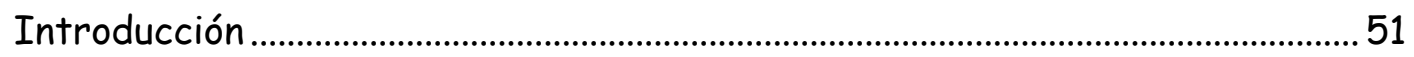

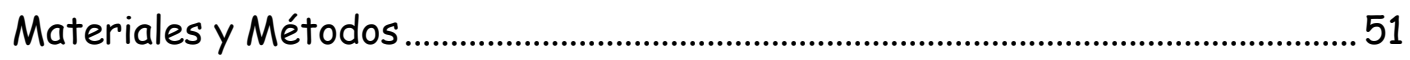

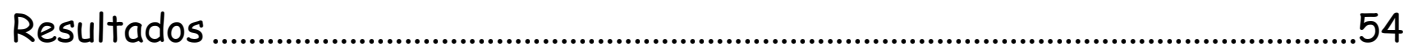

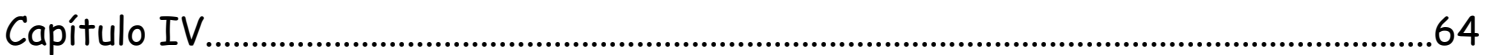

Identificación de áreas prioritarias para la protección de los recursos naturales a través de un análisis multicriterio espacializado ...................................................64

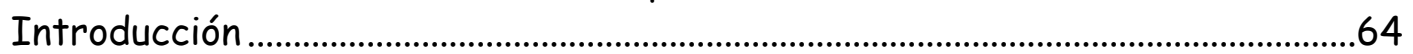

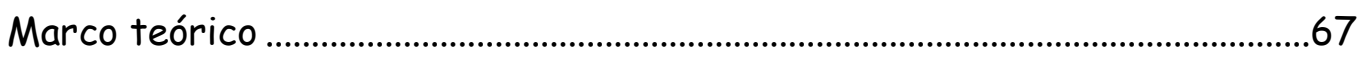

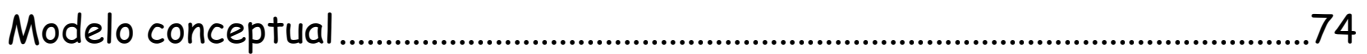

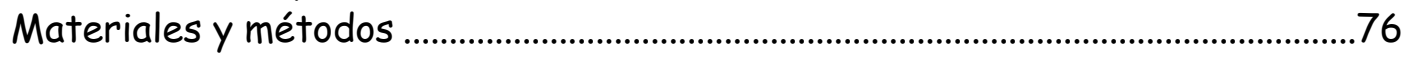

Construcción de las variables: presencia de bosque y vegetación riparia.....77

Construcción del índice de inestabilidad del suelo (IIS) .................................80

Construcción de las variables de distancia al centro urbano, caminos y

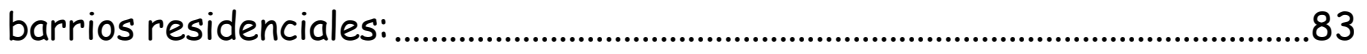

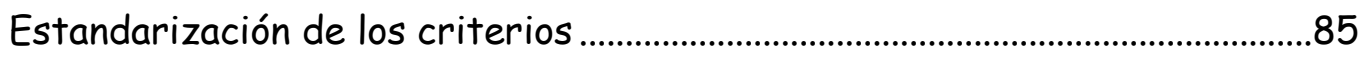

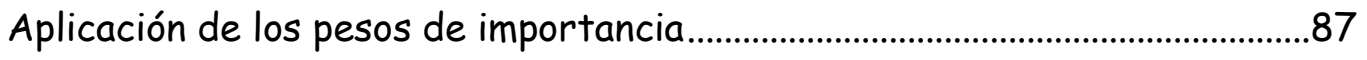




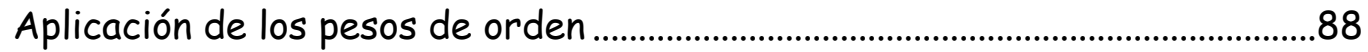

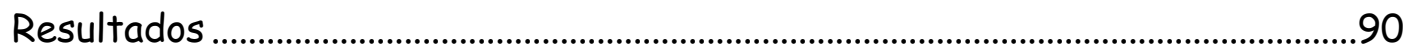

Identificación y mapeo de las áreas prioritarias para la protección de los recursos naturales de las subcuencas de los arroyos Trabunco-Quitrahue.

100

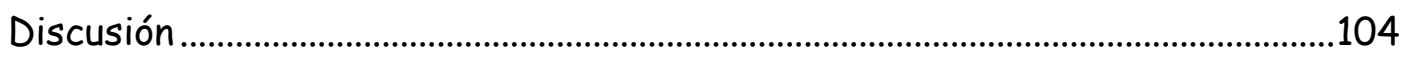

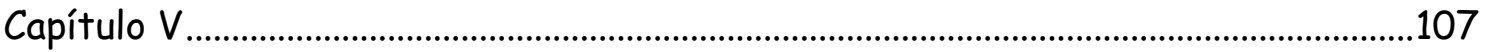

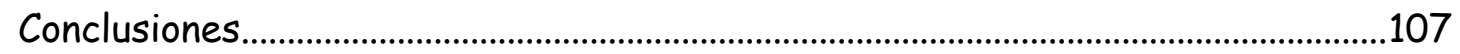

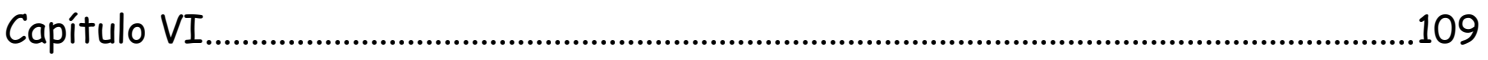

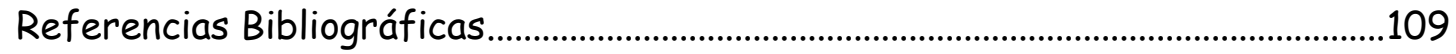

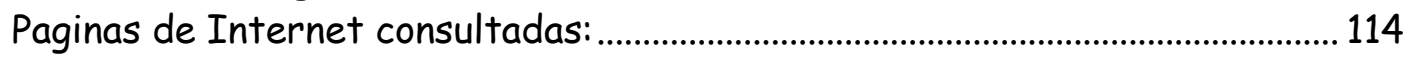

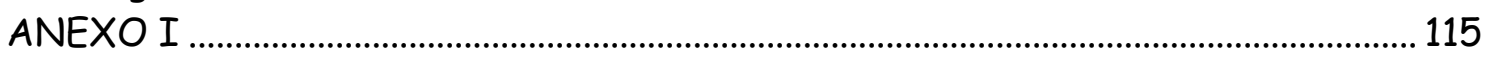

Evolución y características de los Sistemas de Información Geográfica............. 115

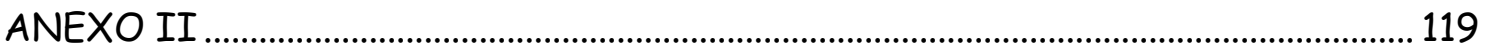

Mapa de Tipos Cobertura de las subuencas de los arroyos Trabunco-Quitrahue 119

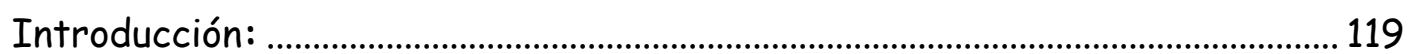

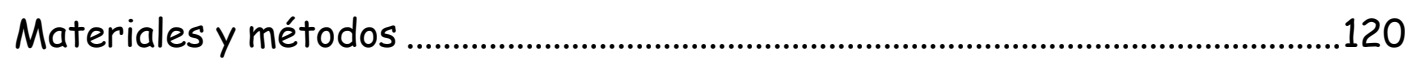

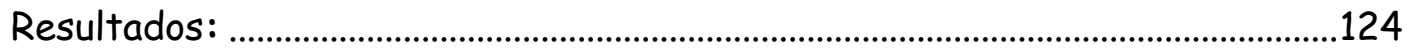




\section{Índice de Figuras}

Figura 1: Provincia de Neuquén, ecorregión de los Bosques Andino Patagónicos, detalle de la cuenca del río Hua Hum y área de estudio.

Figura 2: Diagrama de flujo del esquema planteado para las distintas localidades de la ecorregión de los Bosques Andino Patagónicos..

Figura 3: Crecimiento demográfico de algunas localidades turísticas de Neuquén. 24

Figura 4: Número de pernoctes turísticos para los años 2002 y 2005 ........................24

Figura 5: Número de plazas ofrecidas para los años 2005 y 2007 .............................25

Figura 6: Estrategia metodología a utilizar para la resolución del problema

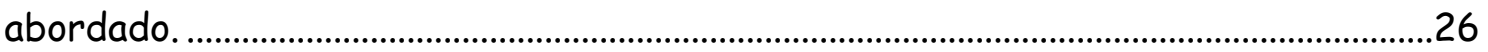

Figura 7: Subcuencas de los arroyos Trabunco-Quitrahue (Neuquén, Argentina). .29

Figura 8: Escala regional: cuenca del río Hua Hum.......................................................34

Figura 9: Climatograma de las subcuencas de los arroyos Trabunco-Quitrahue......38

Figura 10: Sitios de muestreos de agua realizados durante el año 2006..................43

Figura 11: Valores de PS y PRS de los sitios muestreados en el año 2006................44

Figura 12: Diagrama de flujo que sintetiza la EAR de las subcuencas de los arroyos

Trabunco-Quitrahue.

Figura 13: Cuadro síntesis de los pasos seguidos en la realización del DEM y modelos derivados.

Figura 14: Mapa de caminos y arroyos de las subcuencas de los arroyos Trabunco-

Quitrahue.

Figura 15: Mapa de tipos de suelo de las subcuencas de los arroyos Trabunco Quitrahue.

Figura 16: Mapa geológico de las subcuencas de los arroyos Trabunco-Quitrahue.

Figura 17: Mapa geomorfológico de las subcuencas de los arroyos Trabunco Quitrahue.

Figura 18: Mapa de zonas geológicas críticas de las subcuencas de los arroyos Trabunco-Quitrahue.

Figura 19: Mapa tipos de coberturas de las subcuencas de los arroyos TrabuncoQuitrahue.

Figura 20: Mapa de modelo digital de elevaciones de las subcuencas de los arroyos Trabunco-Quitrahue.

Figura 21: Mapa de pendientes de las subcuencas de los arroyos Trabunco Quitrahue.

Figura 22: Mapa de exposiciones de laderas de las subcuencas de los arroyos Trabunco-Quitrahue.

Figura 23: Diagrama de flujo del Análisis Multicriterio Espacial.

Figura 24: Espacio de decisión del riesgo y compensación

Figura 25: Funciones de estandarización de factores utilizadas en los análisis multicriterios. 
Figura 26: Ranking de valoración de importancia de comparación por pares de factores

Figura 27: Diagrama de flujo de los pasos que deben realizarse en el análisis multicriterio espacial de las subcuencas de los arroyos Trabunco-Quitrahue.........73

Figura 28: Capas temáticas de vegetación riparia (a) y bosque (b). ............................79

Figura 29: Mapa del índice de inestabilidad del suelo. ...................................................82

Figura 30: Mapas de las variables distancia a caminos (a) y distancia a ciudad y

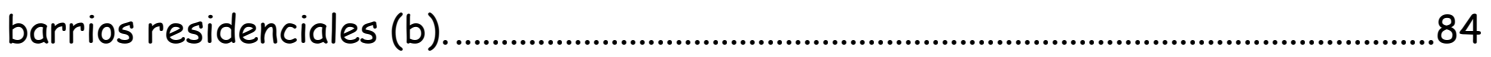

Figura 31: Estandarización del criterio IIS y puntos de control...................................85

Figura 32: Estandarización del criterio distancia a caminos y puntos de control. ..86

Figura 33: Estandarización del criterio distancia a ciudad y barrios residenciales y

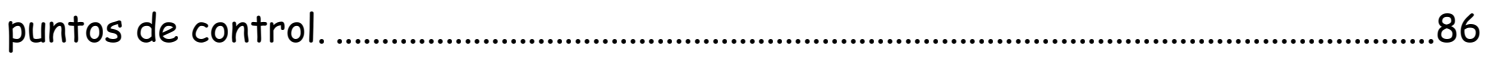

Figura 34: Mapa booleano del criterio bosque y vegetación riparia. ..........................87

Figura 35: Ubicación de los seis escenarios en el espacio de decisión. ........................89

Figura 36: Valores de aptitud, histograma y estadísticos para el Escenario 1........91

Figura 37: Valores de aptitud, histograma y estadísticos para el Escenario 2........92

Figura 38: Valores de aptitud, histograma y estadísticos para el Escenario 3........93

Figura 39: Valores de aptitud, histograma y estadísticos para el Escenario 4........94

Figura 40: Valores de aptitud, histograma y estadísticos para el Escenario 5........95

Figura 41: Valores de aptitud, histograma y estadísticos para el Escenario 6........96

Figura 42: Prioridad de protección de los distintos escenarios de las subcuencas

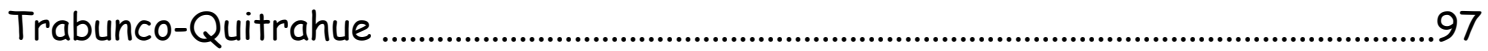

Figura 43: Superficie (en hectáreas) por categoría de prioridad de protección de los seis escenarios. . .99

Figura 44: Mapa de zonas prioritarias para la protección de los recursos naturales de las subcuencas de los arroyos Trabunco-Quitrahue. 103 


\section{Indice de Tablas}

Tabla 1: Características físicas del lago Lácar .............................................................36

Tabla 2: Valoración de algunas especies de fauna presentes a nivel regional ...........41

Tabla 3: Resultados de los muestreos de calidad de agua ............................................42

Tabla 4: Resultados de los análisis bacteriológicos.........................................................42

Tabla 5: Tipo de suelo, profundidad y pendiente media de las subcuencas de los

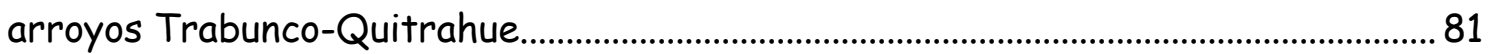

Tabla 6: Estandarización de variables para la elaboración del IIS............................... 81

Tabla 7: Matriz de comparación por pares para evaluar la importancia relativa de

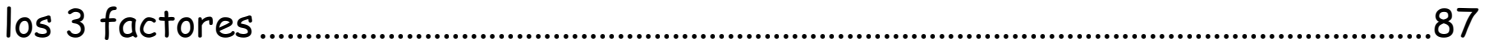

Tabla 8: Factores y pesos de importancia .........................................................................8 


\section{Lista de Abreviaturas}

AHP: proceso de jerarquía analítica

APN: administración de parques nacionales

${ }^{\circ} \mathrm{C}$ : grados centígrados

DEM: modelo digital de elevaciones

$E A$ : evaluación ambiental

EAR: evaluación ambiental regional

EEUU: Estados Unidos

GFyE: grado de fracturación y erosión de las rocas

hab.: habitantes

Ha: hectáreas

$\mathrm{hm}^{3}$ : hectómetro cúbico

IGM: instituto geográfico militar

IIS: índice de inestabilidad del suelo

km: kilómetro

$\mathrm{km}^{2}$ : kilómetros cuadrados

$\mathrm{km} / \mathrm{h}$ : kilómetro por hora

Long.: longitud

$\mathrm{m}$ : metro

$\mathrm{m}^{3} / \mathrm{s}$ : metro cúbico por segundo

Max: máxima

MCE: evaluación multicriterio

Med.: media

ml: mililitros

mm: milímetros

$\mathrm{m} \mu / \mathrm{cm}$ : microgramo por centímetro

$m \mu P / L:$ microgramo de fósforo por litro

$m \mu N / L$ : microgramo de nitrógeno por litro

msnm: metros sobre el nivel del mar

$\mathrm{N}$ : norte

$N^{\circ}$ : número

NE: noreste

$\mathrm{N}-\mathrm{NH}_{4}$ : nitrógeno de amonio

$\mathrm{N}-\mathrm{NO}_{3}+\mathrm{NO}_{2}$ : nitrógeno de nitratos y nitritos

NT: nitrógeno total

O: océano

$O D$ oxígeno disuelto

OWA: promedio ponderado ordenado

$P$ : pendiente del terreno

Pcia: provincia

PNL: parque nacional Lanín

Prof.: profundidad

PRS: fósforo reactivo soluble

PS: profundidad del suelo 
PT: fósforo total

SIG: sistemas de información geográfica

SMA: San Martín de los Andes

SST: sólidos en suspensión

UTM: Universal Transversal Mercator

WLP: combinación lineal ponderada 


\section{Prefacio}

El siguiente trabajo aborda una problemática que se observa principalmente en localidades de la ecorregión de los Bosques Andino Patagónicos, que presentan un patrón de uso del suelo que no incluye explícitamente al componente ambiental. De esta manera, el desarrollo económico, cuya actividad principal es el turismo (en la mayoría de los casos asociado a la naturaleza) y la explosión demográfica, entre otros factores antrópicos, repercuten negativamente sobre los bienes y servicios que los ecosistemas aportan. Tal es así que en muchas de estas localidades andinopatagónicas se perciben importantes problemas ambientales relacionados con la degradación de los recursos naturales a nivel estructural, funcional y estético, iniciando un círculo vicioso que repercute en el estilo de vida de estas comunidades.

De acuerdo a este contexto regional, el trabajo desarrollará una estrategia metodológica con el fin de establecer medidas de mitigación y preventivas que sirvan como lineamientos para la gestión del uso del territorio, en una cuenca hidrográfica de la ecorregión mencionada. La zona seleccionada son las subcuencas de los arroyos Trabunco-Quitrahue, Municipio de San Martín de los Andes (provincia de Neuquén), y forman parte de uno de los sitios demostrativos a nivel mundial, el programa de Ecohidrología de la UNESCO.

La tesis consta de 6 capítulos; el capítulo 1 abarca la introducción, en la que se establece la problemática, se enuncia la metodología y objetivos del trabajo y se hace una referencia al área de estudio.

En los capítulos 2, 3 y 4 se desarrolla la estrategia metodológica, la cual esta estructurada básicamente en tres pasos encadenados y relacionados entre si: una evaluación ambiental regional, un sistema de información geográfica y un análisis multicriterio. Cada uno de estos pasos constituye un capítulo, organizado en introducción, objetivos, materiales y métodos y resultados.

En el capítulo que describe la evaluación ambiental regional se incluye una caracterización ambiental a nivel regional y local, un análisis ambiental que permite detectar los principales conflictos y potencialidades de las subcuencas en estudio. En el capítulo 3 se define la base de datos espacializada, es decir, se construyen diversos mapas temáticos que sirven de insumo para el desarrollo del capítulo 4, en el cual se aplica un análisis multicriterio, que culmina en un mapa de áreas prioritarias para la protección de los recursos naturales de la zona estudiada.

En el capítulo 5 se presentan las conclusiones generales del trabajo y una serie de lineamientos estratégicos para la gestión de uso del suelo, basados en los resultados y conclusiones de los capítulos anteriores. Finalmente el capítulo 6 enumera la bibliografía utilizada en este trabajo de tesis. 


\section{Capítulo I}

\section{Introducción}

\section{Exposición del Problema}

En muchas partes del mundo la explotación de los recursos naturales y la degradación de los recursos acuáticos, terrestres y atmosféricos, por parte de las actividades humanas causan una pérdida irreversible de la diversidad biológica (Vitousek et al., 1986; Daily y Cobb, 1989).

En las últimas décadas, el turismo se ha desarrollado rápidamente en las áreas de montaña en distintas partes del mundo. Este crecimiento ha dado lugar a cambios significativos tanto de tipo económico como social con consecuencias ambientales frecuentemente inesperadas.

La creciente demanda de espacios para fines turísticos y recreativos en áreas protegidas surge de un público ávido por conocer y visitar ambientes naturales, traduciéndose esto en una fuerte presión, para la apertura y puesta en valor de nuevos espacios (Otero y Gallego, 2008).

En la Argentina, este fenómeno se viene manifestando en las últimas décadas en la región patagónica, principalmente en la ecorregión de los Bosques Andinos Patagónicos (Burkart et al., 1999). Esta región (Figura 1) presenta atributos que la hacen única, tales como la inmensidad, lo natural, y densidades humanas muy bajas.

Sin embargo, junto a las características antes mencionadas, comienza a gestarse en 1960, en la ciudad de Neuquén (Figura 1), un proceso de crecimiento para luego transformarse en el principal centro de actividades económicas del Alto Valle del Río Negro y Neuquén. A partir de la década del 70, Neuquén empieza a consolidarse como un importante centro de servicios de la norpatagonia y centro turístico de escala de las corrientes turísticas que tienen como destino la ecorregión de los Bosques Andino Patagónicos.

Este fenómeno trajo importantes inversiones principalmente en obras públicas, orientadas fundamentalmente a infraestructura social, planes de viviendas, escuelas, hospitales, entre otros. Evidentemente todas las políticas del estado benefactor fueron insuficientes ante la fuerte inmigración que se produjo en la 
provincia. La tasa de crecimiento poblacional se fue duplicando año a año, generando numerosos impactos (Suárez y Olivares, 2006).

En las pequeñas localidades turísticas del interior de la provincia de Neuquén (Figura 1), unas décadas más tarde comienzan a reflejarse diversas problemáticas ambientales, producto principalmente de tres condiciones: el acelerado crecimiento poblacional, su importante desarrollo como centros turísticos y la falta de políticas de desarrollo y planificación territorial.

Estas localidades exhiben características comunes particulares, fueron expuestas al mismo proceso de crecimiento y desarrollo; y consecuentemente respondieron frente a esto de manera semejante.

Con estas particularidades, nos referimos a localidades pequeñas, de baja densidad poblacional, de zonas montañosas, con relieves pronunciados, bosques autóctonos, lagos ultraoligotróficos y ríos de deshielo, flora y fauna con varias especies endémicas, generalmente lindantes a un área natural protegida y cuya actividad principal es el turismo y en menor medida la agricultura, la ganadería y/o actividad forestal.

Al consolidarse la ecorregión de los Bosques Andino Patagónicos como un destacado destino turístico, comienza en estas localidades una importante inmigración que desencadena un aumento de la densidad poblacional y por ende un crecimiento urbano desorganizado y como consecuencia un incremento en la infraestructura y servicios (agua potable, cloaca, recolección de basura, etc).

Finalmente la falta de una política de gestión del territorio en base a pautas claras de ordenamiento territorial generó un proceso de degradación de los ecosistemas, en muchos casos mediante el reemplazo de hábitats autóctonos por exóticos y contaminación de cuerpos de agua. Es decir que lo que esta aconteciendo no es otra cosa que la pérdida de bienes y servicios ecosistémicos. Los servicios que proporciona la naturaleza se conocen como "servicios ecosistémicos" y se definen como las condiciones y procesos que genera la naturaleza y que son indispensables para el soporte de la vida humana (Daily, 1997). 


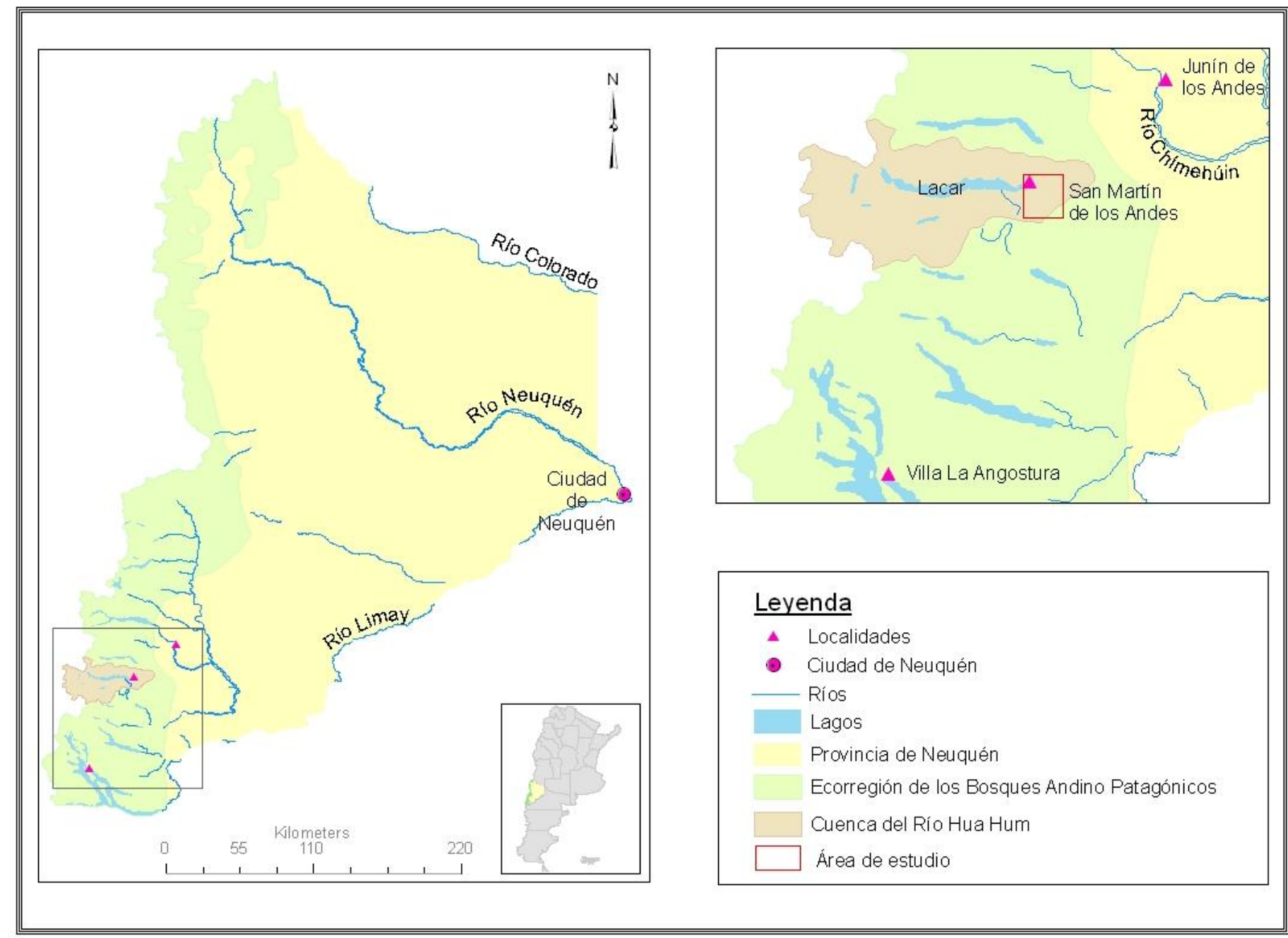

Figura 1: Provincia de Neuquén, ecorregión de los Bosques Andino Patagónicos, detalle de la cuenca del río Hua Hum y área de estudio. 
Este patrón de uso del suelo sin la incorporación de los aspectos ambientales se vio repetido, como ya se dijo, en distintas localidades a lo largo de la ecorregión Andino-Patagónica, desde San Martín de los Andes, Junín de los Andes, Villa La Angostura y también en localidades de provincias vecinas como San Carlos de Bariloche o El Bolsón en la provincia de Río Negro. En la figura 2 se observa un diagrama de flujo que resume el esquema planteado.

Aumento de la densidad poblacional

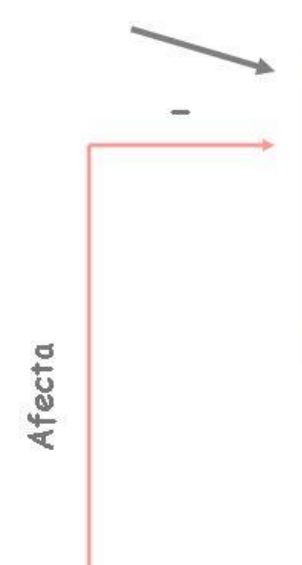

\section{de} de los Bosques Andino Patagónicos (Estilo aldeas de montaña)

Zonas de valiosos paisajes naturales Dedicadas a la actividad turística

Falta de políticas de desarrollo y planificación territorial

$\uparrow$ Infraestructura y Servicios $+$

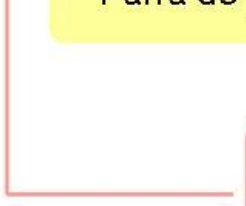

\author{
Aumento de la \\ demanda turística
}

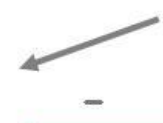

(n)




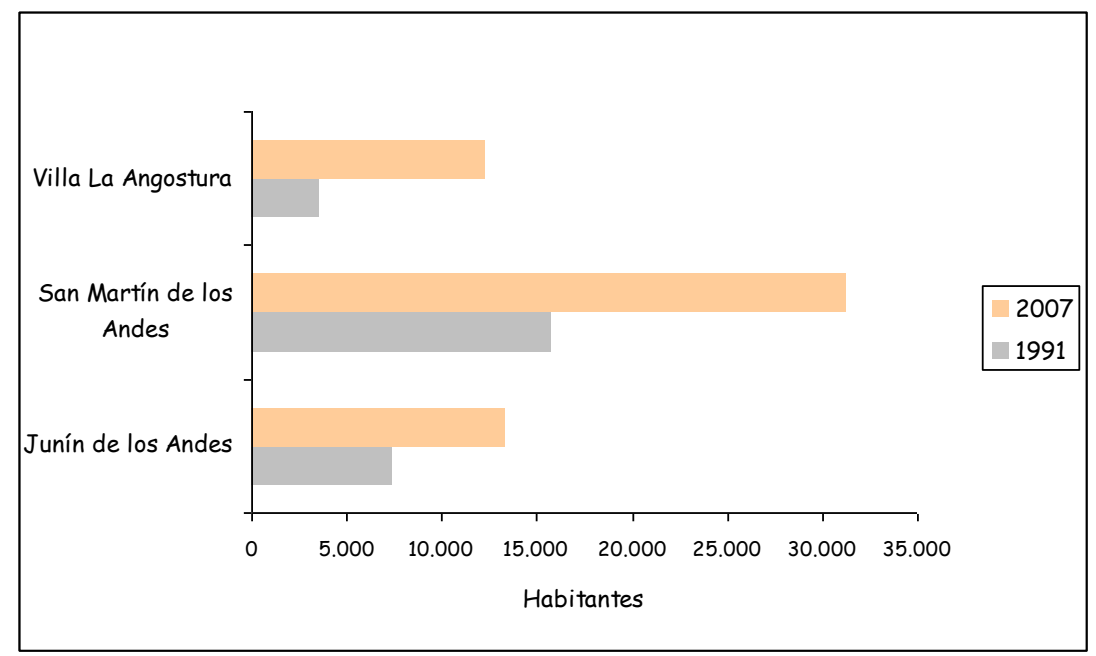

Figura 3: Crecimiento demográfico de algunas localidades turísticas de Neuquén.

En cuanto al crecimiento turístico se puede observar en las localidades de San Martín de los Andes y Villa La Angostura que, en sólo tres años (2002 - 2005) hubo un importante incremento de los pernoctes turísticos (Figura 4), lo mismo ocurrió a nivel de plazas ofrecidas en estas localidades, ya que, como se observa en la figura 5 , se incrementaron en un $16 \%$ en un periodo de dos años.

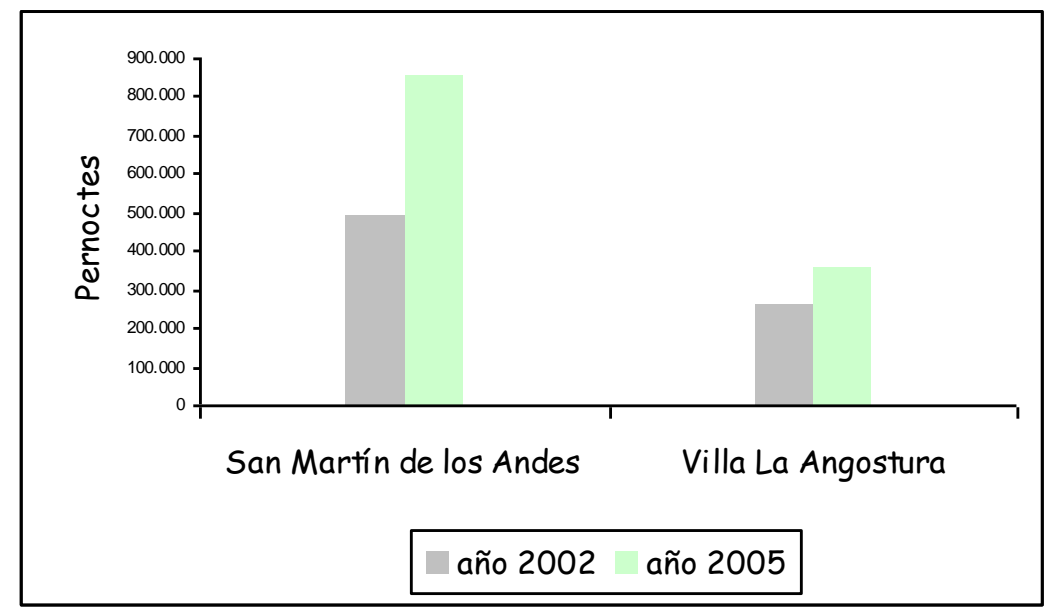

Figura 4: Número de pernoctes turísticos para los años 2002 y 2005. 


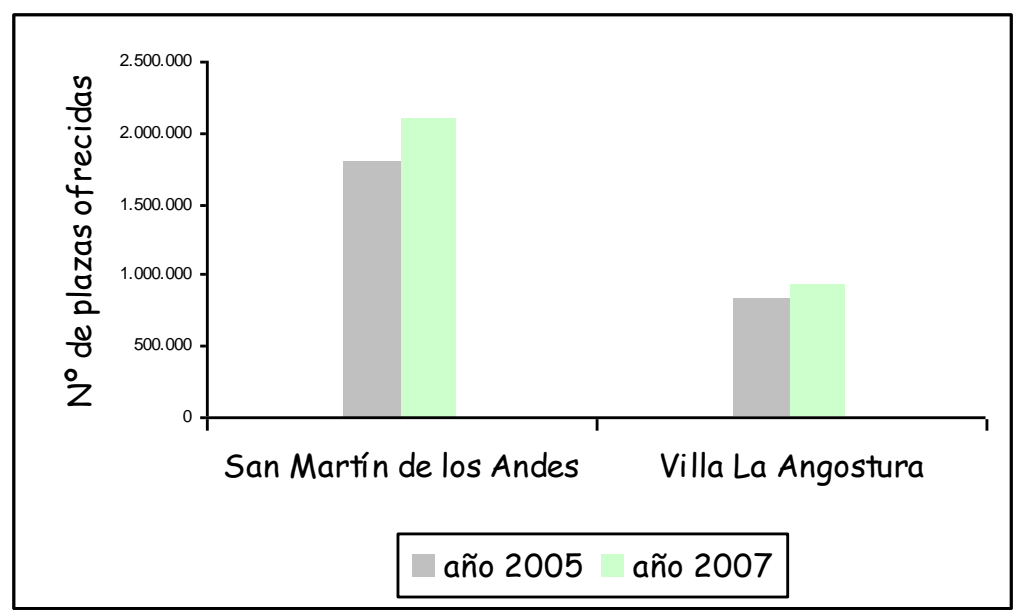

Figura 5: Número de plazas ofrecidas para los años 2005 y 2007.

Este crecimiento ha resultado en una mayor presión sobre los recursos naturales, repercutiendo sobre el medio ambiente. Esto se vio manifestado en los distintos episodios de contaminación de los recursos hídricos de la región, como por ejemplo la contaminación del Río Chimehuín (Junín de los Andes), el lago Lácar y arroyos de la cuenca Pocahullo (San Martín de los Andes) y Río Bonito (Villa La Angostura).

Tal es así que durante la última década el tema se vio reflejado en los medios de comunicación locales y también en el desarrollo de planes y estrategias para el saneamiento y monitoreo de los arroyos de la zona. Todos estos impactos interfieren directamente con el enfoque de desarrollo de estas localidades, el cual se orienta principalmente al turismo en contacto con la naturaleza, manifestado en sus propagandas de "villa turística ecológica" y "aldeas de montaña". Es decir que el impacto sobre el ambiente al cabo de unos años terminará repercutiendo negativamente en la actividad turística, basada en los atributos naturales y paisajísticos de estos ambientes.

Esta situación no es exclusiva de la región, sino que está generalizada a nivel global. Es reconocido actualmente que en todo el planeta los recursos naturales están sujetos cada vez más a una gran presión inducida por el hombre. Para hallar soluciones conciliando los objetivos de producción, desarrollo y protección ambiental, es importante que haya una amplia comprensión de las interacciones que existen entre el hombre y los ecosistemas.

\section{Planteo metodológico}

Abordada esta problemática, este trabajo se enfocará en el desarrollo de una estrategia metodológica basada en una sucesión de pasos (Figura 6) que concluirán principalmente en una serie de recomendaciones estratégicas basadas en medidas mitigatorias como así también preventivas para el medio ambiente. 


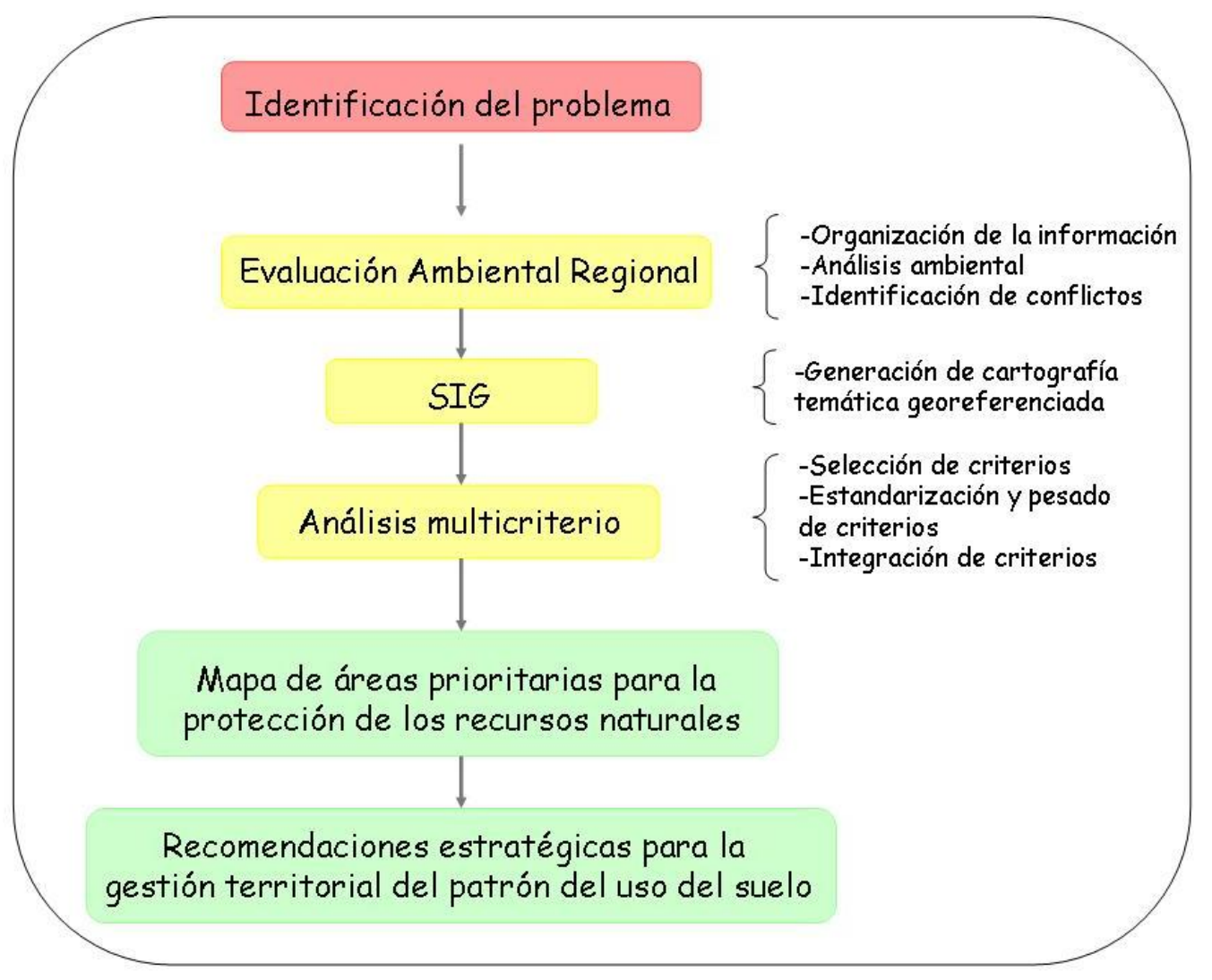

Figura 6: Estrategia metodología a utilizar para la resolución del problema abordado.

Una de las formas de mitigación más tradicionales es la conservación de áreas naturales y también el establecimiento de zonas con diferentes grados de vulnerabilidad y sensibilidad. El propósito de la mitigación es la reducción de la vulnerabilidad, es decir, un conjunto de medidas que se pueden tomar para contrarrestar o minimizar los impactos ambientales negativos que pudieran tener algunas intervenciones antrópicas. La asignación de unidades de tierra para usos específicos, conocido como zonificación, es una opción útil para mitigar los conflictos y una herramienta clave para la administración de áreas naturales (Walther, 1986).

Para abordar una problemática ambiental, un punto crucial es la integración de la información específica de un lugar referenciada por varias disciplinas (agricultura, silvicultura, edafología, hidrología, etc.) con la información sobre el contexto y las dinámicas culturales, sociales y económicas. Para ello las evaluaciones ambientales son una herramienta útil a la hora de organizar esta información, realizar un análisis del área y emitir un diagnóstico acerca de los conflictos ambientales que se desarrollan en un sitio determinado.

Igualmente, la combinación de toda la información es ideada como un proceso de aprendizaje de todos los actores y sienta las bases para procesos equitativos de planificación, negociación y toma de decisiones. Esto sólo puede tener éxito si la 
información se transmite efectivamente a los actores y si los conocimientos se comparten igualitariamente, mejorándose así la transparencia y la confiabilidad.

Un aspecto importante en la planificación de la conservación, es la selección y evaluación de áreas de conservación mediante un conjunto de criterios. La capacidad de los Sistemas de Información Geográfica (SIG) en el manejo de los aspectos espaciales de la conservación ha impulsado el uso del análisis multicriterio para la evaluación, priorización y selección de zonas potenciales de conservación.

Es a partir de 1990 que comienzan a utilizarse las capacidades de los SIG integradas a la toma de decisiones multicriterios, (Mui Hou y Minoura, 2004). Los análisis multicriterios pueden utilizarse para mejorar la planificación ambiental en un contexto territorial al incluir las variables ambientales espacializadas en un SIG a fin de facilitar la toma de decisiones sobre los usos potenciales de un territorio (Ascough et al., 2002).

Por lo expuesto, este trabajo aspira abordar una problemática regional a través de una estrategia metodológica que pueda ser aplicada a nivel local, pero que a su vez sirva para ser aplicada en localidades con características y problemáticas similares como ocurre en la ecorregión de los Bosques Andino Patagónicos.

Se intentará afrontar el tema de degradación de los recursos naturales en localidades patagónicas a través de la mitigación, específicamente, estableciendo áreas sensibles, vulnerables o de prioridad para ser conservadas y poder reestablecer de esta forma, los bienes y servicios ambientales que los ecosistemas proveían y conjuntamente prevenir mayores impactos sobre el ambiente.

En este estudio se propone una estrategia metodológica para la identificación de dichas áreas, a través de una evaluación ambiental en la cual se organiza la información y se identifican los principales conflictos, y posteriormente se realiza una combinación de análisis multicriterio (utilizado comúnmente en la toma de decisiones) integrado a un SIG, el cual del da un componente espacial indispensable para trabajar en temas de zonificación.

La selección del área de estudio es una cuenca tipo de la ecorregión mencionada, las subcuencas de los arroyos Trabunco-Quitrahue de la ciudad de San Martín del los Andes. La elección de este sitio es debida a varias cuestiones que lo hacen recomendable para el desarrollo de este tipo de trabajos. Por un lado constituye uno de los Sitios Demostrativos del Programa de Ecohidrología de la UNESCO, y también es propulsado por la Universidad Nacional de La Plata, como consecuencia de ello se cuenta con abundante información al respecto.

Otra cuestión es el hecho de utilizar a la cuenca hidrográfica como objeto de estudio y no a la ciudad u otra unidad administrativa por las siguientes razones. La 
cuenca hidrográfica constituye la principal unidad territorial donde el agua, proveniente del ciclo hidrológico, es captada, almacenada, y descargada mediante escurrimiento. En este ámbito se produce una estrecha interdependencia entre los sistemas biofísicos y el sistema socio-económico.

Aunque existan otras unidades político-administrativas que deben ser consideradas como las provincias, municipios, etc.; estas unidades no presentan necesariamente el carácter integrador de la cuenca. El recurso hídrico es una resultante que sintetiza a través de su régimen hídrico y de las características de la calidad del agua, tanto las condiciones naturales de la cuenca como los efectos de las intervenciones del hombre sobre la misma, razón por la cual constituye un indicador importante de la salud de los ecosistemas acuáticos y terrestres (Calcagno, 2003).

Por esta razón, y a fin de efectuar una adecuada gestión de los recursos naturales a nivel de la cuenca, es necesario establecer patrones de uso del territorio que aseguren el adecuado funcionamiento de los ecosistemas naturales y antrópicos presentes en la misma. Esto implica asignar usos alternativos del suelo a determinadas porciones del territorio en función de sus características y potencialidades naturales.

\section{Objetivo General:}

Identificar áreas prioritarias para la conservación de los recursos naturales de las subcuencas de los arroyos Trabunco-Quitrahue (provincia de Neuquén, $R$. Argentina).

Objetivos Particulares:

(C) Elaborar una evaluación ambiental regional determinando los principales conflictos y potencialidades de las subcuencas de los arroyos TrabuncoQuitrahue.

(e) Identificar y mapear las áreas prioritarias para la conservación de los recursos naturales, basado en un modelo de evaluación multicriterio a escala de subcuencas.

(C) Efectuar recomendaciones para apoyar la gestión de las subcuencas en base a evidencia científica. 


\section{Área de Estudio}

El área de estudio son las subcuencas de los arroyos Trabunco-Quitrahue (Figura 7), ubicada en el departamento Lácar (provincia de Neuquén, R. Argentina). Está comprendida entre los paralelos $40^{\circ} 15^{\prime}$ y $40^{\circ} 23^{\prime}$ de Latitud Sur y los meridianos $71^{\circ} 25^{\prime}$ y $71^{\circ} 36^{\prime}$ de Longitud Oeste, y forma parte de la cuenca del río Hua Hum, gran parte de la cual se ubica dentro del Parque Nacional Lanín.

Estas pequeñas subcuencas tienen una superficie total de 4.927 hectáreas, forman parte del ejido de San Martín de los Andes y constituyen un nexo entre la zona urbana y centro de deportes invernales Chapelco. Es un área compleja, ya que en ella se realizan diferentes usos del territorio: actividades rurales, recreativas y principalmente turísticas.

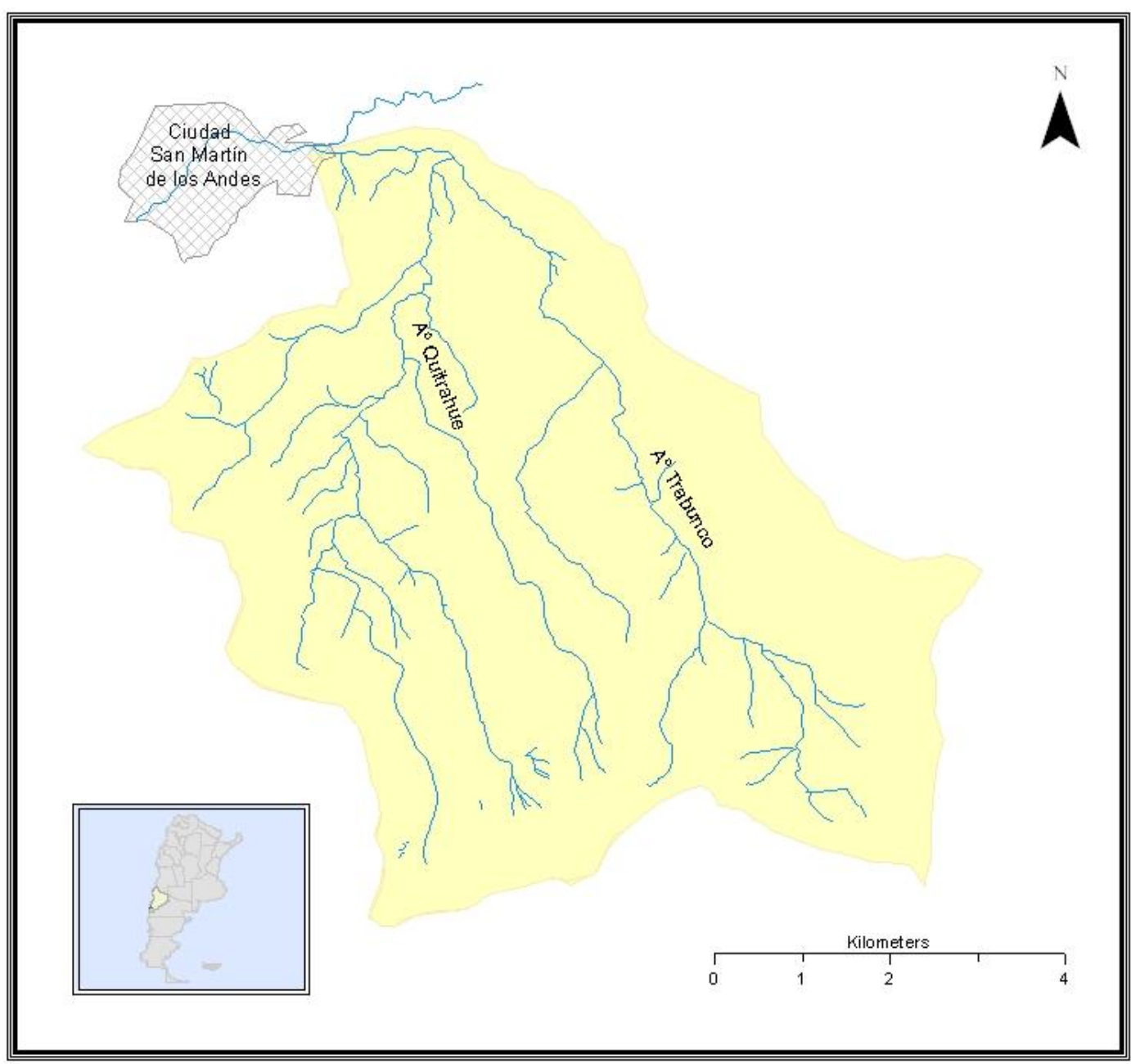

Figura 7: Subcuencas de los arroyos Trabunco-Quitrahue (Neuquén, Argentina). 


\section{Capítulo II}

\section{Evaluación Ambiental de las subcuencas de los arroyos Trabunco-Quitrahue}

\section{Introducción}

Las Evaluaciones Ambientales (EA) proveen información estructurada y organizada para la toma de decisiones sobre el manejo de sistemas ecológicos y ambientales (Sarandón, 2000). Es, en consecuencia, una de las herramientas fundamentales de la gestión ambiental (Sarandón et al., 2003) especialmente útiles en el contexto de las evaluaciones de impacto ambiental y de la planificación de usos del territorio (Gaviño y Sarandón, 2002).

Cuando la EA se define espacialmente en relación a una unidad natural (cuenca hidrográfica) y/o antrópica (municipio, área natural protegida) se denomina Evaluación Ambiental Regional (EAR).

Las EAR son estudios ambientales que también pueden realizarse cuando existen propuestas de varias actividades de desarrollo en una región determinada. Son útiles para definir el área natural de estudio; para seleccionar modelos de desarrollo entre distintas alternativas; para la identificación de impactos ambientales acumulados o cruzados (entre proyectos simultáneos en la misma zona), y definición de medidas para evitarlos o atenuarlos; para la identificación de interacciones ambientales o conflictos entre varios proyectos, en los cuales los impactos de un proyecto podrían reducir los beneficios de otros; para la formulación de criterios a incluir en los proyectos particulares, permitiendo la identificación de áreas sensibles; y para la selección de sitios y lineamientos para la planificación del uso de la tierra (Banco Mundial, 1991; CEPAL/ILPES/PNUMA, 1986).

Las EAR son empleadas también cuando ciertas actividades de desarrollo son planificadas para un área relativamente reducida y cuyos impactos son potencialmente acumulativos. El área de estudio es normalmente definida basándose en consideraciones físicas y/o biológicas (área climática, tipo de hábitat, cuenca de un río, fronteras), sirven además para la identificación de vacíos de información, la definición de programas de seguimiento y control ambiental y la identificación de elementos políticos e institucionales para lograr el desarrollo sustentable en la región de análisis (Sarandón et al., 2002). 
Si bien las EAR, pueden aplicarse a unidades políticas o institucionales, como un municipio o un área natural protegida, es preferible que se apliquen a unidades naturales como una cuenca hidrográfica, ya que ellas son unidades de planeamiento del territorio apropiadas para la gestión de los recursos naturales.

La finalidad de las EAR es facilitar la identificación de áreas homogéneas, la zonificación ambiental, y la identificación de áreas críticas, siendo especialmente útiles para la planificación de usos en el territorio (Sarandón, 1997; Sarandón et al., 1997; Sarandón et al., 1999; Guerrero Borges et al., 1999; Gabellone et al., 2003).

El objetivo de la evaluación ambiental es identificar los conflictos y potencialidades más relevantes que presenta el área, así como también, organizar la información disponible para la generación de una línea de base ambiental.

\section{Materiales y métodos}

Las subcuencas de los arroyos Trabunco-Quitrahue han sido objeto de estudios multidisciplinarios desde hace unos 15 años entre ellos se encuentran: el Convenio entre la Dirección de Recursos Hídricos y la Municipalidad de San Martín de los Andes (Convenio DNRRHH-SMA, 1994); la creación del Comité Consultivo Técnico para el saneamiento del lago Lácar (1992), también forma parte del Sitio Demostrativo del Programa Regional de Ecohidrología -Programa Internacional de UNESCO.

De esta manera se encuentran disponibles varios planes y estudios específicos del área, con diferente grado de detalle del ambiente natural y socioeconómico. Algunos de estos documentos son:

- Plan de Muestreo de la cuenca del arroyo Pocahullo y lago Lácar (1992), con el fin de conocer la situación sanitaria y estado trófico de los mismos.

- Plan de Sistematización de los arroyos Trabunco-Quitrahue. Convenio Secretaria de Obras Públicas y Comunicaciones de la Nación- Dirección Nacional de Recursos Hídricos y Municipalidad de San Martín de los Andes (1995) Provincia de Neuquén.

- Relevamiento Topográfico de los arroyos Pocahullo, Trabunco y Calbuco, Plan de sistematización de la cuenca Lacar- río Hua Hum, Dirección de Gestión Ambiental. Municipalidad de San Martín de los Andes (Damiáni, 1999).

En cuanto a la metodología empleada, la EA esta organizada en dos bloques principales:

1) Caracterización ambiental, la cual esta estructurada en tres partes: la primera hace referencia al área de estudio y sus pobladores, la segunda corresponde a un 
breve análisis a escala regional representada por la cuenca del río Hua Hum y la tercera parte, un análisis a una escala local: las subcuencas de los arroyos Trabunco-Quitrahue en la que se determinan los aspectos biofísicos y socioeconómicos.

2) Análisis ambiental, en el que se identifican los principales conflictos y potencialidades del área.

La metodología utilizada para la caracterización ambiental, fue principalmente la recopilación bibliográfica a través de diversas publicaciones, planes de manejo y estudios específicos de la zona, así como también se utilizó información reunida a partir de charlas y entrevistas informales con los pobladores de la zona, realizada durante dos viajes de campaña. Para el análisis ambiental se identificaron y definieron los conflictos y potencialidades de la zona y se elaboró un diagrama de flujo que sintetiza la situación de las subcuencas.

\section{Resultados}

\section{1) Caracterización Ambiental}

\section{Área de estudio y primeros pobladores de la ciudad de San Martín de los Andes}

El área de estudio comprende las subcuencas de los arroyos Trabunco-Quitrahue, forma parte de la cuenca del río Hua Hum. La misma se encuentra formando parte del ejido de San Martín de los Andes.

Se ubica en el departamento Lácar, gran parte de la cual se sitúa dentro del Parque Nacional Lanín. El departamento tiene una superficie de $4.710 \mathrm{~km}^{2}$ y su densidad poblacional es de $5 \mathrm{hab}$. $/ \mathrm{Km}^{2}$. Su localidad cabecera es la ciudad de San Martín de los Andes.

El valle donde hoy se asienta la ciudad fue habitado durante cientos de años por distintas comunidades indígenas, Pehuenches, Mapuches y otros. Eran cazadores recolectores, y tenían una organización social muy desarrollada. En 1883 llegan por primera vez tropas del Ejército Argentino a lo que hoy conocemos con el nombre de Vega Maipú. No hubo enfrentamientos con las comunidades que habitaban el valle, sino que se firmaron acuerdos de paz.

En 1898 se funda San Martín de los Andes, la última ciudad fundada en el marco de la campaña al desierto. Nacida como un destacamento militar, los primeros civiles eran los prestadores de servicios del ejército. Posteriormente el entorno boscoso 
permitió a colonos europeos el desarrollo de la industria maderera, mientras que en la zona de la vega, se desarrollaba la agricultura y la ganadería.

En 1937 se crea el Parque Nacional Lanín, con el fin de reservar las especies autóctonas para el aprovechamiento de las futuras generaciones. Es así como se restringe casi por completo la industria maderera. Para ese entonces esa era la principal actividad económica de la región.

La Administración de Parques Nacionales comienza a promover el turismo en la región. Se promociona el turismo de verano, con los atractivos naturales como primera motivación.

En 1963 se instala la primera silla doble como medio de elevación en el Cerro Chapelco. El esquí era practicado por los pobladores desde 1940, pero fue la instalación de este medio la que permitió el desarrollo como centro de esquí.

A partir de este momento San Martín de los Andes se perfila como un importante centro turístico, con los Parques Nacionales en verano, y el esquí en el invierno. Este desarrollo económico fomenta la migración desde las grandes ciudades y en la década del 80 al 90 la ciudad crece a razón de 1.000 habitantes por año.

\section{Escala Regional: la cuenca del río Hua Hum}

La cuenca del río Hua Hum se encuentra en el departamento Lacar, Neuquén (Figura 8). En el 2004 la población estimada para este departamento era de 26.090 habitantes (según Dirección General de Estadísticas y Censos de Neuquén) y la principal fuente de ingresos el turismo y la actividad forestal.

La cuenca es una depresión de forma alargada en dirección este-oeste, resultado de la acción glaciaria del pleistoceno. En su interior se encuentra el lago Lácar ubicado a $630 \mathrm{~m}$ snm. El largo aproximado es de $22 \mathrm{~km}$. y su ancho 3,5 km., continuándose al este con las vegas de San Martín de los Andes y Maipú. Al oeste se encuentra el lago Nonthue, como una prolongación natural del Lácar. Allí nace el río Hua Hum que desemboca en el océano Pacífico, a través del río Valdivia (Convenio DGRH- UNLP, 1996). 


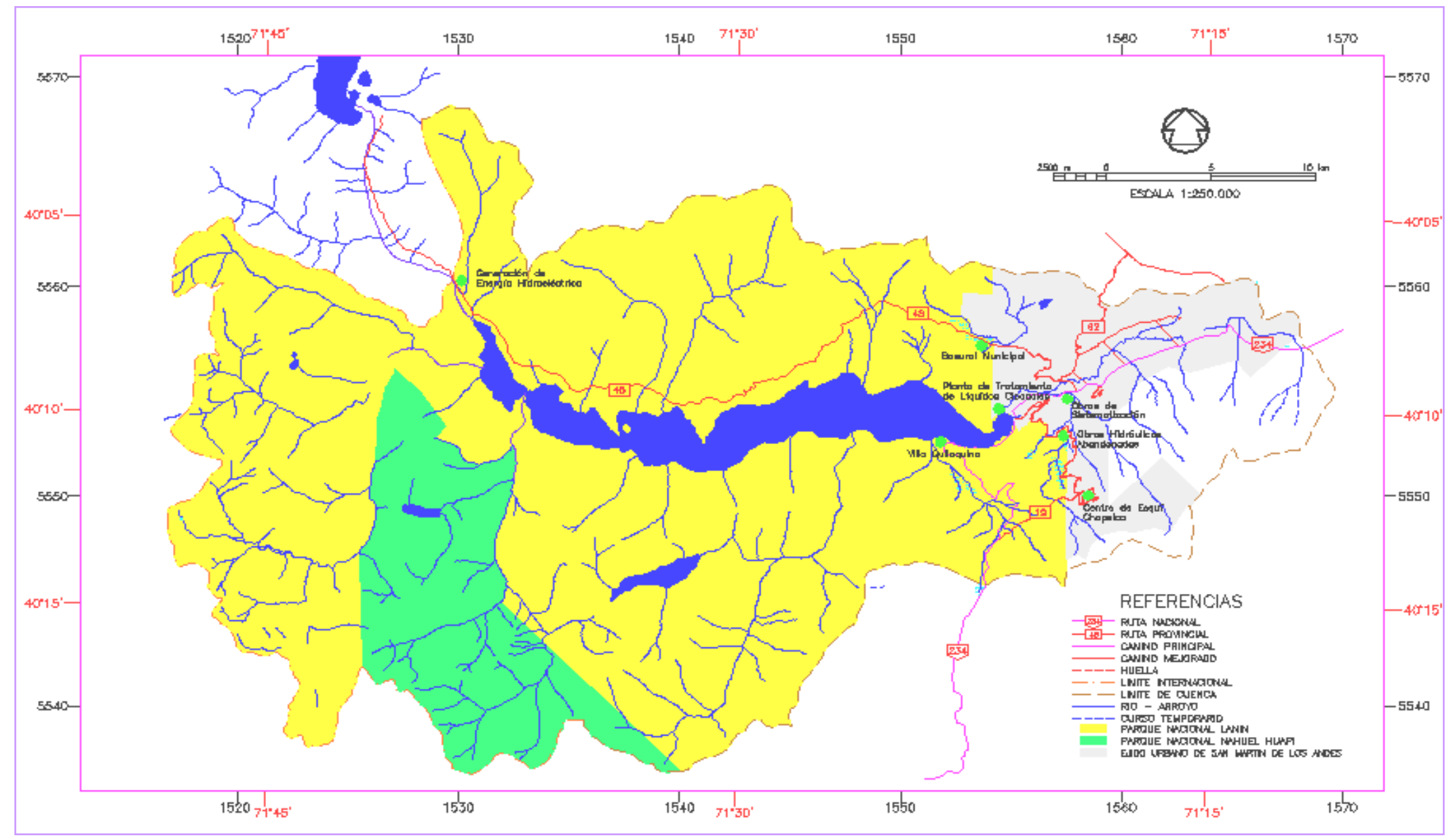

Figura 8: Escala regional: cuenca del río Hua Hum. 
Gran parte de la cuenca se ubica dentro del Parque Nacional Lanín (PNL). El parque ocupa un largo de 170 kilómetros y su ancho máximo desde la frontera cordillerana con Chile hacia el este es de 40 kilómetros.

De las 412.000 hectáreas que conforman el área protegida, el 13,8\% son Reserva Natural Estricta, de las 355.215 restantes, el 61,08\% actúan como área de amortiguación de impactos ambientales, permitiéndose en ellas sólo el uso recreativo extensivo. Las otras 195.007 hectáreas $(38,92 \%)$ están sometidas a un complejo patrón de usos. En el año 2001 fueron 38.717 los visitantes que pasaron por el PNL (Brunstein y Sarandón, 2004).

El sector central sur del PNL abarca las cuencas del lago Lácar y Lolog. La cuenca del lago Lácar es la más baja del parque y la única que drena hacia el océano Pacifico a través del río Hua Hum.

El clima varía en sentido este-oeste, fundamentalmente debido a las precipitaciones, con isohietas de $4.000 \mathrm{~mm}$ en la frontera con Chile reduciéndose hasta $1.200 \mathrm{~mm}$ en el sector oriental. Este gradiente junto a la altitud y la exposición de las laderas son consecuencia de las asociaciones vegetales más comunes de la región: bosques densos húmedos en el occidente, bosques mesófilos en el centro y bosques semiabiertos y ralos junto a matorrales y estepas herbáceas en el oriente (Convenio DGRH- UNLP 1996).

La orografía de la región es, en gran medida, responsable de la abundante cantidad de lluvia que reciben las áreas adyacentes a las montañas. Hacia el este, las lluvias disminuyen bruscamente, dando paso a un ambiente de transición o ecotono hasta llegar a la estepa. Los mayores registros pluviométricos se verifican de mayo a agosto, resultando junio el mes pico. Las nevadas ocurren de mayo a octubre (Monjeau et al., 2005).

El sistema hídrico formado por los lagos Lácar y Nonthue tiene una superficie de 5.314 hectáreas y recibe radialmente las aguas de numerosos arroyos. Por el sector norte aportan al sistema los arroyos Quiñilhue, Quechuquina, Quitantahue y Quillahuintos, entre los más importantes. Por el este, escurriendo por la vega Maipú, el arroyo Calbuco y afluentes. De la unión del Calbuco con el emisario de los arroyos Trabunco y Quitrahue se forma el arroyo Pocahullo, el cual atraviesa la ciudad de San Martín de los Andes y desemboca en el Lácar. Por el sector sur aportan el arroyo Pil Pil, que nace el bajo Los Leones, donde llegan las aguas del arroyo Partido; el arroyo Grande, es uno de los de mayor extensión.

El río Hua Hum es el emisario final de la cuenca, dentro del territorio argentino se extiende unos 2,5 kilómetros aproximadamente, antes de alcanzar el límite internacional recibe por la margen derecha las aguas del arroyo Pichi Hua Hum. Estimaciones efectuadas, indican que el módulo del río es del orden de los $50 \mathrm{~m}^{3} / \mathrm{s}$, 
los aforos efectuados por parte de organismos chilenos aguas arriba de su entrada al lago Pirehueico dan valores de $68 \mathrm{~m}^{3} / \mathrm{s}$.

El lago Lácar se caracteriza como un lago de montaña profundo, y de origen glacial, tiene una profundidad máxima de $277 \mathrm{~m}$ y una profundidad media de $166 \mathrm{~m}$. La temperatura del lago oscila entre los $14^{\circ} \mathrm{C}$ en la superficie y los $4,4^{\circ} \mathrm{C}$ a $70 \mathrm{~m}$ de profundidad en verano. De acuerdo a la clasificación de Wetzel (1975), es un lago monomíctico templado; presenta estratificación directa en verano y mezcla en invierno y las aguas son ligeramente alcalinas.

Su estado trófico global es ultraoligotrófico pero cambia a oligomesotrófico en la bahía, afectada por la ciudad de San Martín de los Andes (Pedroso et al., 1993). Su uso esta ligado a la recreación, deportes náuticos y pesca deportiva.

En la tabla 1 se observan las características físicas del lago Lácar (http://www.hidricosargentina.gov.ar/Indice-Lacar).

Tabla 1: Características físicas del lago Lácar

\begin{tabular}{|l|l|}
\hline Características Físicas & \\
\hline Superficie & $49 \mathrm{~km}^{2}$ \\
\hline Volumen & $8.134 \mathrm{hm}^{3}$ \\
\hline Profundidad máxima & $277 \mathrm{~m}$ \\
\hline Profundidad media & $166 \mathrm{~m}$ \\
\hline Longitud de la costa & $58 \mathrm{~km}$ \\
\hline Tiempo de residencia & 5,8 años \\
\hline Área de la cuenca & $1.048 \mathrm{~km}^{2}$ \\
\hline
\end{tabular}

\section{Escala Local: las subcuencas de los arroyos Trabunco-Quitrahue}

Características socioeconómicas:

Las subcuencas Trabunco-Quitrahue constituyen un nexo entre la zona urbana y el centro de esquí Chapelco. A éste se accede por la ruta nacional $N^{\circ} 234$ (camino de Los Siete Lagos) que bordea el lago Lácar y luego se empalma con la ruta provincial No19.

La zona presenta el asentamiento de dos comunidades mapuches: la comunidad Vera es la que se encuentra más cercana al casco urbano y se conforma de dos parajes: Trabunco Arriba y Trabunco Abajo. Dicha comunidad todavía no tiene la totalidad de sus tierras escrituradas como propiedad comunitaria. 
Parte de su territorio se encuentra dentro del ejido municipal y, el resto está en jurisdicción provincial. Se cuenta con la entrega formal del denominado Lote $69 \mathrm{~B}$, pero queda por definir una porción territorial en el Lote $69 \mathrm{~A}$.

La otra, es la comunidad Curruhuinca, es más numerosa en cuanto a población. Se ubica en las márgenes norte y sur del lago Lácar y se estructura en cuatro parajes distantes entre sí. Solo el Paraje Puente Blanco se encuentra en territorio provincial y dentro del área de estudio y se asienta sobre el camino de acceso a la base del centro de esquí Chapelco. Los demás parajes que integran ésta comunidad se disponen en su totalidad dentro de la jurisdicción del Parque Nacional Lanín (www.chapelco.com).

Debido a la presencia del centro de esquí y su cercanía a la ciudad (21 km) recibe la influencia del área urbana en cuanto a turismo y actividades recreativas aunque también conserva características de área rural de producción primaria (dadas por las comunidades antes mencionadas). Por lo tanto es un área de alta complejidad con respecto a los usos.

En la misma también se encuentran dos barrios privados recientemente creados ubicados a 1.400 metros de altura, linderos al centro de esquí; el barrio "Los Techos" y el barrio "Las Pendientes", que además cuenta con pista de esquí propia.

\section{Características biofísicas:}

El clima en las subcuencas es frío y húmedo (Figura 9). La temperatura máxima media en el mes de julio es de $7,7^{\circ} \mathrm{C}$ y la mínima media es $1^{\circ} \mathrm{C}$. En el mes de enero la máxima media es de $25^{\circ} \mathrm{C}$ y la mínima media de $9,4^{\circ} \mathrm{C}$. La temperatura media del mes más cálido es de $15,5^{\circ} \mathrm{C}$ y la media del mes más frío es de $4^{\circ} \mathrm{C}$. Las heladas tempranas se registran a partir del mes de marzo y las tardías en el mes de octubre. Por lo tanto el periodo libre de heladas es durante los meses de noviembre a febrero. La precipitación media anual es de $1.450 \mathrm{~mm}$, con máximos de $1.872 \mathrm{~mm}$, concentradas en el periodo abril - septiembre. Las precipitaciones nivales aumentan en función de la altitud. A partir de la cota $1.300 \mathrm{~m} \mathrm{snm} \mathrm{la} \mathrm{nieve}$ permanece en el suelo entre los meses de mayo a septiembre. Los vientos predominantes soplan del oeste, la velocidad media es de $20 \mathrm{~km} / \mathrm{h}$. Predominan las exposiciones nor-noroeste a lo largo de su extensión, lo que determina un alto grado de soleamiento y luminosidad durante el año $y$ por ende una menor disponibilidad de humedad. 


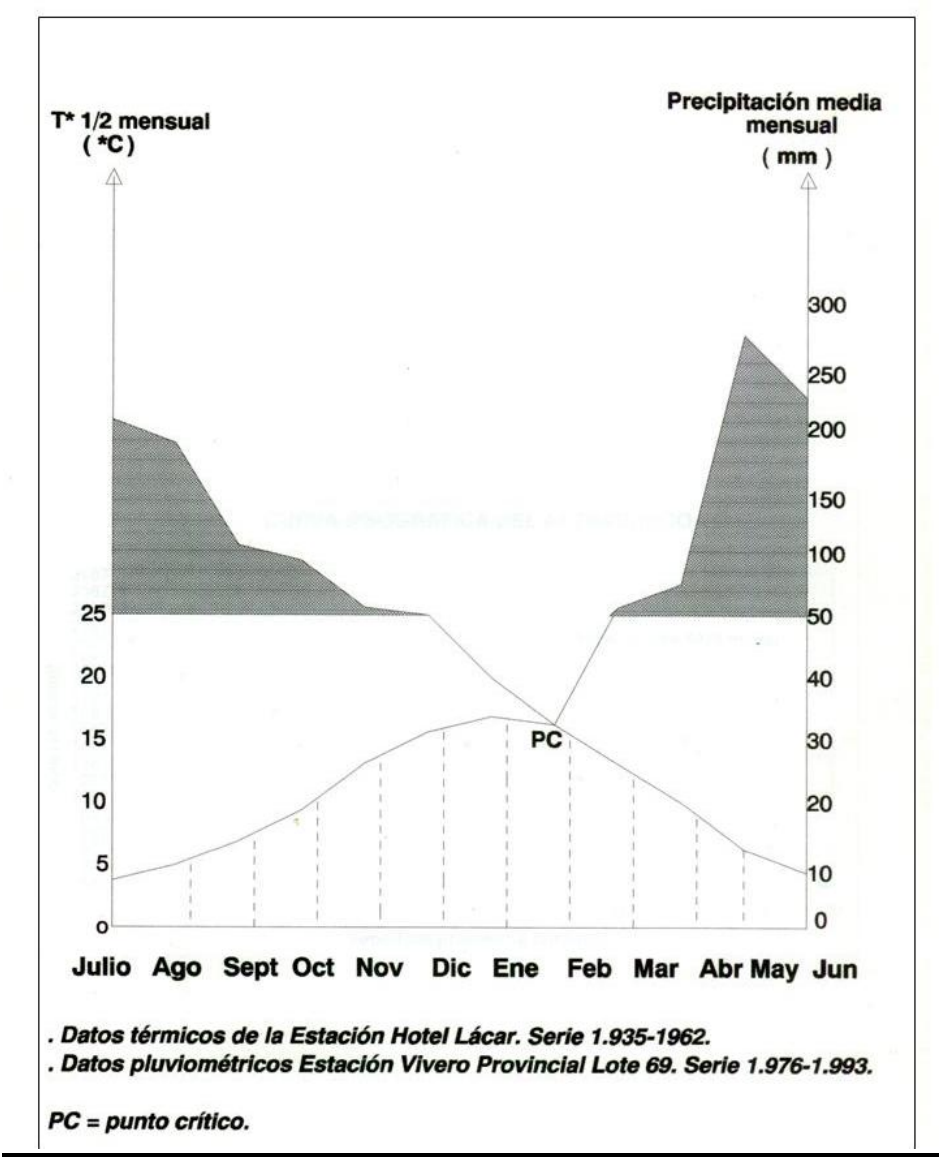

Figura 9: Climatograma de las subcuencas de los arroyos Trabunco-Quitrahue. (Convenio DNRRHH-SMA, 1994).

La geomorfología es derivada de la acción glaciaria que afectó al área. Se reconocen al menos tres etapas de englazamiento al comienzo del Pleistoceno (Deza et al., 1995). En la primera de ellas una "calota" de hielo cubrió todo el valle del lago Lácar y de la actual Vega Maipú, dejando emerger algunas cumbres y parte del Cordón Chapelco. El drenaje del área era hacia el Atlántico.

En una segunda etapa la "calota" redujo su tamaño, el paisaje alcanzó el aspecto de glaciares de transección, oportunidad en la que se depositó un arco morénico que cerró el valle, endicando el primitivo lago Lácar, pasando a tener drenaje hacia el Pacífico. En la tercera etapa se produjeron nuevos depósitos glaciarios sobre los anteriores.

Otro rasgo geomorfológico es la presencia de derrumbes de rocas de gran magnitud. Estos derrumbes se desarrollan en rocas volcánicas (tobas y basaltos) pertenecientes a la formación Ventana. Los basaltos que presentan mayor resistencia a la erosión, sobreyacen a rocas más blandas y erodables como las tobas. 
Según el mapa de zonas geológicas críticas de las subcuencas de los arroyos Trabunco-Quitrahue desarrollado por la Dirección de Minería de la Provincia de Neuquén, el área presenta rocas con alto, moderado y bajo grado de fracturación y erosión. Según este mapa las zonas con un alto grado de erosión y fracturación corresponderían a dos tipos litológicos según el mapa geológico: gravas y arenas por un lado, y basaltos y aglomerados volcánicos por otro.

El relieve en general es colinado y escarpado, se observan valles y cañadones abruptos, por lo que se caracteriza por una topografía accidentada con grandes $y$ continuos contrastes de pendientes. A partir de los 1.100 metros comienza una serie de aterrazados con exposición N y NE que se intercalan entre las elevaciones hasta alcanzar el límite inferior de la cuenca. El menor valor de cota es de 675 metros y es donde se encuentra la ciudad de San Martín de los Andes, y el punto más alto se encuentra en la cima del Cerro Chapelco con 2.394 metros.

Para la caracterización física de una cuenca existen algunos índices provenientes de la geomorfología que sirven para definir a la cuenca en sí y su red de drenaje. Entre estos se encuentran el área de la cuenca, el número de orden de un curso de agua, la longitud media, la relación de bifurcación, la densidad de drenaje y la frecuencia de los cursos.

Para el cálculo de estos índices se utilizó el programa ArcView 3.2 con el cual se midió la superficie total de ambas subcuencas en hectáreas y las longitudes de los cursos en metros y luego se aplicaron las fórmulas correspondientes.

Las subcuenca de los arroyos Trabunco-Quitrahue, en conjunto, tienen una superficie 4.927 hectáreas. Para la red de drenaje se estableció el número de orden de los cursos principales el cual es una medida de la ramificación de la red fluvial. Para el arroyo Trabunco el número de orden fue igual a 3 y la longitud media de 2.202 metros y para el arroyo Quitrahue igual a 4, y la longitud media de 945,2 metros. La densidad de drenaje es de $1,2 \mathrm{~km} / \mathrm{km}^{2}$ y la frecuencia de los cursos (que se basa en el número total de cursos sobre el área de la cuenca) es de $1 \mathrm{~km}^{-1}$

Los suelos son derivados de cenizas volcánicas que permanecen húmedas (andisoles) evolucionando hacia alófanos complejados con la materia orgánica. Son suelos profundos, oscuros, con altos contenido de materia orgánica. Su secuencia característica es $A-A C-C$ o multisecuencias de esos horizontes. Son suelos con una alta porosidad en todo el perfil, lo que determina que tengan una alta retención hídrica y una muy buena aireación. Tienen una alta permeabilidad al agua y por lo tanto buen drenaje.

Biogeográficamente la región se encuentra en el Dominio Subantártico: Provincia Subantártica: Distrito del Bosque Caducifolio. En las comunidades vegetales de este distrito dominan los árboles caducifolios como: "Ñire" (Nothofagus 
antarctica), "Lenga" (N. pumilio), "Rauli" (N. procera), y "Roble Pellín" (N. oblicua); También existen perennifolios como el "Ciprés de la cordillera" (Austrocedrus chilensis), "Cañas colihue" (Chusquea culeou), "Juncales" (Scirpus spp.), etc.

La región también presenta comunidades del Distrito Alto andino Austral, Provincia Alto andina, Dominio Andino-Patagónico. Es un distrito discontinuo que se forma a modo de islotes por encima de la Provincia Subantártica, ocupa las altas montañas del centro y sudoeste de Neuquén, las comunidades son muy heterogéneas: estepas graminosas de Poa obvallata y Festuca weberbaueri, etc. (Cabrera, 1971).

El bosque se desarrolla gracias a los vientos húmedos del Pacífico que, al chocar y elevarse en la cordillera, se enfrían y condensan la humedad que se descarga en forma de lluvias. Hay heladas durante todo el año y los inviernos son rigurosos y con nevadas. El deshielo produce numerosos arroyos que desembocan en grandes lagos de escasa productividad.

EI PNL presenta un bajo a moderado nivel de biodiversidad, pero concentra comunidades ecológicas de altísimo valor de conservación por ser exclusivas en la Argentina, con una restringida distribución y escasa presencia regional (www.parquenacionallanin.gov.ar).

En la cabecera de las subcuencas, la vegetación es la estepa graminosa (Distrito Alto andino Austral), al descender aparece el matorral de Lenga achaparrada que luego se continua con el bosque alto de Lenga, en ambas aparecen inclusiones del pastizal de montaña (gramíneas y ciperáceas) y zonas con mallines.

En la zona media la vegetación es más heterogénea: se encuentra el bosque de Lenga, y también se desarrolla un bosque con especies de Coihue, Ñire y Radal con inclusiones de pastizal de montaña (especies tales como neneo, coirón y gramíneas) y cañaverales de caña colihue en las partes erosionadas. En la porción baja de las subcuencas la vegetación dominante es el bosque de Coihue y Ciprés con zonas de pastizal de ciperáceas y gramíneas donde se realizan actividades de ganadería extensiva y la extracción de madera.

La fauna de la región presenta un elevado número de endemismos. Entre los mamíferos se encuentran el "Huemul" (Hipocamelus bisulcus), "Pudú" (Pudu pudu), "Puma" (Felis concolor), "Gato huiña" (Felis guigna), "Zorro colorado" (Dusicyion culpaueus), "Zorro patagónico" (Pseudalopex culpaeus), "Zorro gris chico" (D. griseus), "Hurón menor" (Galictis furax), "Monito de monte"(Dromiciops australis), diversos murciélagos y roedores.

También hay especies introducidas como la "Liebre europea" (Lepus europaeus), "Conejo europeo" (Oryctolagus cuniculus), "Jabali" (Sus scrofa) y "Ciervo colorado" (Cervus elaphus), estas dos últimas de importancia en la caza deportiva. 
Algunas de las especies de aves presentes son: "Cauquén" (Chloephaga picta), "Agachona" (Attagis sp.), "Carpintero gigante" (Campephilus magellanicus), "Cisne cuello negro" (Cygnus melancorhyfus), "Gallareta" (Fulica sp.), "Pato zambullidor" (Oxyura sp.), "Cóndor andino" (Vultur griphus), "Jote" (Cathartes aura), "Picaflor rubí" (Sephanoides sephanoides), "Chucao" (Scelorchilus rubecula), "Rayadito" (Aphrastura spinicauda), "Fío-fío" (Elaenia albiceps), "Diucón" (Xolmis pyrope), "Zorzal patagónico" (Turdus falcklandii), "Paloma araucana" (Columba araucana), "Tero común"(Vallenus chilensis), "Bigua" (Phalacrocorax olivaceus), etc.

Es importante la presencia de especies endémicas de anfibios en esta región: el "Sapito Vaquero" (Rhinoderma darwinii), la rana palmada de arroyo (Alsodes gargola), restringida a las costas de arroyos y lagos de altura intermedia. Entre los reptiles, están presentes varias especies de lagartijas que son comunes en la región, como Liolaemus chilensis y L. pictus.

Con respecto a la ictiofauna nativa se encuentran las "Truchas criollas" o "Percas" (Percichthys colhuapensis), el "Pejerrey patagónico" (Odontesthes microlepidotus, el "Puyen" (Galaxias maculatus), el "Bagre aterciopelado" (Olivaichthys viedmensis), "Bagre de los torrentes" (Hatcheria macraei), y la "Peladilla" (Aplochiton sp.). Entre las exóticas de valor deportivo se encuentran la "Trucha arco-iris" (Oncorhynchus mykkis), "Trucha marrón" (Salmo trutta) y "Trucha de arroyo"(Salvelinus fontinalis). En la tabla 2 se describen algunas de las especies mencionadas con diferentes valoraciones (www.parquenacionallanin.gov.ar; www.medioambiente.gov.ar).

Tabla 2: Valoración de algunas especies de fauna presentes a nivel regional

\begin{tabular}{|c|c|c|c|c|c|c|}
\hline Especie & Endémica & Rara & $\begin{array}{c}\text { Amenazada } \\
\text { (CITES) }\end{array}$ & Carismática & $\begin{array}{l}\text { Importancia } \\
\text { económica }\end{array}$ & Exótica \\
\hline Huemul & $x$ & & $x$ & $x$ & & \\
\hline Pudú & $x$ & & $x$ & $x$ & & \\
\hline Ciervo colorado & & & & & $x$ & $x$ \\
\hline Puma & & & $x$ & & & \\
\hline Gato huiña & & $x$ & $x$ & & & \\
\hline Jabalí & & & & & $x$ & $x$ \\
\hline Monito de monte & & $x$ & & & & \\
\hline Cóndor & & & $x$ & $x$ & & \\
\hline Sapito vaquero & $x$ & $x$ & & & & \\
\hline $\begin{array}{l}\text { Rana palmada de } \\
\text { arroyo }\end{array}$ & $x$ & $x$ & & & & \\
\hline Trucha arco iris & & & & & $x$ & $x$ \\
\hline Trucha de arroyo & & & & & $x$ & $x$ \\
\hline
\end{tabular}


La hidrología comprende los arroyos Trabunco y Quitrahue cuyas nacientes están ubicadas en el cordón del cerro Chapelco que se dispone en dirección norte-sur desde la Vega Maipú hasta el río Caleufú. En la zona baja ambos arroyos confluyen y desembocan en el arroyo Pocahullo el cual atraviesa la ciudad de San Martín de los Andes y desemboca en el lago Lácar.

En cuanto a la calidad de las aguas de las cuencas, se tomaron los datos de Temporetti et al. (2006), que fueron realizados a través del convenio entre la Municipalidad de San Martín de los Andes, el Centro Regional Universitario Bariloche (UN del Comahue), el programa de Hidrología de la UNESCO y la UNLP.

El muestreo de calidad de aguas fue realizado en mayo del 2006, para los cuales se establecieron 7 sitios sobre los arroyos Quitrahue y Trabunco, afluentes al lago Lácar. Los sitios se distribuyen de la siguiente manera (Ver figura 10).

En cada sitio de muestreo se midió: temperatura, ph, conductividad eléctrica, oxígeno disuelto (OD), fósforo reactivo soluble (PRS), fósforo total (PT), nitrógeno total (NT), nitrógeno de nitratos y nitritos (N-NO3+NO2), nitrógeno de amonio (N-NH4), sólidos en suspensión (SST), y bacterias coliformes. A continuación en las tablas 2 y 3 se observan los resultados de los análisis efectuados para cada sitio (Temporetti et al. 2006).

Tabla 3: Resultados de los muestreos de calidad de agua

\begin{tabular}{|c|c|c|c|c|c|c|c|c|c|c|}
\hline $\begin{array}{l}\text { Sitio de } \\
\text { Muestreo }\end{array}$ & $\begin{array}{l}\mathrm{T} \\
{ }^{\circ} \mathrm{C}\end{array}$ & $\mathrm{PH}$ & $\begin{array}{c}\text { Conductividad } \\
\mu \mathrm{g} / \mathrm{cm}\end{array}$ & $\begin{array}{l}O D . \\
\mathrm{mgO} \\
{ }_{2} / \mathrm{L}\end{array}$ & $\begin{array}{c}\text { PT } \\
\mu g P / \\
L\end{array}$ & $\begin{array}{c}\text { PRS } \\
\mu g P / \\
L\end{array}$ & $\begin{array}{c}N T \\
\mu g \\
N / L\end{array}$ & $\begin{array}{c}\mathrm{N}- \\
\mathrm{NO} 3+\mathrm{N} \\
\mathrm{O} 2 \\
\mu \mathrm{g} / \mathrm{L}\end{array}$ & $\begin{array}{c}\mathrm{N}- \\
\mathrm{NH} 4 \\
\mu g \\
\mathrm{~N} / \mathrm{L}\end{array}$ & $\begin{array}{l}\text { SST } \\
\mathrm{mg} / \mathrm{L}\end{array}$ \\
\hline G1 & 3,6 & 6,89 & 37,9 & 11,3 & 38,0 & 15,0 & 270,0 & 66,0 & $<5,0$ & 15,9 \\
\hline G2 & 3,3 & 7,18 & 79,4 & 8,5 & 28,0 & 5,0 & 763,0 & 23,0 & 257,0 & 24,6 \\
\hline G3 & 2,5 & 7,51 & 59,9 & 7,6 & 18,0 & 5,0 & 0 & 17,0 & $<5,0$ & 2,7 \\
\hline G4 & 3,6 & 7,68 & 76,7 & 9,2 & 17,0 & 6,0 & 105,0 & 11,0 & $<5,0$ & 3,6 \\
\hline 65 & 4,0 & 7,52 & 47,1 & 12,6 & 24,8 & 14,1 & 64,7 & 5,8 & $<5,0$ & 3,6 \\
\hline G6 & 5,0 & 7,75 & 75,5 & 11,7 & 38,3 & 13,4 & 114,6 & 6,0 & $<5,0$ & 4,7 \\
\hline$G 7$ & 4,7 & 7,72 & 64,3 & 12,7 & 22,9 & 10,4 & 117,6 & 21,0 & $<5,0$ & 5,3 \\
\hline
\end{tabular}

Tabla 4: Resultados de los análisis bacteriológicos

\begin{tabular}{|c|c|c|}
\hline $\begin{array}{c}\text { Sitio de } \\
\text { Muestreo }\end{array}$ & $\begin{array}{c}\text { Coliformes Totales } \\
\text { N.M.P./100 ml }\end{array}$ & $\begin{array}{c}\text { Coliformes Fecales } \\
\text { N.M.P./100 ml }\end{array}$ \\
\hline G1 & 49 & 22 \\
\hline G2 & 130 & 130 \\
\hline$G 3$ & 130 & 79 \\
\hline$G 4$ & 130 & 79 \\
\hline$G 5$ & 130 & 79 \\
\hline$G 6$ & 4.600 & 800 \\
\hline$G 7$ & 1.600 & 240 \\
\hline
\end{tabular}




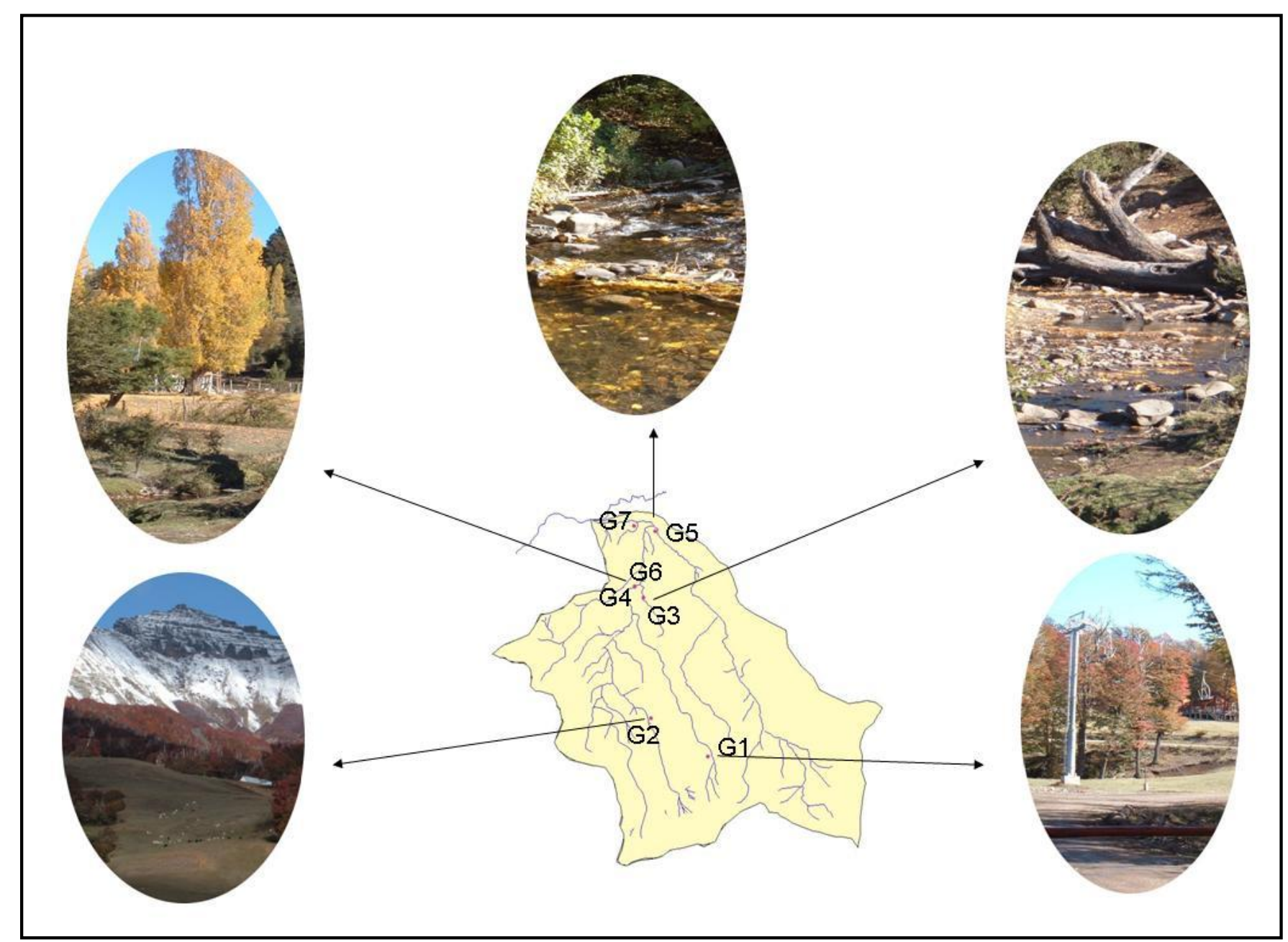

Figura 10: Sitios de muestreos de agua realizados durante el año 2006. 
Los resultados indican valores de temperatura que oscilaron entre los 2,5 y $5^{\circ} \mathrm{C}$, la conductividad presentó valores por encima del valor promedio establecido para ríos de la Patagonia $(48,8 \mu \mathrm{g} / \mathrm{cm})$ en los sitios $62,63,64,66,67$.

Con respecto a los nutrientes, el valor promedio para toda la cuenca fue de 26,7 $\mu g P / L$ en el caso del fósforo total y $9,8 \mu \mathrm{gP} / \mathrm{L}$ para el PRS, siendo los valores promedios para los ríos patagónicos de 20,8 $\mu \mathrm{gP} / \mathrm{L}$ y $6,8 \mu \mathrm{gP} / \mathrm{L}$ respectivamente (Figura 11).

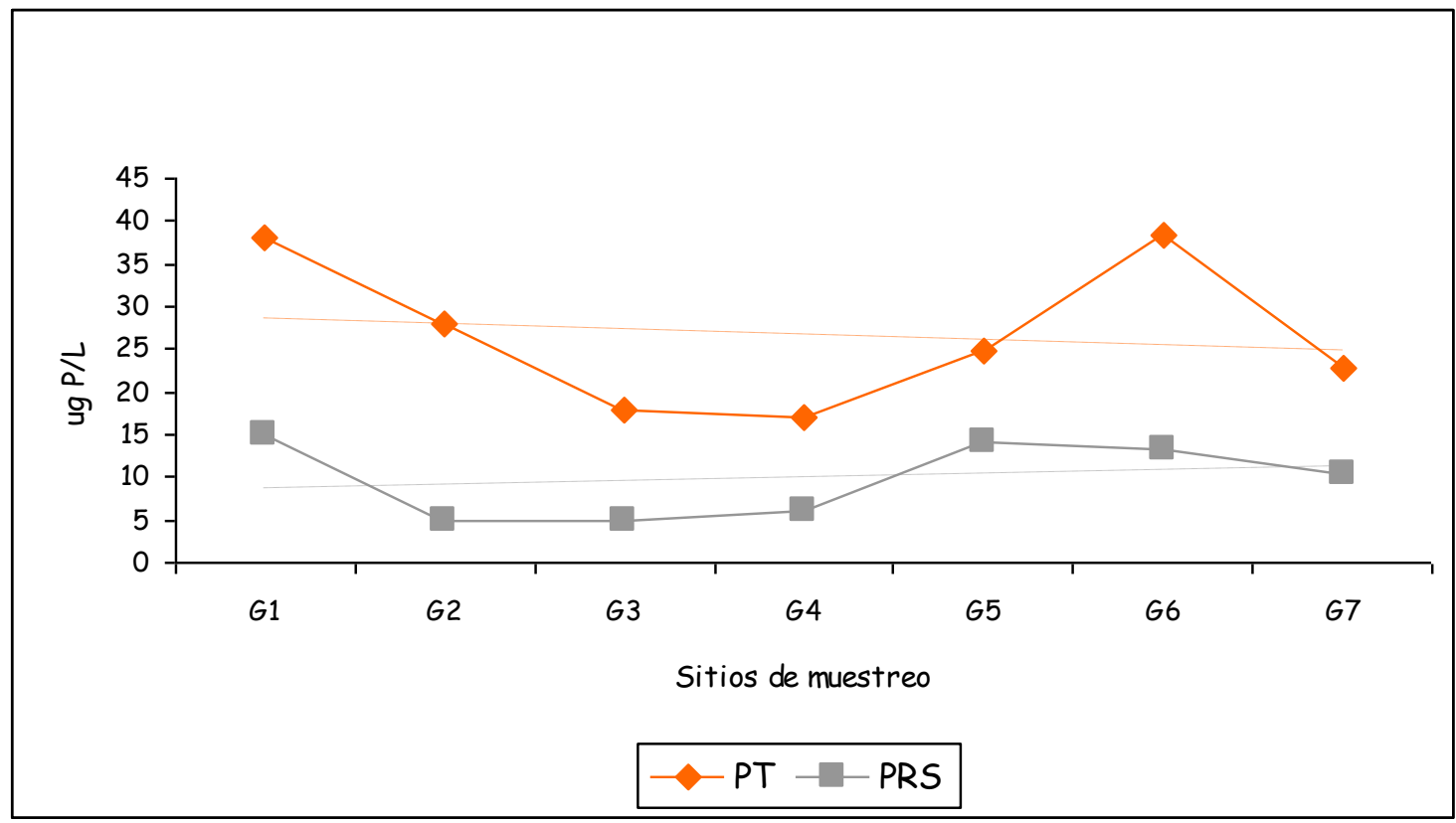

Figura 11: Valores de PS y PRS de los sitios muestreados en el año 2006. En líneas punteadas se observan los valores promedios para los ríos patagónicos.

Sin embargo hubo sitios con valores que se ajustan a los de referencia, como los sitios $G 3$ y $G 4$ y otros que lo duplicaron como el $G 1, G 5$ y $G 6$ para el caso del PRS.

Para el nitrógeno total, los valores más altos se encuentran en la parte de la cuenca alta, siendo los sitios $62(763 \mu \mathrm{g} / \mathrm{L})$, y $G 1(270 \mu \mathrm{g} / \mathrm{L})$, sin embargo a medida que nos acercamos a la cuenca baja, estas concentraciones van disminuyendo.

El valor más bajo $(64,7 \mu \mathrm{g} N / L)$ se presenta en el sitio $G 5$ correspondiente al único lugar de muestreo tomado sobre el arroyo Trabunco.

En el caso de las fracciones disueltas el promedio para el N-NO3+NO2 fue de $21,4 \mu \mathrm{g} / \mathrm{L}$ encontrándose el valor máximo en el sitio $61(66 \mu \mathrm{g} N / L)$ y el valor mínimo en el sitio $G 5(5,8 \mu \mathrm{g} N / \mathrm{L})$.

En cuanto a los valores bacteriológicos, las aguas no son aptas para bebida ya que según el Código Alimentario Argentino exige la ausencia de coliformes en $100 \mathrm{ml}$, y ninguno de los sitios cumple esta condición. 
Por otro lado las normas de calidad de agua de la Agencia de Protección Ambiental de los Estados Unidos (EPA, 1980) establece en $200 \mathrm{NMP} / 100 \mathrm{ml}$ de coliformes fecales como límite máximo aceptable para la natación, de esta manera solo en los sitios $G 6$ (800 NMP/100ml) y $G 7(240 \mathrm{NMP} / 100 \mathrm{ml})$ se exceden estos límites, por lo tanto en estos sitios no sería recomendable la práctica de esta actividad recreativa.

\section{2) Análisis ambiental}

\section{Conflictos y potencialidades detectados}

Sobre la base de la caracterización ambiental, los estudios realizados en los diferentes convenios y los viajes de campo, se han identificado los siguientes conflictos y potencialidades en las subcuencas de los arroyos Trabunco-Quitrahue.

\section{Conflictos}

Alteración de los recursos hídricos por contaminación: la cual es principalmente de tipo puntual ocasionada por falta de tratamiento de los efluentes cloacales en algunas zonas de las subcuenca como por ejemplo en el Centro de esquí Chapelco y su posterior vertido en los arroyos. Esta situación pone en riesgo la salud de las comunidades mapuches ubicadas aguas abajo del mismo, las cuales hacen uso directo del recurso. Los arroyos Trabunco y Quitrahue como se observó en el muestreo de calidad de agua, son recursos hídricos sensibles al incremento de nutrientes, materia orgánica y coliformes, así como también el lago Lácar de características ultraoligotróficas, lo que podría aumentar el riesgo de eutrofización por los aporte de origen humano (efluentes cloacales) o agropecuario (aportes de la ganadería).

\section{Conflicto por el uso de los recursos hídricos de las subcuencas} Trabunco-Quitrahue: Si bien hay abundancia de los recursos hídricos debido a la presencia de arroyos y el lago, existe una sobre demanda del mismo en la estación estival, específicamente del arroyo Trabunco. En esta época el arroyo es explotado por diversos usos. En el arroyo Trabunco se encuentra la toma de agua Paraje Puente Blanco de la cual se extrae agua para consumo humano y riego. El Centro de esquí Chapelco extrae agua para riego y actividades recreativas. También el arroyo debe mantener su caudal ecológico que sostiene a las comunidades acuáticas existentes en él. Todos estos usos generan conflictos entre los pobladores y las empresas privadas. 
Riesgo de degradación de ecosistemas naturales: El Bosque Andino Patagónico en el cual se encuentra inmersa la cuenca hidrográfica presenta una mayor fragilidad ambiental relativa en comparación a otros ecosistemas. Entre otras debido a su condición "insular", al estar aislado geográficamente de otros ecosistemas boscosos, al presentar características muy particulares en cuanto a clima, topografía y tipo de suelo; y por su falta de adaptación frente al desarrollo de algunos usos de la tierra tales como el ganadero, forestal y turístico (APN, 2004).

Sustrato geológico inestable: En algunos sectores los distintos grados de fracturación de las rocas, pueden causar avalanchas y deslizamientos de suelos, por ejemplo la zona de la cuenca baja presenta un sustrato con rocas de moderado a alto grado de facturación y erosión por lo cual se deben restringir o evitar las obras de infraestructuras y el asentamiento humano (Mapa de Zonas Geológicas Críticas, figura 18), a su vez esto también trae aparejado el deterioro del suelo y por lo tanto la pérdida de sus funciones.

Riesgo de incendios: La coincidencia del periodo de bajas precipitaciones con la época estival condiciona el riesgo de incendios forestales. Esta situación puede verse incrementada por las actividades de los turistas y acampantes desarrolladas en la zona.

Riesgo de Erosión: Las elevadas pendientes que presentan la cuenca y las zonas con suelo desnudo favorecen los procesos de erosión en el área. También la falta de ordenación de las actividades de extracción de madera y de ganadería disminuye la cobertura del suelo, por lo cual todos estos factores incrementan el proceso erosivo.

Conflicto por la posesión de tierras Mapuches-Municipio-Provincia: Esta problemática no solo repercute en los aspectos legales de posesión de tierra y conformación de propiedad comunitaria de las Comunidades mapuches, sino que también obstaculiza la planificación del uso de la tierra y la administración y aprovechamiento de los recursos naturales presentes en la zona.

Aumento de la densidad poblacional: El crecimiento demográfico en los últimos años puede caracterizarse como explosivo para el ejido de San Martín de los Andes. Esto se ve acompañado por el crecimiento de barrios cerrados (Los techos y Las pendientes), aumento de residuos sólidos, efluentes cloacales y pluviales, así como también aumento de la demanda de agua potable y servicios. En general este proceso no se ve acompañado por un crecimiento equivalente de la infraestructura y los servicios de manera ordenada y planificada. Como consecuencia se produce la pérdida de bienes y servicios ecosistémicos tales como: 
deterioro de la calidad de las aguas del lago Lácar y de los arroyos de la cuenca, así como también degradación del paisaje, erosión y deforestación.

Avance del área urbana sobre los límites del PNL: La falta de planificación urbana y el aumento de la población favorecen el asentamiento humano en zonas periféricas. Esta situación sumada a la contiguiidad al Parque Nacional Lanín lleva al avance de la ciudad hacia el parque generando conflictos no solo legales sino también ambientales como por ejemplo degradación del paisaje, contaminación, deforestación, etc.

Potencialidades:

Abundancia de recursos hídricos a una escala regional: La presencia de arroyos y el lago Lácar son una fuente importante de recursos hídricos los cuales pueden ser aprovechados de manera sustentable para consumo directo (población), producción (acuicultura; riego), o uso recreativo. El uso sustentable del recurso hídrico depende de una adecuada planificación y gestión integrada de cuencas.

Recursos forestales: El bosque es una fuente de recursos madereros, que con el manejo apropiado y de manera sustentable puede ser una actividad alternativa beneficiosa para los pobladores. También en la subcuenca Trabunco se encuentra un vivero forestal, con plantines de especies nativas y en el cual también se realizan forestaciones de especies autóctonas y exóticas como por ejemplo Pinus ponderosa. Estas dos situaciones pueden ser aprovechadas de manera conjunta para el desarrollo de la zona. Esto depende de una adecuada estrategia de aprovechamiento integral a fin de minimizar los conflictos con otros usos de los ecosistemas nativos del área (recreativos, servicios ambientales, protección de cuencas, etc.).

Ecosistemas de servicios: los ecosistemas presentes en el área prestan ciertos servicios ambientales. Por un lado, la presencia del bosque nativo, además de aportar un importante elemento al paisaje, forma parte del mantenimiento de los mecanismos reguladores del sistema natural, especialmente del ciclo hidrológico local y del microclima, aporta oxígeno a la atmósfera y capta el dióxido de carbono, es el hábitat de especies en peligro de extinción y también de especies de importancia económica. Además de los servicios prestados por el bosque, otros ecosistemas también contribuyen al funcionamiento del sistema natural. Los pastizales y mallines de la cuenca captan los nutrientes provenientes de la escorrentía 
superficial, disminuyendo la carga orgánica de los cursos de agua y minimizando el riesgo de eutrofización de los cuerpos de agua ubicados aguas abajo, ayudan al control de las inundaciones, regulando el flujo de agua, y funcionan como trampas de sedimentos, minimizando los episodios de colmatación de desagües, alcantarillas y obras de toma. Los arroyos tienen la capacidad de autodepurar y reciclar los nutrientes y contaminantes, condicionando la cantidad (caudal, frecuencia), la calidad (contaminantes, sedimentos, nutrientes) y usos potenciales (bebida, riego, etc.), del agua que llega a la ciudad de San Martín de los Andes. También el suelo provee una gran variedad de servicios ecosistémicos, además de actuar como sustrato para las plantas, juega un rol fundamental en la filtración y purificación del agua caída por lluvia.

Ecosistemas naturales en muy buen estado de conservación: Los ecosistemas boscosos de las subcuencas presentan un buen estado de conservación de la biodiversidad nativa local. Si bien, la biodiversidad es baja a moderada, comparada con otras regiones del país, las comunidades ecológicas aquí presentes son de alto valor de conservación por ser exclusivas de la Argentina, tener una distribución restringida y poca presencia regional. También en la región se encuentran especies endémicas como por ejemplo el huemul, el pudú, el sapito vaquero, la rana palmada de arroyo. Esta diversidad genética en el bosque nativo le confiere una ventaja frente a eventuales episodios de perturbación natural o antrópica, ya que le permite al bosque nativo su recuperación natural. Además, esta diversidad es fuente potencial de especies o variedades con resistencia al fuego, a enfermedades provocadas por patógenos, insectos, etc.

Atractivos turísticos: EL paisaje natural en general y la presencia de bosques nativos, arroyos, lago, montañas, en particular, son una fuente importante de atractivos turísticos.

En la zona y alrededores es posible realizar todo tipo de actividades recreativas como por ejemplo caminatas, ciclismo, avistaje de fauna silvestre, caza y pesca deportiva, turismo de aventura, deportes extremos, deportes invernales, etc.

Dichas actividades se pueden llevar a cabo en cualquier época del año, y son de bajo impacto con respecto a los disturbios que puedan ocasionar al ambiente.

Población con conciencia conservacionista vinculada a las actividades turísticas: Las subcuencas de los arroyos TrabuncoQuitrahue forman parte del ejido de San Martín de los Andes, la ciudad turística más importante de Neuquén, la cual se basa en los 
atractivos paisajes naturales. Por esta razón la población de SMA presenta una visión conservacionista de los recursos naturales y del paisaje. Esto es una gran ventaja, debido a que el desarrollo del área va a estar influenciado por esta visión.

Como síntesis de la EAR se puede establecer, que existe un riesgo de degradación de los recursos naturales en las subcuencas, principalmente en los recursos agua, suelo y el bosque nativo. Entre ellos se encuentran principalmente: el aumento de la densidad poblacional, el crecimiento urbano sin planificación, episodios de deforestación, la erosión y el deslizamiento de laderas. Tales acciones traen aparejadas consecuencias específicas, como la pérdida de hábitat, suelo, bosque y contaminación de los cursos de agua. En la figura 12 se observa un diagrama de flujo que sintetiza esta situación. Queda expuesto de esta manera que deben tomarse medidas concretas en las subcuencas, que disminuyan 0 , de ser posible, eliminen esta situación.

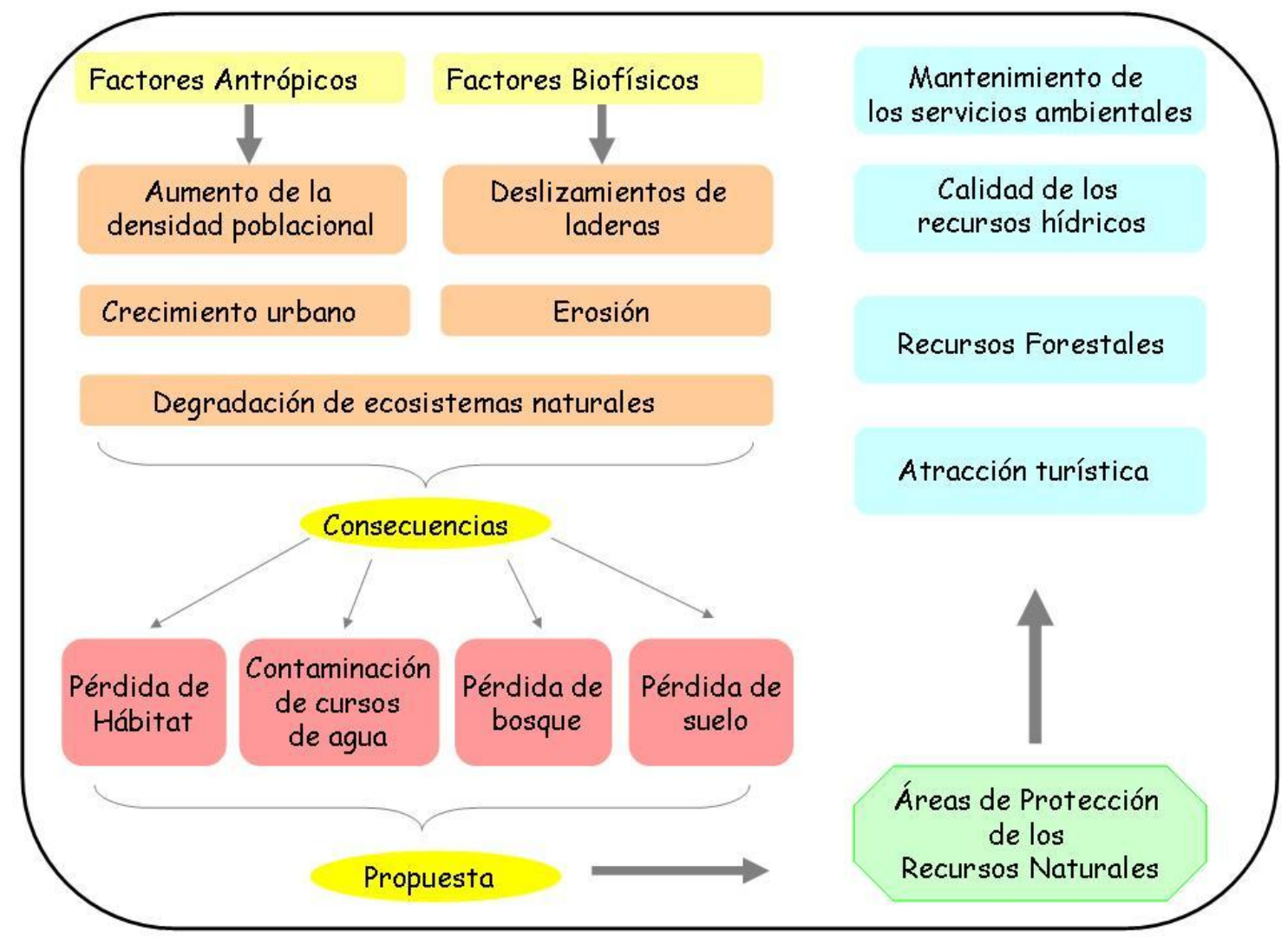

Figura 12: Diagrama de flujo que sintetiza la EAR de las subcuencas de los arroyos Trabunco-Quitrahue.

Existen muchos mecanismos para llevar a cabo una mejora o restauración del ambiente, por ejemplo, elaboración de políticas dirigidas a ello, aplicación de planes de ordenamiento territorial, comités de cuencas, sanciones con multas para empresas contaminantes, etc. También la conservación de espacios naturales, de 
diferente magnitud es una herramienta muy utilizada mundialmente para la protección de los recursos naturales.

La idea de preservar áreas naturales surge cuando se promueve mantener porciones de ecosistemas terrestres o acuáticos, con el objetivo de eliminar o mitigar la influencia negativa del hombre hacia las áreas naturales (Hernández, 2003). Por lo tanto la conservación de los recursos naturales es de fundamental importancia para mantener los procesos ecológicos esenciales que garantizan el funcionamiento de los ecosistemas y la base productiva de un país.

La conservación del medio ambiente debe considerarse como un sistema de medidas sociales, socioeconómicas y técnico-productivas dirigidas a la utilización racional de los recursos naturales, la conservación de los complejos naturales típicos, escasos o en vías de extinción, así como la defensa del medio ante la contaminación y la degradación.

En este contexto se propone, como medidas mitigatorias y preventivas la identificación de áreas sensibles cuya función principal sea la protección de los recursos naturales de las subcuencas. Las áreas seleccionadas podrían funcionar como zonas en las cuales pueden controlarse los procesos de degradación mencionados anteriormente, potenciando las características favorables de la cuenca en cuanto al mantenimiento de los bienes y servicios ecosistémicos y de los atractivos turísticos y paisajísticos de la misma. 


\section{Capítulo III}

\section{Sistema de Información Geográfica (SIG) de las subcuencas Trabunco-Quitrahue}

\section{Introducción}

Un SIG es un sistema asistido por computadora para la adquisición, almacenamiento, análisis y visualización de datos geográficos. Existen una gran variedad de herramientas software para asistir estas tareas. Sin embargo, estas herramientas pueden variar significativamente unas de otras, en parte debido a la forma en que representan y trabajan con los datos geográficos, pero además debido al énfasis relativo que le dan a estas operaciones (Eastman, 2003). Para mayor información sobre las cualidades de estos sistemas consultar el Anexo I, en el cual se hace una breve referencia de la evolución de los SIG y sus principales características.

El objetivo del sistema de información geográfica de las subcuencas de los arroyos Trabunco-Quitrahue es constituir una base de datos espacial, en la cual los mapas que la conforman y sus variables puedan ser utilizados en un contexto geográfico para el análisis y generación de modelos que permitan la selección de sitios o áreas sensibles para la protección de los recursos naturales.

\section{Materiales y Métodos}

Para la confección del SIG se recopiló información cartográfica que fue digitalizada, también se contó con información digital que fue georreferenciada, y a su vez se generó información nueva a través de diferentes análisis de las imágenes satelitales.

Toda la base de datos se encuentra referenciada al sistema de coordenadas Gauss Krüger Faja 1, datum Campo Inchauspe, elipsoide de referencia: Internacional 1909. También se estableció la escala de trabajo en 1:60.000.

Como insumo para la generación de los diferentes mapas temáticos se utilizaron cartas topográficas del Instituto Geográfico Militar (IGM) escala 1:50.000 y las siguientes imágenes satelitales: 
- Satélite Landsat 5: sensor TM, fecha febrero de 1987 Path 232, Row 088. EarthSat- Orthorectified, bandas: 1,2,3,4,5,7,8 en formato TIFF, elipsoide de referencia: WGS 84; datum: WGS 84; proyección UTM, unidades: metros. Fuente: ftp://ftp.glcf.umiacs.umd.edu.

- Satélite Landsat 7: sensor ETM+, fecha diciembre del 2001, Path 232, Row 088. EarthSat- Orthorectified, bandas: $1,2,3,4,5,7,8$ en formato TIFF, elipsoide de referencia: WGS 84; datum: WGS 84; proyección UTM, unidades: metros. Fuente: ftp://ftp.glcf.umiacs.umd.edu

- Satélite Landsat 7: sensor ETM+, fecha febrero del 2007, Path 232, Row 088. EarthSat- Orthorectified, bandas: $1,2,3,4,5,7,8$ en formato TIFF, elipsoide de referencia: WGS 84; datum: WGS 84; proyección UTM, unidades: metros. Fuente: Comisión Nacional de Actividades Espaciales (CONAE).

Con cada imagen se trabajó de la siguiente manera: se utilizó el programa ERDAS IMAGINE 8.5 se unieron las bandas y se obtuvo un "layer" en formato IMG con la escena completa, la cual luego se recortó, acotándose al área de estudio y a posteriori se reproyectó al sistema de referencia establecido anteriormente.

A partir de las imágenes, las cartas topográficas y los puntos de control tomados en un viaje de campo, se delineó el límite de cuenca y se elaboró el mapa base. También se extrajeron los caminos y arroyos presentes en las subcuencas, que fueron digitalizados y transformados a archivos vectoriales.

Se elaboró un modelo digital de elevaciones para la zona a partir de cartas topográficas del IGM. Las cartas se escanearon y se georreferenciaron con el programa ERDAS IMAGINE 8.5.

Se exportaron como archivos IMG (los cuales son archivos raster) al programa ArcView 3.2 en el cual se digitalizaron las curvas de nivel, y se transformaron en un archivo vectorial, a partir del cual se generó el Modelo Digital de Elevaciones (DEM) el cual fue incluido en el SIG.

A partir del DEM se crearon con un módulo espacial de ArcView 3.2 el modelo digital de pendientes y el modelo digital de exposiciones de laderas de la cuenca. En la figura 13 se observa el cuadro síntesis de las tareas realizadas. 


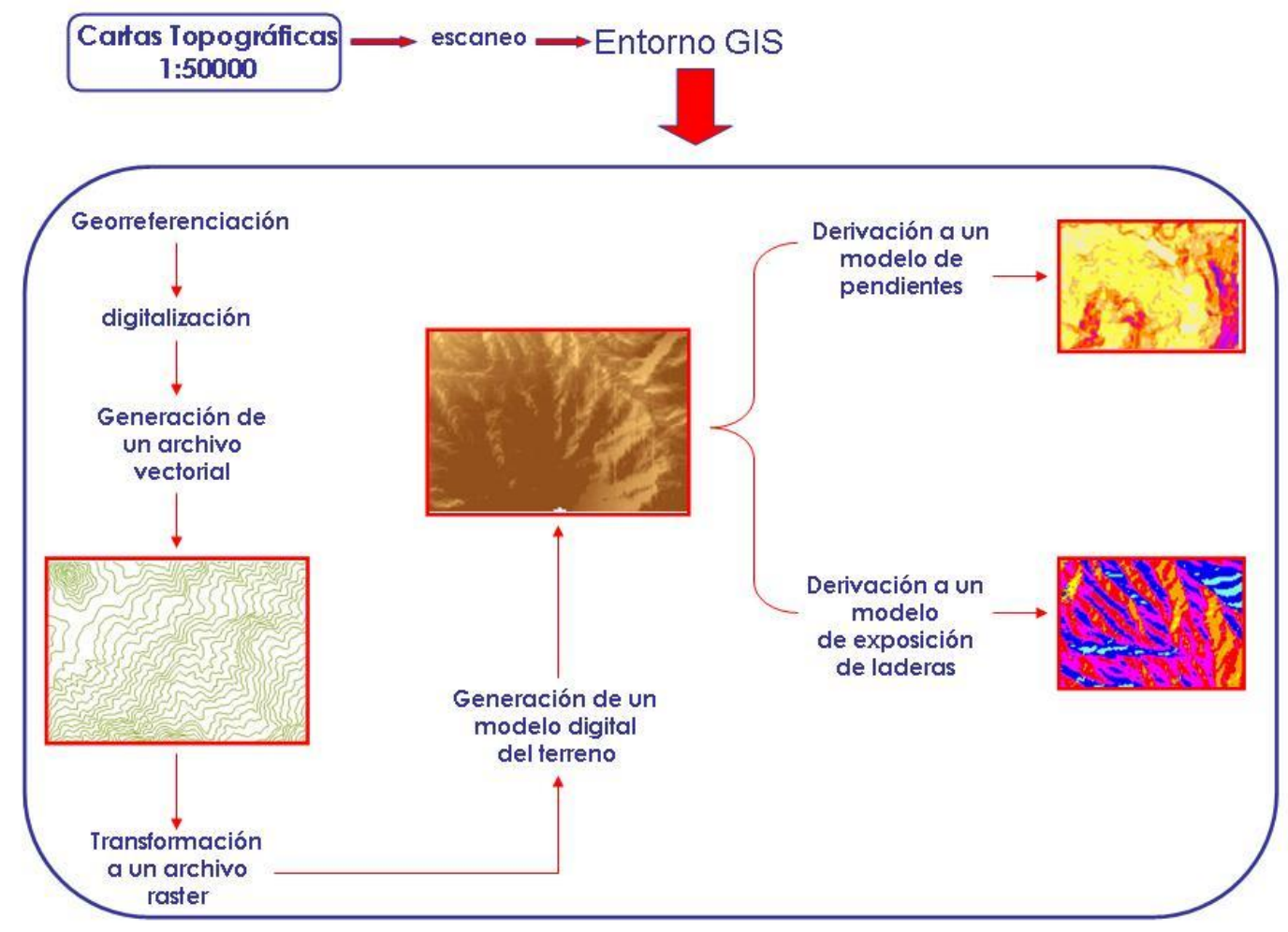

Figura 13: Cuadro síntesis de los pasos seguidos en la realización del DEM y modelos derivados.

También se contaba con diferentes archivos digitales resultado de los estudios multidisciplinarios realizados en la cuenca desde hace unos 15 años por diferentes técnicos y entidades, provenientes del Convenio DNRRHH-SMA (1994).

-Mapa de suelo de la cuenca Trabunco-Quitrahue. Fuente: Broquel et al., 1995.

-Mapas geológico, geomorfológico, y de zonas geológicas críticas de la cuenca Trabunco-Quitrahue. Fuente: Deza et al., 1995.

Estos archivos se importaron al programa ArcView 3.2 en el cual se transformaron en archivos vectoriales; y se reproyectaron al sistema de coordenadas establecido.

También se elaboró un mapa de tipos de coberturas de la cuenca a partir de la imagen Lansat ETM + del 2007, el cual se llevó a cabo a través de un proceso combinado de clasificación supervisada y no supervisada. En el Anexo II se describe detalladamente todo el proceso de elaboración del mapa de coberturas. 


\section{Resultados}

EL SIG quedó conformado por varios archivos y como se describió en la metodología se utilizaron tanto archivos vectoriales como raster. Por lo expuesto la base de datos quedó establecida de la siguiente manera: ocho archivos vectoriales y cuatro archivos raster que forman los siguientes mapas temáticos:

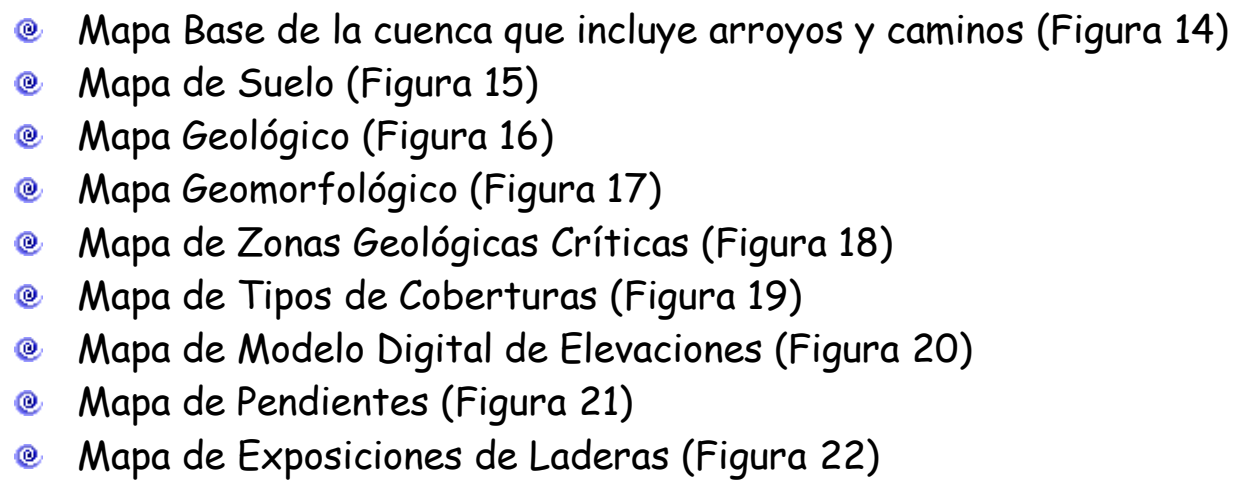

Todos estos mapas temáticos están relacionados a una tabla de atributos en las que se detallan las características de los mismos. 


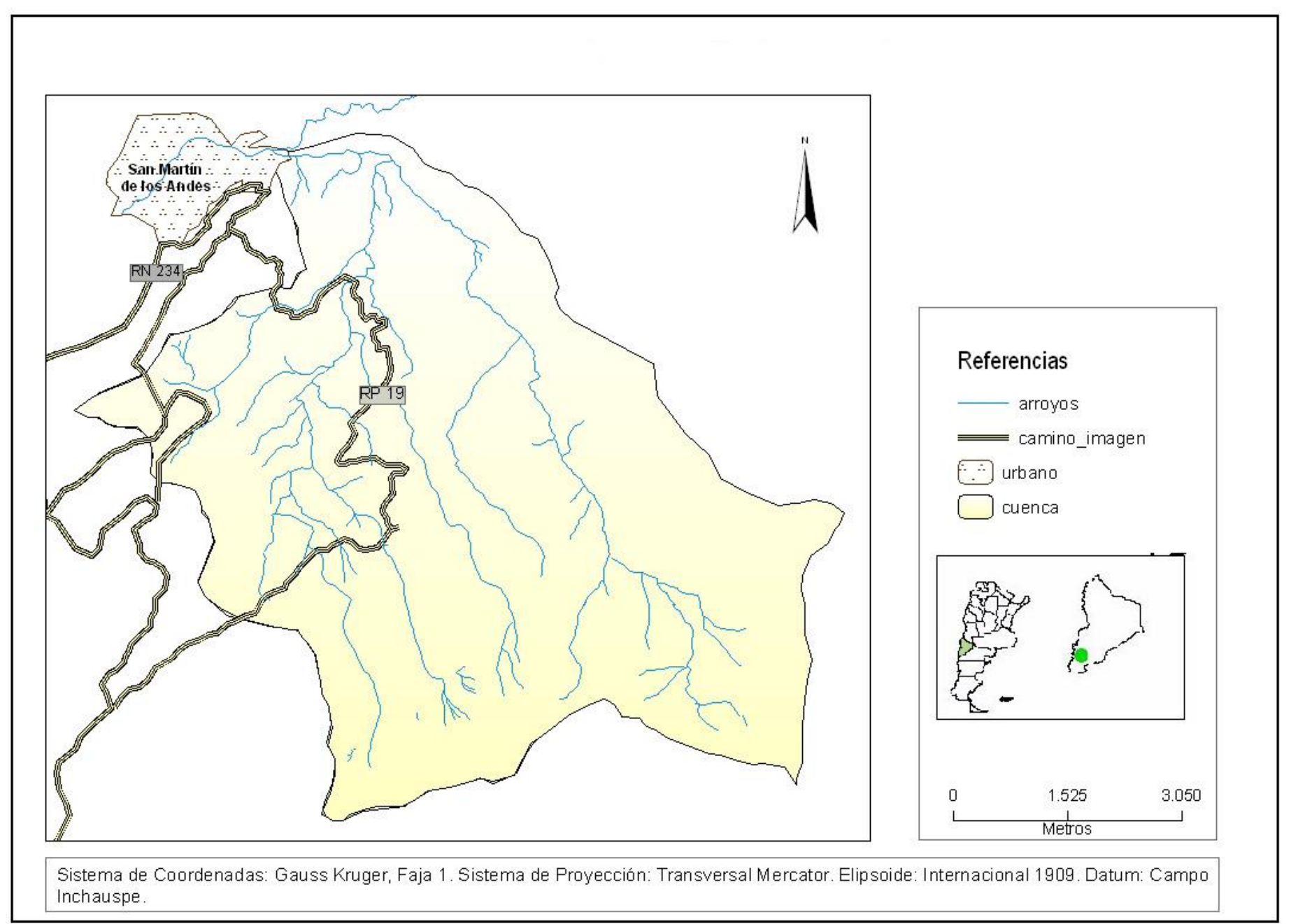

Figura 14: Mapa de caminos y arroyos de las subcuencas de los arroyos Trabunco-Quitrahue. 


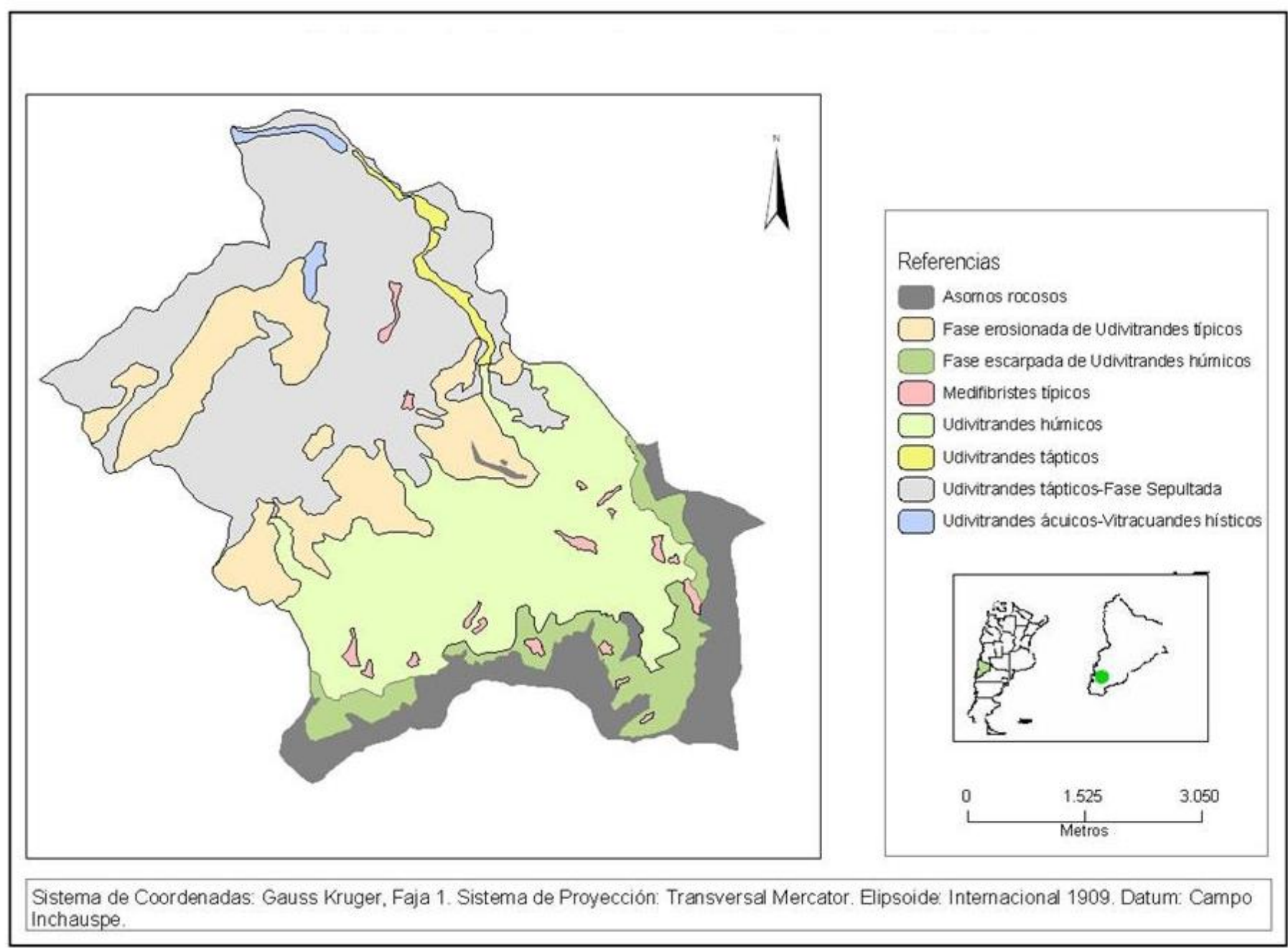

Figura 15: Mapa de tipos de suelo de las subcuencas de los arroyos Trabunco-Quitrahue. 


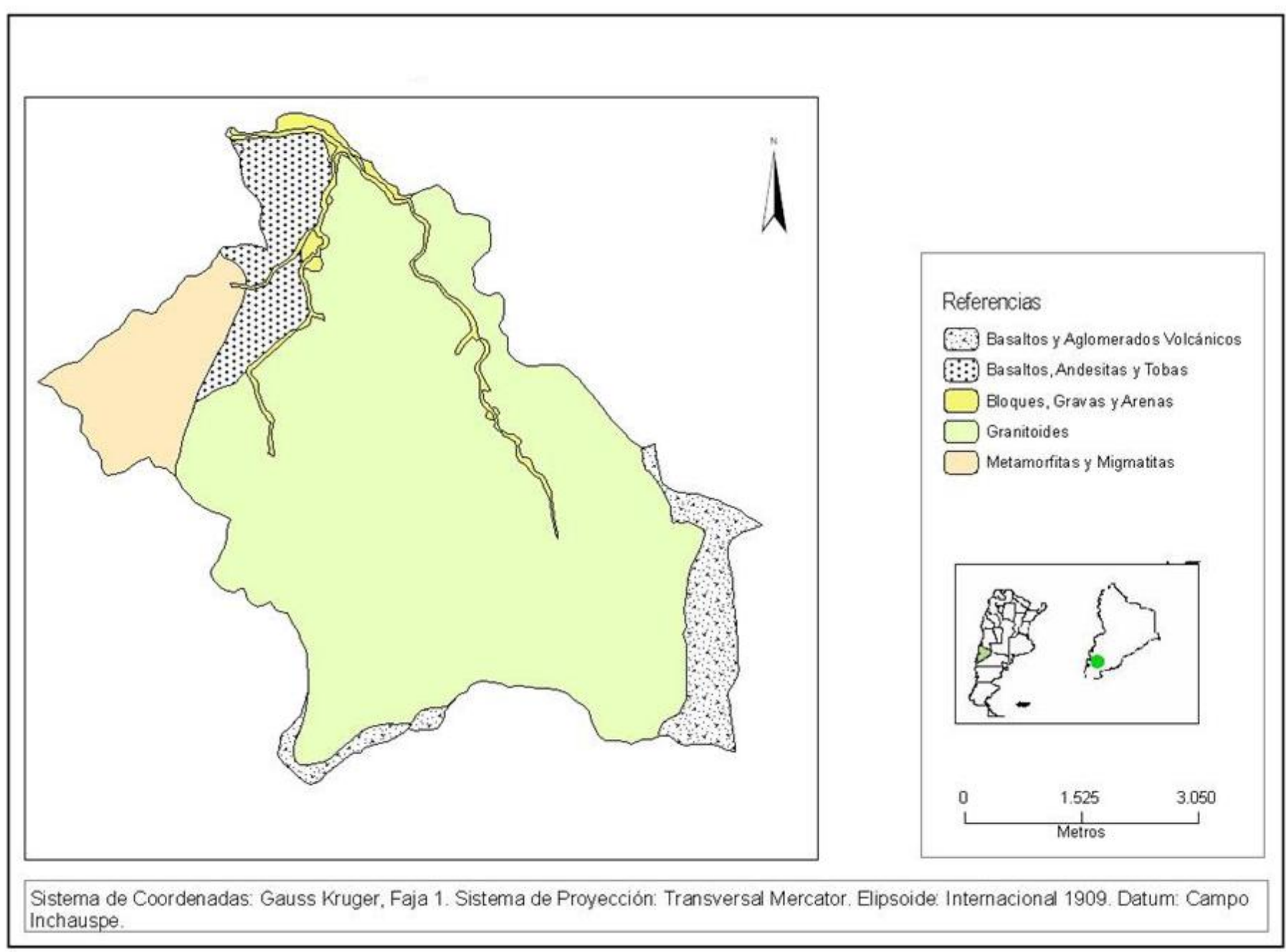

Figura 16: Mapa geológico de las subcuencas de los arroyos Trabunco-Quitrahue. 


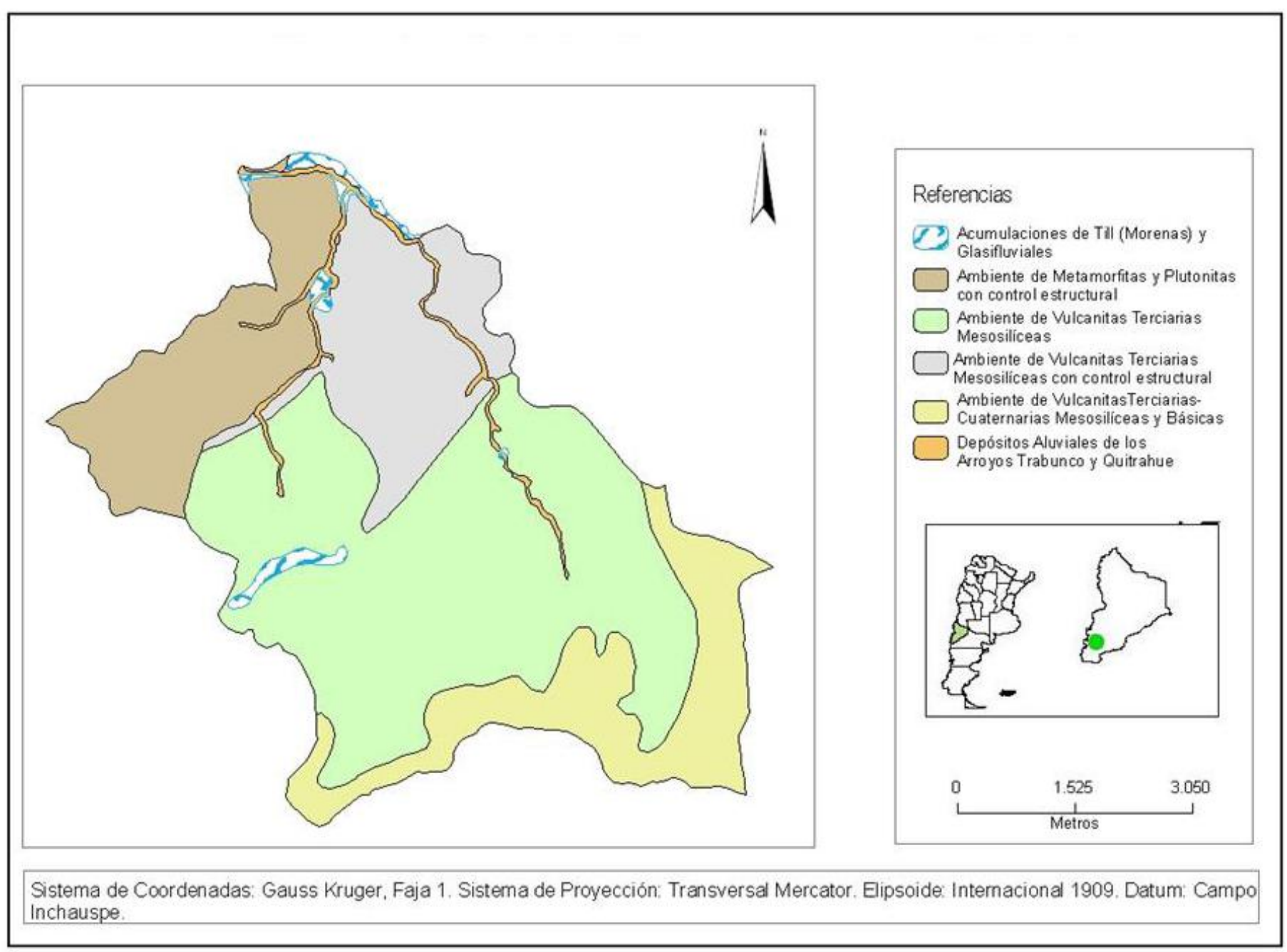

Figura 17: Mapa geomorfológico de las subcuencas de los arroyos Trabunco-Quitrahue. 


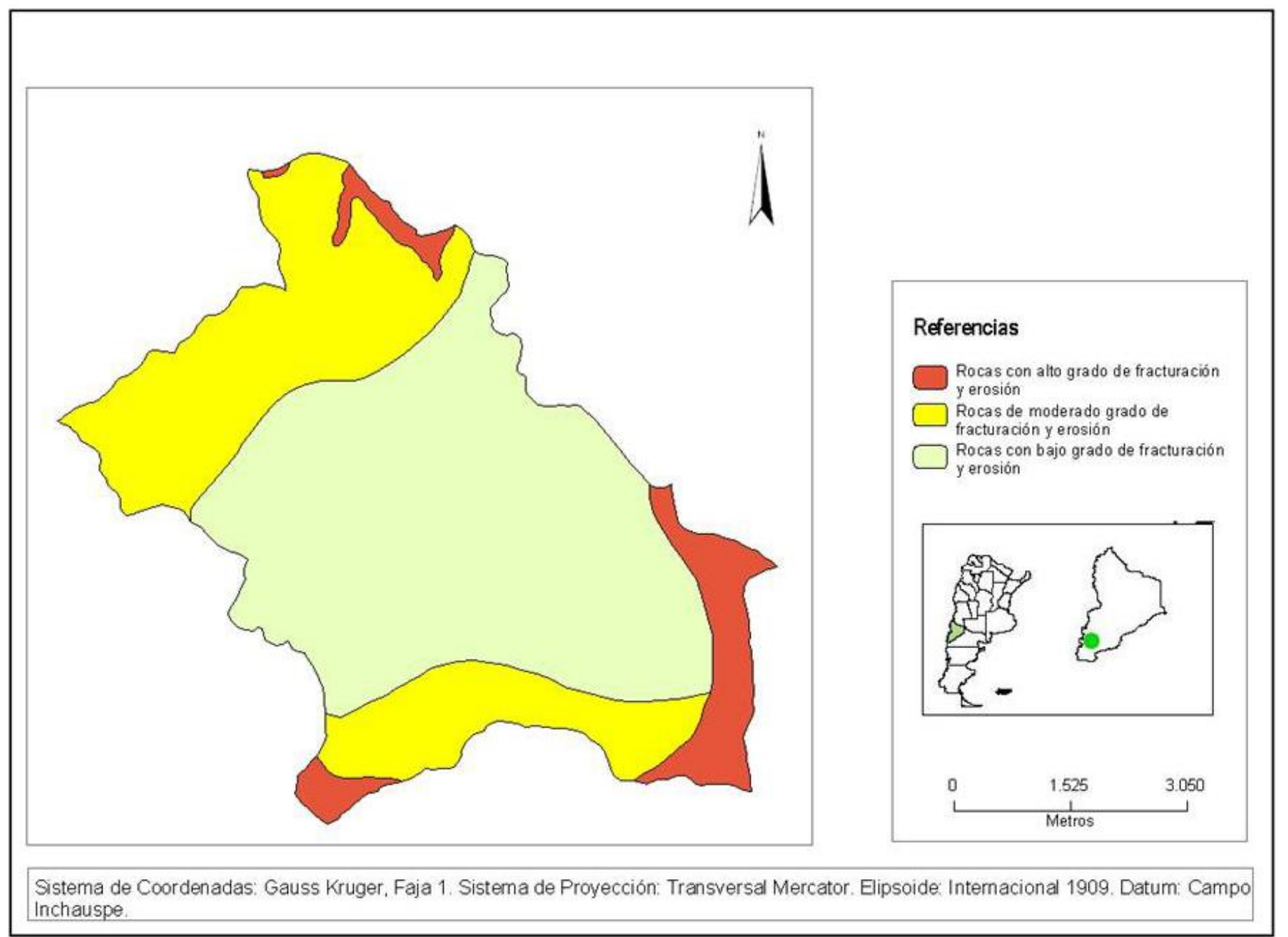

Figura 18: Mapa de zonas geológicas críticas de las subcuencas de los arroyos Trabunco-Quitrahue. 


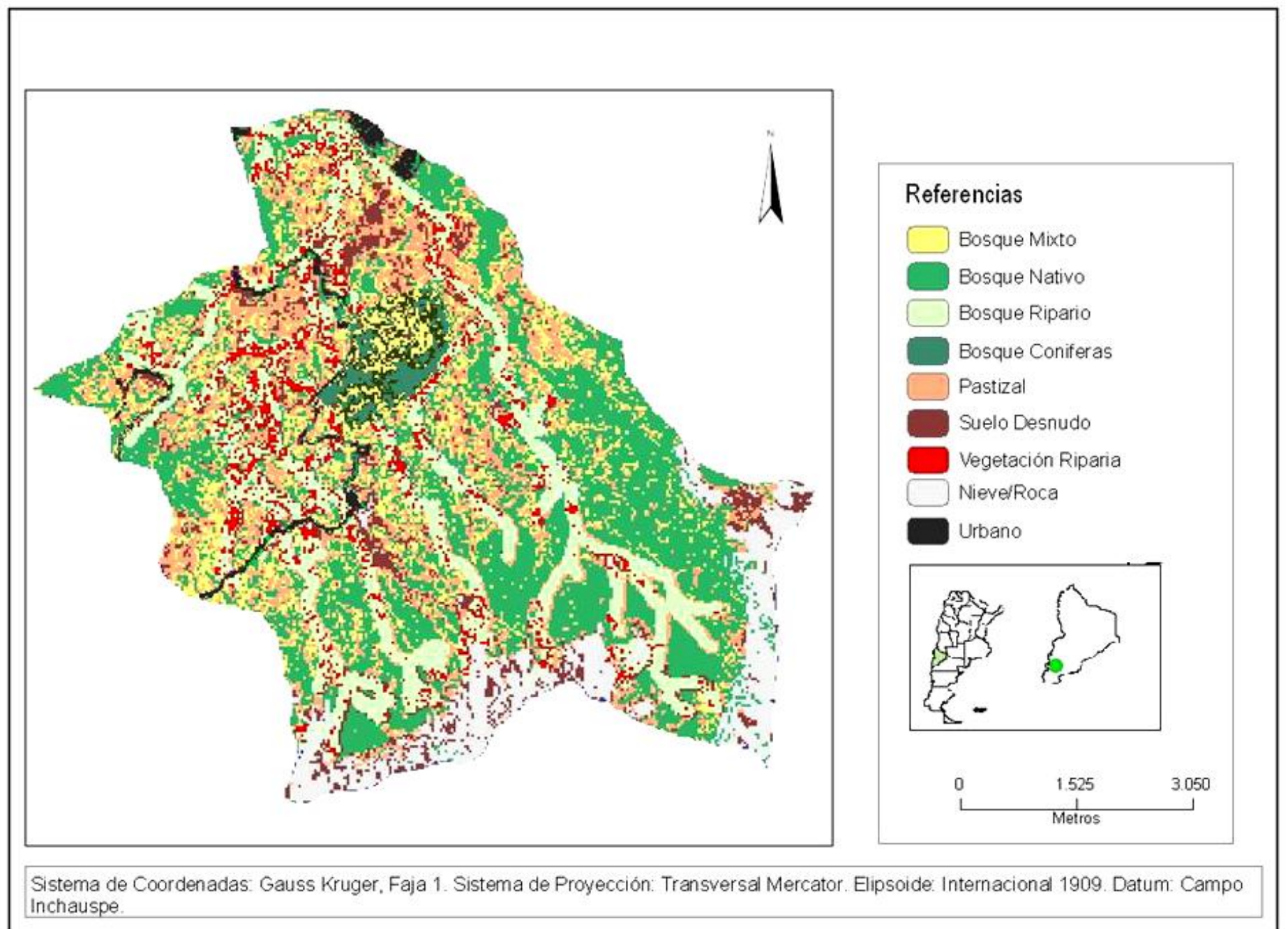

Figura 19: Mapa tipos de coberturas de las subcuencas de los arroyos Trabunco-Quitrahue. 


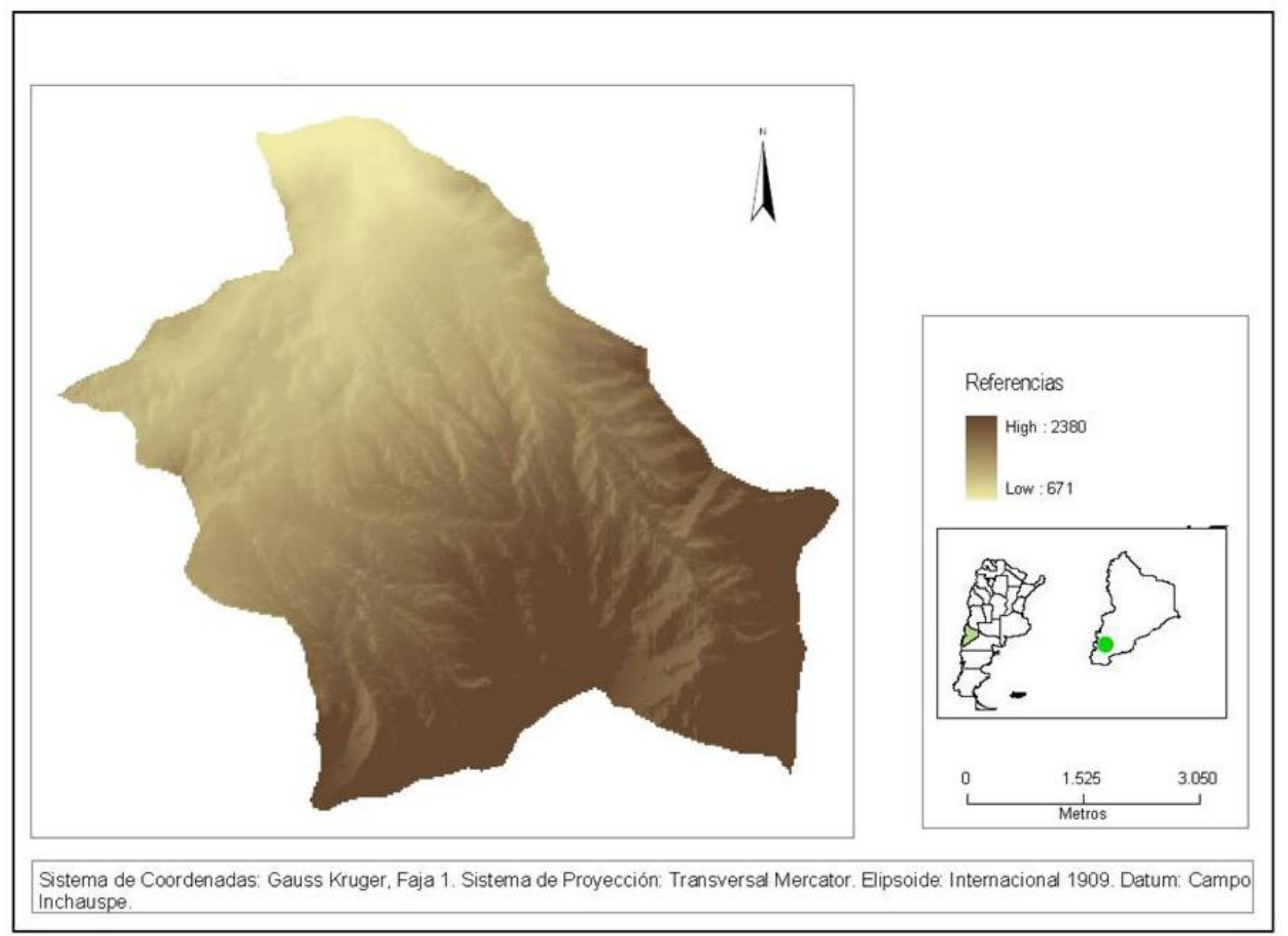

Figura 20: Mapa de modelo digital de elevaciones de las subcuencas de los arroyos Trabunco-Quitrahue. 


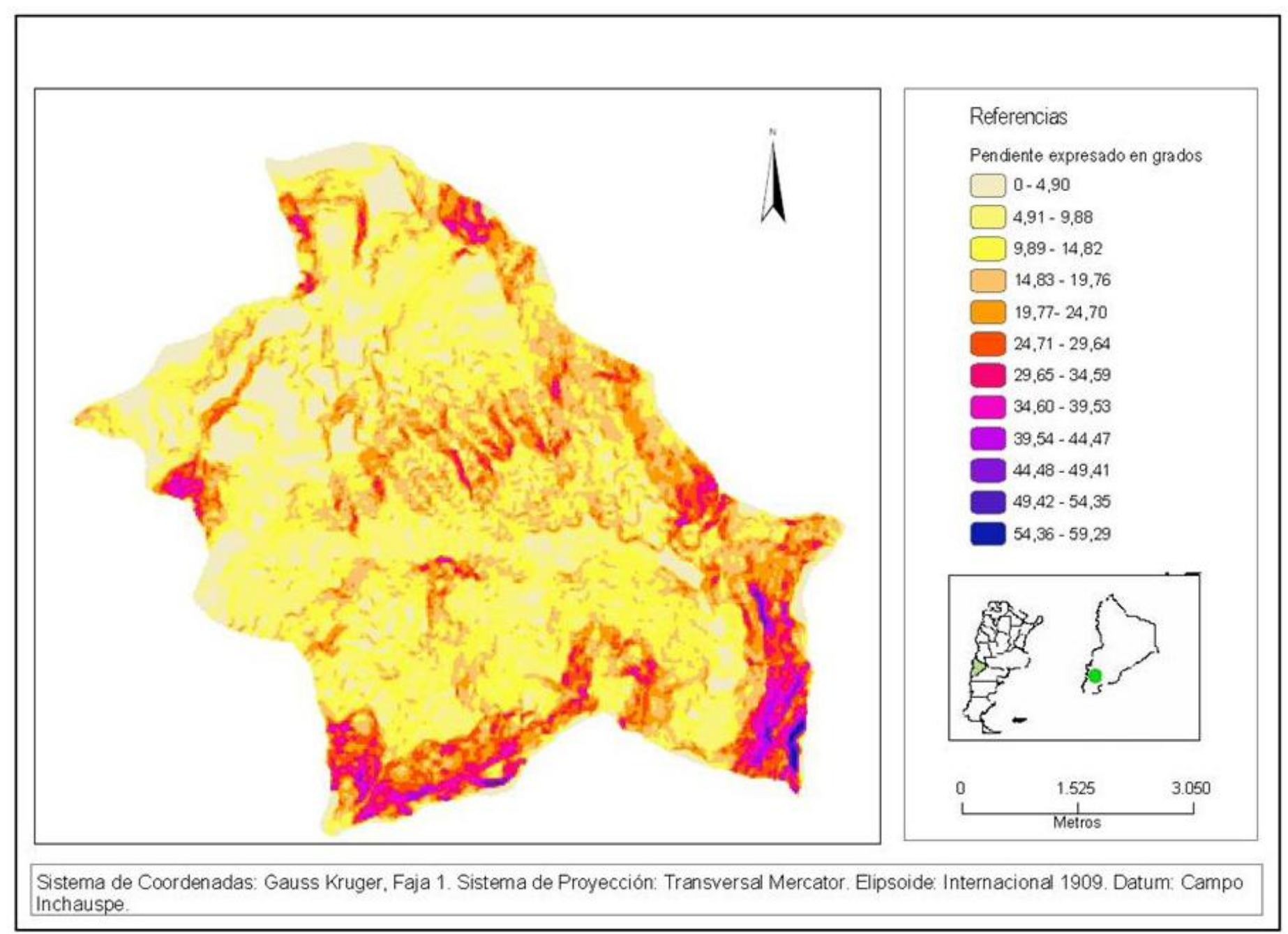

Figura 21: Mapa de pendientes de las subcuencas de los arroyos Trabunco-Quitrahue. 


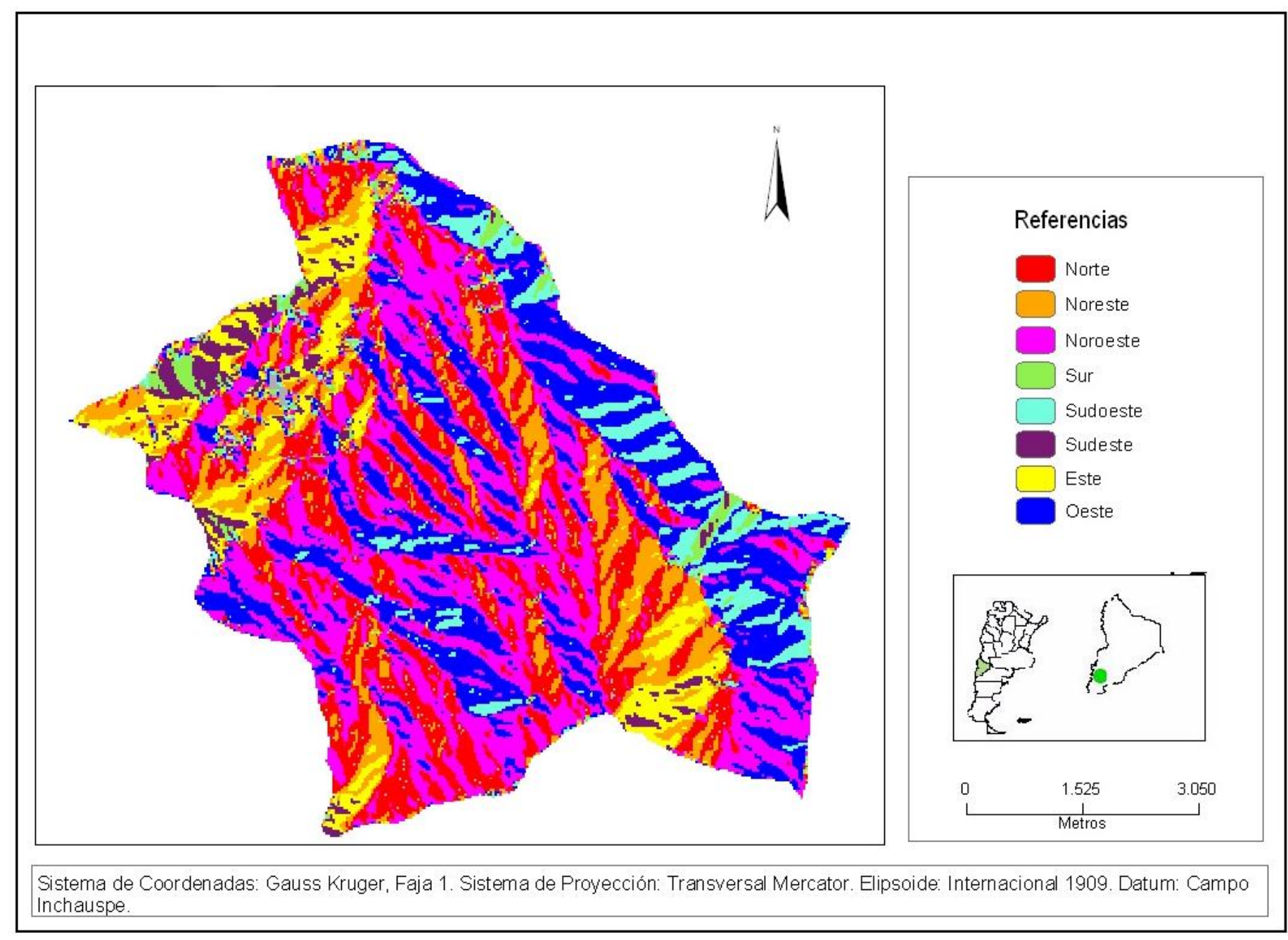

Figura 22: Mapa de exposiciones de laderas de las subcuencas de los arroyos Trabunco-Quitrahue. 


\section{Capítulo IV}

\section{Identificación de áreas prioritarias para la protección de los recursos naturales a través de un análisis multicriterio espacializado}

\section{Introducción}

Al planificar una intervención territorial es necesario elaborar estrategias e instrumentos que faciliten la toma de decisiones basadas en la información ambiental disponible. Esto implica definir un procedimiento lógico que guíe el proceso de toma de decisiones (Eastman, 2001).

La evolución histórica de la aplicación de modelos a la resolución de problemas de recursos naturales muestra un cambio en los objetivos de los modelos desde lo científico a lo técnico y más recientemente a la gestión y administración de sistemas ambientales (Bereciartua, 2003).

Cualquier decisión involucra la posibilidad de elegir entre varias opciones, lo cual significa necesariamente una comparación de los atributos que las distinguen. Un análisis multicriterio es la formalización matemática de este proceso de elección.

El análisis multicriterio constituye una de las maneras de modelizar los procesos de decisión (Figura 23). Mediante este procedimiento los tomadores de decisión pueden estimar las posibles consecuencias, de modo de obtener una mejor comprensión de las vinculaciones entre sus acciones y sus objetivos. 


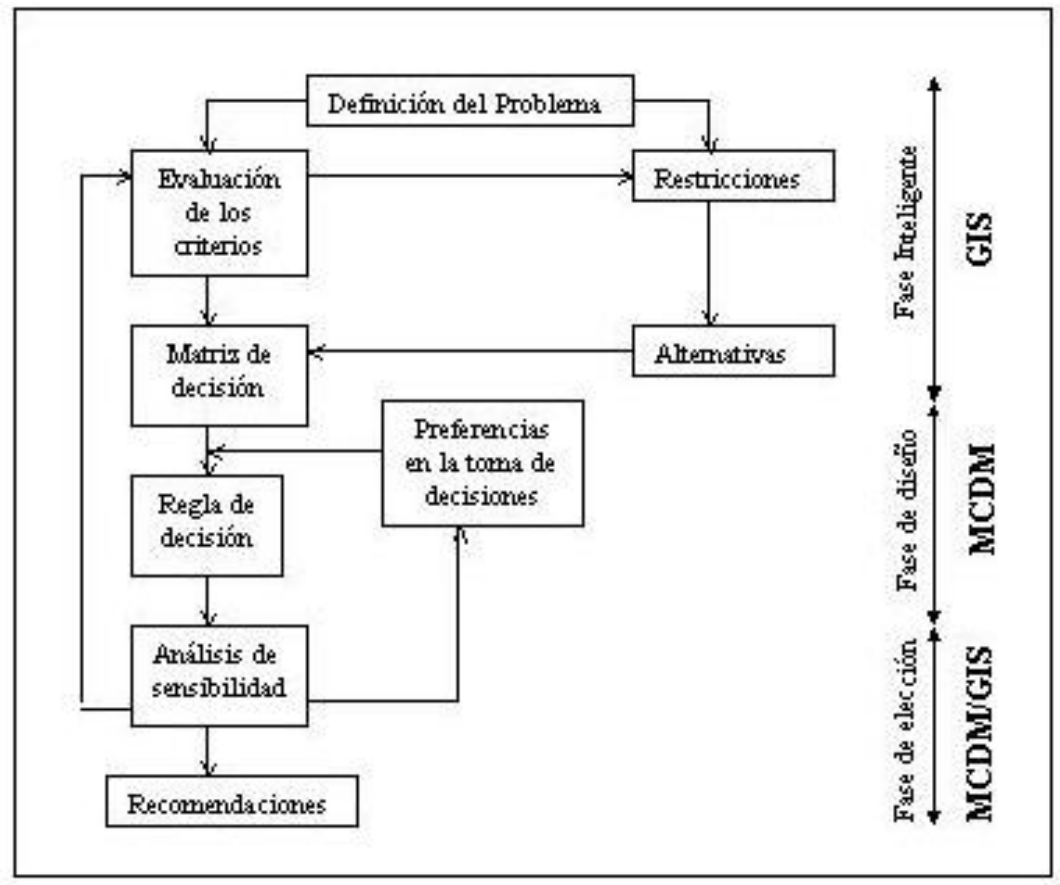

Figura 23: Diagrama de flujo del Análisis Multicriterio Espacial (Modificado de Ascough et al., 2002).

Por lo tanto los principios a considerar para el desarrollo de un análisis multicriterio para la toma de decisiones, son (Malczewski, 1999):

$1=$ El modelo es desarrollado siguiendo los principios de generalización y simplificación de la realidad, este debe ser fácil de entender y simple de comunicar e informar.

2- El número de criterios de evaluación deben ser definidos de forma que el modelo describa de la mejor manera posible la problemática, con la menor cantidad de criterios posibles, cuanto más criterios de evaluación son utilizados en el desarrollo del modelo, más complicado se hace el mismo.

3- La evaluación de los criterios debe ser explícita, cuantificable, operacional, no redundante y simple.

La integración de los análisis multicriterios con las técnicas SIG ha avanzado considerablemente desde los enfoques de superposición de mapas convencionales hacia los análisis de aptitud de uso del suelo (Carver, 1991; Eastman, 1999; Malczewski, 1999).

Durante las últimas décadas estas prácticas se han ido implementando en el ambiente SIG incluyendo distintos procedimientos tales como: la combinación lineal ponderada (WLC) y sus variantes (Carver, 1991; Eastman, 1999) y las operaciones 
de superposición booleana. Estas rutinas son consideradas las más sencillas y comúnmente usadas. Por lo tanto el análisis multicriterio se logra generalmente a través de uno de estos procedimientos.

En la superposición booleana todos los criterios son reducidos a declaraciones lógicas de adecuación y luego combinados por medio de uno o más operadores como la intersección (AND) y la unión (OR).

En la combinación lineal ponderada los criterios continuos (factores) son estandarizados en un rango numérico común, y luego combinados por medio de un promedio ponderado, dando un "mapa de aptitud" continuo. El resultado de esta agregación llamada $\left(R_{i}\right)$ es calculado para cada celda (i), por la siguiente ecuación:

$$
R_{i}=\Sigma_{j} w_{j} x_{i j}
$$

donde $x_{i j}$ es el valor de la celda (i) para el criterio $j$ y $w_{j}$ es el peso de este criterio.

La razón por la cual esta técnica es una de las más utilizadas radica en el hecho de que puede ser aplicada a través de cualquier SIG con capacidades de superposición básica. Eastman (1999), así como Malczewski (1999), destacan que la WLC involucra la aceptación de dos supuestos: la linealidad y aditividad. La linealidad implica que el beneficio de una mayor entrada de un criterio es constante e independiente de las características del problema, y la aditividad implica la independencia entre las variables (criterios).

Además de la facilidad con la que estos enfoques pueden implementarse, la estrategia booleana domina los enfoques vectoriales, mientras que la WLC domina las soluciones en los sistemas raster. Pero claramente, ninguno es mejor que el otro, simplemente representan dos perspectivas muy diferentes sobre el proceso de decisión.

Existe una tercera opción para el análisis multicriterio conocida como promedio ponderado ordenado (OWA) (Eastman y Jiang, 1996). Este método ofrece un espectro completo de estrategias de decisión a lo largo de las dimensiones primarias del grado de intercambio involucrado y del grado de riesgo en la solución. El enfoque es similar a la WLC, con la excepción de que aparece un segundo grupo de pesos (Eastman y Jiang, 1996; Yager, 1988).

De manera general el procedimiento para la conformación del modelo multicriterio debe (Eastman, 2001; Guerrero Borges et al., 2005):

$>$ definir el objetivo (Ej.: identificación de áreas críticas, frágiles, prioritarias; etc.) 
$>$ elaborar un modelo conceptual del sitio óptimo (en función de características físicas, bióticas y socioeconómicas)

$>$ identificar criterios de decisión (factores y condicionantes), utilizando indicadores ambientales. Estos criterios toman en cuenta variables del medio físico, biótico y socioeconómico.

El objetivo del análisis multicriterio aplicado al presente estudio es identificar espacialmente las áreas sensibles, prioritarias para la protección de los recursos naturales de las subcuencas de los arroyos Trabunco-Quitrahue.

\section{Marco teórico}

El análisis multicriterio, conocido como promedio ponderado ordenado, provee un continuo entre operadores difusos que van desde la lógica de intersección a la lógica de unión, es decir además de los pesos en los factores, aplica un segundo grupo de pesos, los "pesos de orden" los cuales controlan la manera en la cual los factores (criterios) ponderados son agregados (Eastman y Jiang, 1996; Yager, 1988).

Los pesos de factores son pesos que se aplican en factores específicos, es decir, todos los píxeles de una imagen particular de factores reciben el mismo peso de factor. Éstos indican el grado relativo de importancia que cada factor posee para determinar la aptitud de un objetivo, esto se aplica en la metodología de combinación lineal ponderada.

Los enfoques booleanos son funciones extremas que resultan en soluciones adversas al riesgo cuando se emplea el operador AND, o bien en soluciones riesgosas cuando se emplea el operador $O R$. En el primero, un valor alto de adecuación agregada para una posición dada (píxel) sólo es posible si todos los factores tienen valores altos. En el segundo, un valor alto en cualquier factor produce un valor agregado alto, aún si todos los demás factores tienen valores muy bajos.

La operación AND puede describirse como el mínimo, ya que el valor mínimo para cualquier píxel determina el valor agregado final. De manera similar, la operación $O R$ puede llamarse el máximo, ya que el valor máximo para cualquier píxel determina el valor agregado final.

La solución AND es adversa al riesgo porque el valor para cada factor es al menos tan bueno como el valor agregado final. La solución OR es riesgosa porque el valor agregado final sólo dice el valor de adecuación para el único factor más adecuado. 
En la metodología OWA el uso de los pesos de orden, permiten soluciones agregadas que se encuentran en cualquier parte dentro del continuo de riesgo entre AND y OR.

Los pesos de orden son bastante diferentes a los pesos de factor. No se aplican a ningún factor específico. En cambio, son aplicados sobre una base de píxel por píxel en valores de factor determinados por su orden de puntaje entre los factores en cada posición (píxel).

Es decir, el peso de orden 1 es asignado al criterio de menor puntaje para ese píxel (el atributo con el valor más bajo), el peso de orden 2 es asignado al criterio de puntaje siguiente para ese píxel, y así sucesivamente. Entonces, es posible que un solo peso de orden pueda ser aplicado a los píxeles desde cualquiera de los criterios dependiendo de su orden de puntaje relativo. El grado de intercambio está gobernado por la distribución relativa de los pesos de orden entre los factores evaluados. Entonces, si la suma de los pesos de orden está repartida en partes iguales entre los criterios, hay un intercambio fuerte. En cambio, si todo el peso es asignado a un solo rango de criterios, no hay intercambio.

Para un conjunto dado de $n$ criterios, OWA se define como vinculado a un conjunto de pesos de orden $v=v_{1}, v_{2}, \ldots v_{n}$ tal que $v_{j} \in[0,1]$, $j=1,2, \ldots n$, entonces $\Sigma_{j} v_{j}=1$. Dado entonces un conjunto de valores de atributos $x_{i 1}, x_{i 2}, X_{\text {in }}$ asociados con una localización ith (raster):

\section{$O W A=\Sigma_{j} v_{j} z_{i j}$}

Donde $z_{\mathrm{i} 1} \geq z_{\mathrm{i} 2} \geq \ldots . \geq z_{\text {in }}$ es la secuencia obtenida por reordenamiento de los valores de los atributos: $x_{i 1}, x_{i 2}, \ldots . ., x_{i n}$ en orden descendente (Yager, 1988). El proceso de reordenamiento es fundamental para los operadores OWA. Se trata de asociar un peso, $v_{j}$, con una posición de orden particular de los valores de los atributos $x_{i 1}$, $x_{i 2}, \ldots . ., x_{\text {in }}$ en la ienesima ubicación. Por lo tanto, un valor particular de $x_{i j}$ no está asociado con un peso $v_{j}$, sino más bien se le asigna un orden de peso.

El método OWA es particularmente interesante porque provee un rango de procedimientos de agrupamiento. Permite a los usuarios cambiar la forma de combinación de los criterios desde un método de mínimo riesgo (AND lógico), donde un valor alto de aptitud para un píxel dado solo es posible si en todos los factores tienen valores altos para incluirlo en el grupo de decisión.

En el otro extremo el riesgo es máximo ( $O R$ lógico), ya que un valor alto en cualquier criterio es suficiente en sí mismo para avalar la inclusión en el grupo de decisión sin tener en cuenta si los demás factores tienen valores bajos.

De este modo las diferentes combinaciones de pesos de orden permiten establecerse en cualquier posición del espacio de decisión (Figura 24) y por lo 
tanto obtener diferentes resultados en cuanto a situaciones de menor o mayor riesgo, así como también distintos grados de compensación.

Por lo tanto, en la situación intermedia donde todos los pesos de orden son iguales resulta en la metodología de combinación lineal ponderada, a mitad de camino entre los extremos, donde no se considera que los criterios sean necesarios ni suficientes; el fuerte apoyo por la inclusión en el grupo de decisión de un criterio puede ser nivelado por un apoyo menor de otro. Entonces, ofrece un intercambio completo y por lo tanto la situación intermedia entre un riesgo mínimo a un riesgo máximo.

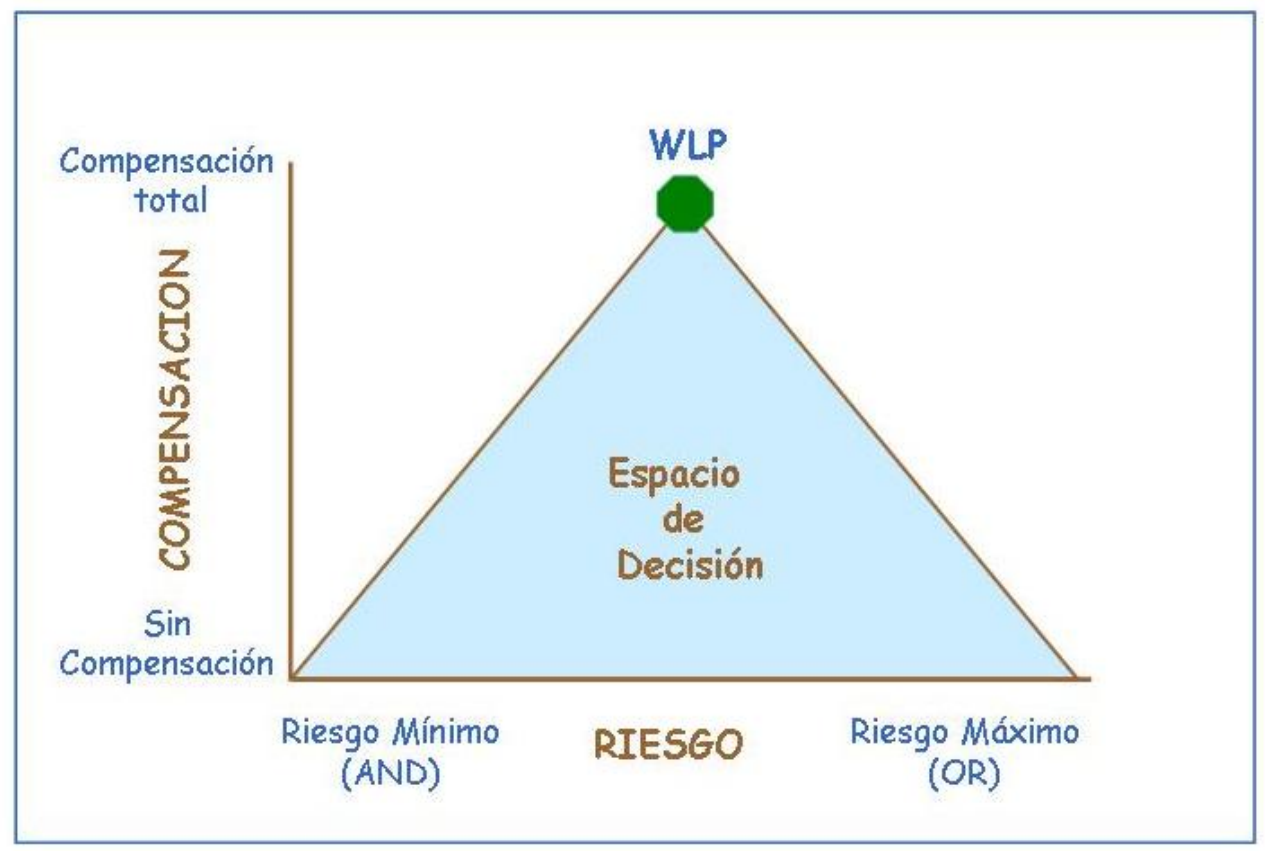

Figura 24: Espacio de decisión del riesgo y compensación (basado en Eastman, 2003).

Debido a la naturaleza de esta metodología es interesante para el objetivo "áreas prioritarias de protección de los recursos naturales", plantear diferentes escenarios. Es decir escenarios que puedan abarcar desde una situación más conservadora y sin riesgo, pasando por escenarios de riesgo intermedio hasta una situación más riesgosa. Esto se lleva a cabo aplicando diferentes pesos de orden a los criterios establecidos.

Como se indicó anteriormente, el análisis multicriterio se ocupa de cómo combinar la información de varios criterios para formar un solo índice de evaluación. Debido a las diferentes escalas sobre las cuales se miden los criterios, es necesario estandarizar los factores antes de combinarlos y transformarlos, de manera tal que todos los mapas de factores se correlacionen positivamente con la adecuación.

Para este trabajo se utilizará el método OWA pero con la incorporación de los pesos de importancia. Por tal motivo, en el enfoque convencional de OWA (OWA= 
$\Sigma_{\mathrm{j}} v_{\mathrm{j}} z_{\mathrm{ij}}$ ), debe ser necesario incorporar los pesos de importancia de los criterios, $w_{j}$ a la ecuación general.

Eastman (1999) propone una modificación para incorporar el criterio de pesos, wj, en el procedimiento de OWA. Se sugirió la siguiente fórmula (WOWA) para la agregación:

$$
\text { WOWA }=\Sigma_{j}\left(v_{j} w_{j} z_{i j} / \Sigma_{j} v_{j} w_{j}\right)
$$

En la ecuación anterior puede ser reconocida la combinación lineal ponderada modificada. Las ponderaciones se obtienen multiplicando los pesos de importancia de los criterios por los pesos de orden.

Por otro lado, la estandarización, es un paso importante, ya que depende del criterio del investigador y del conocimiento de las variables con respecto al objetivo del trabajo. Existen distintos métodos como el determinista, probabilístico o de conjuntos difusos que pueden aplicarse según el tipo de variable que conforme el criterio (Voogd 1983; Massam 1988; Thomas y Huggert, 1980; Klir y Yuan, 1995; Eastman et al. 1993, Eastman, 1999; Ross, 1995).

Cada criterio puede ser de dos tipos como se explicó anteriormente: restricciones - factores. Los factores continuos de la toma de decisiones multicriterio son funciones de pertenencia de grupos difusos, mientras que las restricciones booleanas son funciones de pertenencia de grupos rígidos.

Hay muchas funciones para estandarizar los factores continuos: sigmoidal, en forma de J, lineal, etc. (Ver figura 25). La función de pertenencia sigmoidal ("en forma de $s^{\prime \prime}$ ) es tal vez la más comúnmente usada en la teoría de grupo difuso.

Como se observa en la figura 25 se requieren las posiciones (del eje $X$ ) de 4 puntos de inflexión que manejan la forma de la curva. Esta misma función puede tomar formas diferentes: monotónicamente creciente, monotónicamente decreciente, simétrica, etc.

La función en forma de $\mathrm{J}$ también es bastante común, aunque en la mayoría de los casos la función sigmoidal es mejor para ciertas variables. Por último se puede observar en la figura 25 la función lineal y sus variantes.

En la evaluación multicriterio, la pertenencia a grupo difuso se usa en la estandarización de criterios. Exactamente qué función debe usarse depende del entendimiento de la relación entre el criterio y el grupo de decisión, y en la disponibilidad de información para inferir la pertenencia difusa. En la mayoría de los casos, la función sigmoidal o bien la lineal son suficientes (Eastman, 2003).

Los valores resultantes de la estandarización se encuentran en el rango de 0 a 1 (escala real) o de 0 a 255 (escala bytes). A valores más cercanos a 1 ó 255, mayor 
el valor de aptitud del factor y de la probabilidad de pertenecer al grupo de decisión. Un punto crucial en la estandarización es la elección de los puntos finales en los cuales la pertenencia de grupo alcanza 0,0 ó 1,0 (ó 0 y 255).

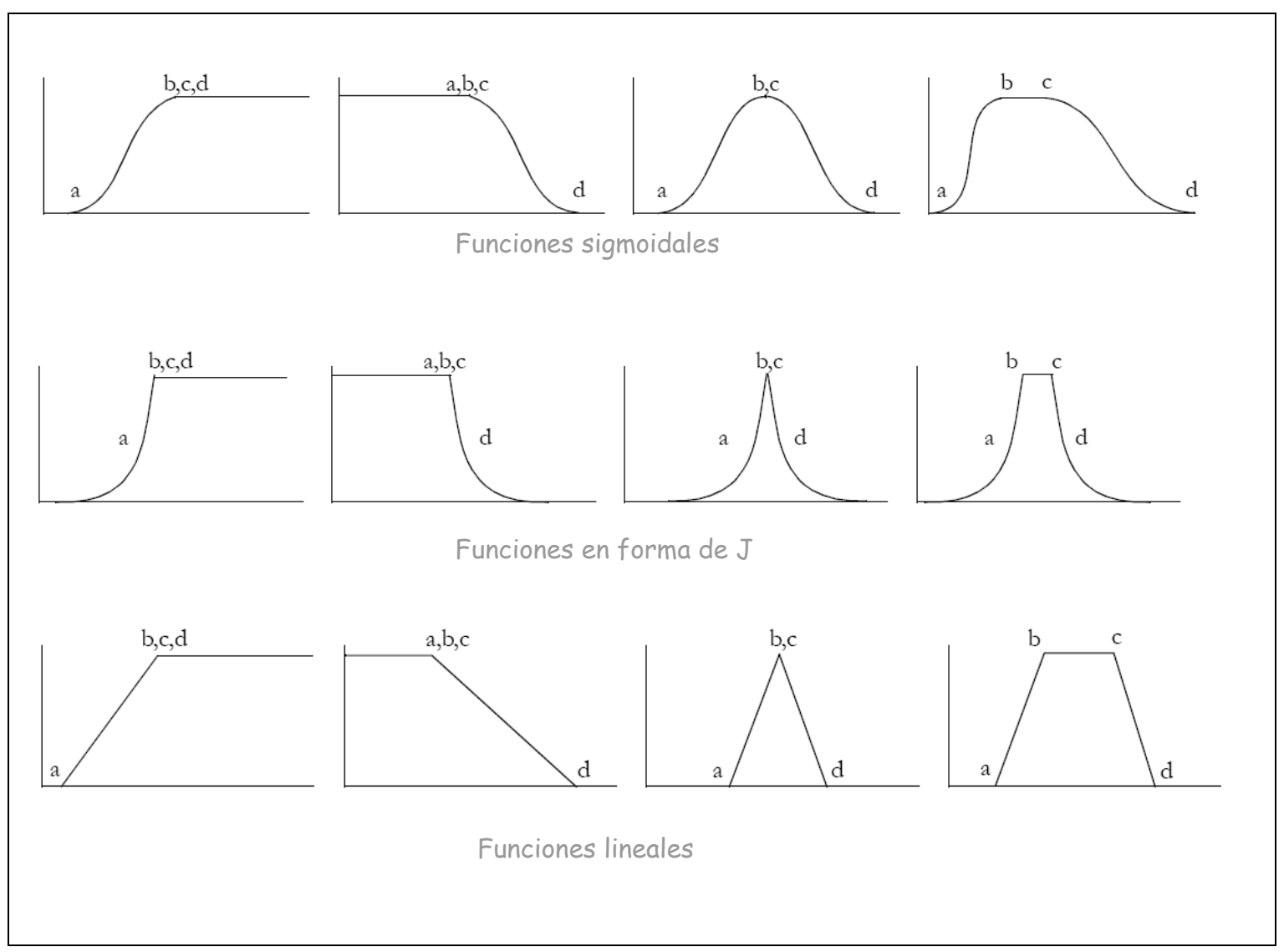

Figura 25: Funciones de estandarización de factores utilizadas en los análisis multicriterios.

Otro de los pasos en el análisis multicriterio es la asignación de pesos de importancia a cada factor. Existe una variedad de técnicas para la creación de pesos de importancia a las variables o factores.

En los casos muy simples, la asignación de la ponderación de los criterios puede lograrse dividiendo 1,0 por los criterios. Sin embargo, cuando el número de criterios es mayor $y$ las consideraciones son muchas, es dificultoso hacer evaluaciones de pesos de un grupo completo.

Aquí se utilizará la técnica de comparación por pares desarrollada por Saaty (1977) en el contexto de un proceso de toma de decisión conocido como Proceso de Jerarquía Analítica (AHP). Esta metodología compara los factores de a pares lo 
cual tiene la ventaja de proveer una estructura organizada para las discusiones de grupo y de ayuda al mismo a la toma de decisiones.

En el procedimiento para el análisis multicriterio, es necesario que los pesos sumen uno. En la técnica de Saaty, los pesos de esta naturaleza pueden derivarse tomando el vector propio principal de una matriz recíproca cuadrada de comparaciones por pares entre criterios.

Las comparaciones se ocupan de la importancia relativa de los dos criterios involucrados al determinar la adecuación para el objetivo planteado. Los puntajes se proveen sobre una escala continua de 9 puntos (Figura 26).

Por ejemplo, si se considera que la proximidad a los arroyos es mucho más importante que el gradiente de las pendientes para determinar un objetivo dado, se debe ingresar un 7 de esta escala. Si ocurre el caso contrario (el gradiente de las pendientes es mucho más importante que la proximidad a los arroyos), se debe ingresar $1 / 7$ (Eastman, 2001).

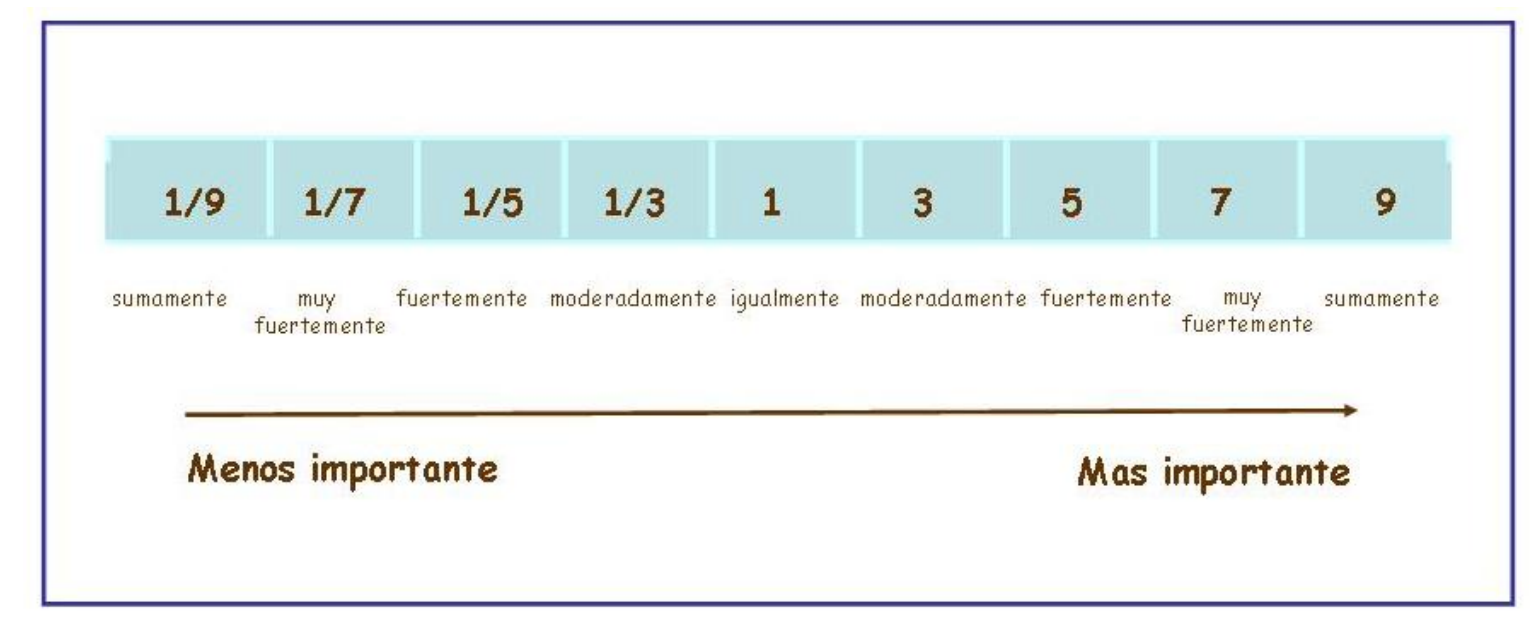

Figura 26: Ranking de valoración de importancia de comparación por pares de factores (Tomado de Eastman, 2001).

Como síntesis de esta sección, se puede observar en la figura 27 , el diagrama de flujo, en el que se indican todos los pasos y procesos involucrados en este trabajo, para la generación del mapa de áreas sensibles y prioritarias para la protección de los recursos naturales a partir de un análisis multicriterio especializado. 


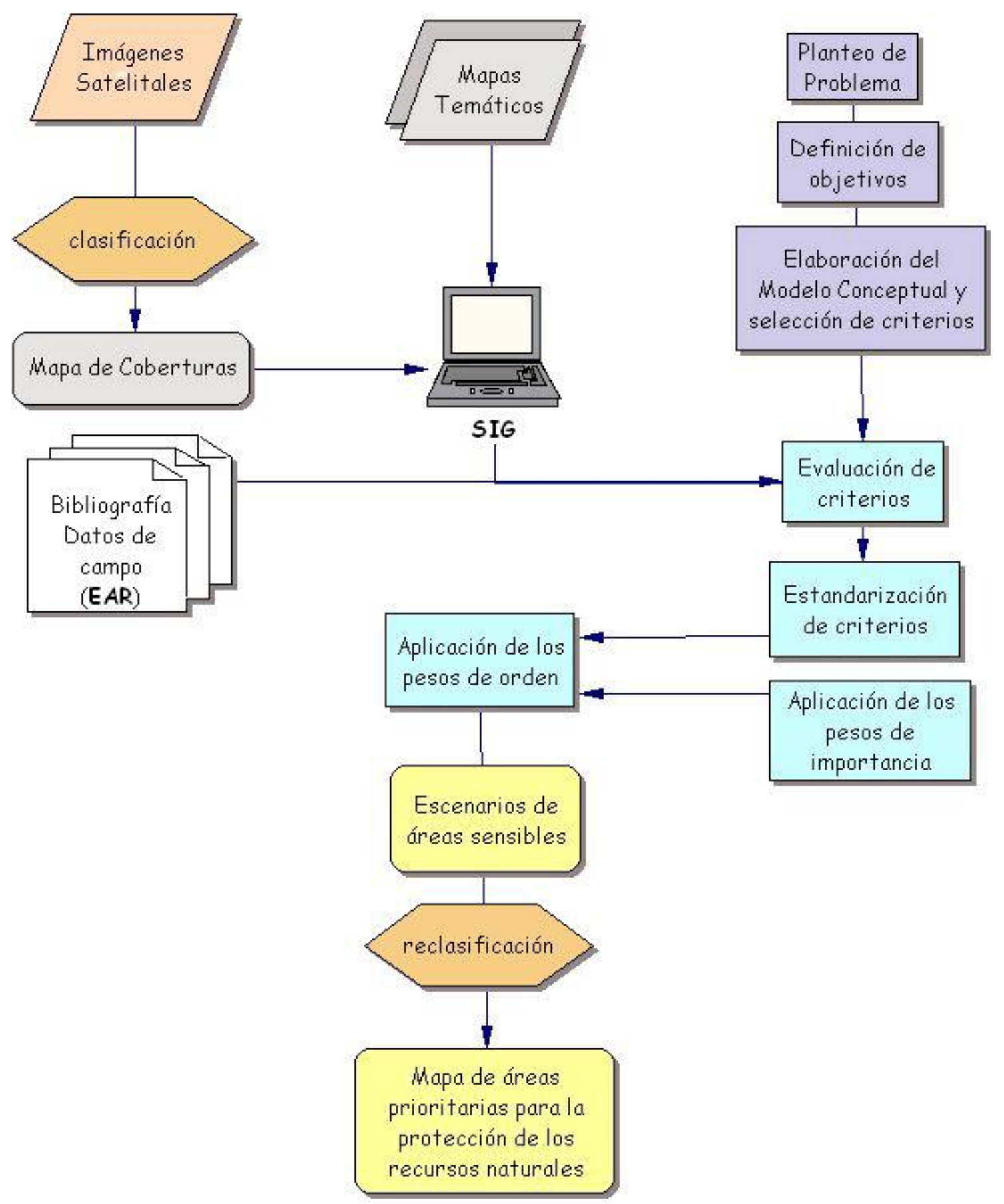

Figura 27: Diagrama de flujo de los pasos que deben realizarse en el análisis multicriterio espacial de las subcuencas de los arroyos Trabunco-Quitrahue. 


\section{Modelo conceptual}

Como se indicó anteriormente, en el procedimiento para la conformación del modelo multicriterio, en principio se debe definir el objetivo, que en este caso es identificar espacialmente las áreas sensibles y prioritarias para la protección de los recursos naturales de las subcuencas de los arroyos Trabunco-Quitrahue y elaborar un modelo conceptual del sitio óptimo (en función de características físicas, bióticas y socioeconómicas).

El modelo conceptual, se definió a través de la lectura de publicaciones especializadas, charlas con expertos y vecinos de las subcuenca TrabuncoQuitrahue.

Las áreas definen su sensibilidad y por lo tanto pasarían a ser prioritarias para su protección de acuerdo a las siguientes características:

Las áreas de mayor sensibilidad deberían estar ocupadas por el bosque: los bosques son esenciales para el bienestar a largo plazo de las poblaciones locales, la solidez de las economías nacionales y la subsistencia de la biosfera terrestre en general. En las subcuencas Trabunco-Quitrahue dichos ecosistemas presentan un buen estado de conservación de la biodiversidad nativa local.

Las comunidades ecológicas aquí presentes son de alto valor de conservación para la Argentina, debido a que tienen una distribución restringida y poca presencia regional, a su vez, algunas de las especies presentes en la región son endémicas de la misma. Los bosques son valiosos por mucho más que los bienes que producen (madera, látex, fruta, plantas medicinales y otros productos no maderables, caza para la alimentación). La existencia de los bosques, sus componentes, interacciones y funciones también ofrecen servicios que influyen en la calidad del agua, el clima, suelos, efectos de fenómenos naturales como fuertes vientos y lluvias, ciclo de nutrientes, descomposición de desechos, valores estéticos, culturales y religiosos.

De acuerdo a la evidencia científica disponible, el bienestar de las poblaciones depende en gran medida del flujo de servicios que los ecosistemas forestales brindan; al mismo tiempo, este flujo depende de la forma en que los ecosistemas son afectados por las actividades humanas (MEA, 2005).

Los servicios ecosistémicos forestales se ven afectados por la degradación y eliminación de los bosques. Por lo tanto, los bosques constituyen uno de los más importantes proveedores de servicios ecosistémicos, fundamentales para sustentar la vida. Entre estos servicios se incluyen (Daily, 1997):

- El mantenimiento de la calidad del aire y de un clima favorable.

- La protección de las funciones hidrológicas y la provisión de agua de calidad para el consumo. 
- La generación y mantenimiento de los suelos y su fertilidad.

- La protección de la diversidad biológica.

- La polinización de cultivos económicamente importantes

- El control biológico de plagas agrícolas.

- La provisión de madera y de una amplia gama de productos no maderables.

- Recursos genéticos usados en programas de mejoramiento de cultivos, etc.

Las áreas más sensibles deberían incentivar la conservación del suelo: el suelo es un componente importante del ecosistema, además es complejo y dinámico, en él se efectúan procesos físicos y transformaciones químicas esenciales para la vida. (Daily et al, 1997). Los organismos del suelo, las plantas, la topografía, el material parental, la textura y la edad del mismo, son factores que influyen en la formación y caracterización de un suelo.

El suelo provee una gran variedad de servicios ecosistémicos que son fundamentales para la vida y que están fuertemente interrelacionados. Además de proveer un soporte físico para las plantas, proporciona nutrientes resultado de las funciones de la actividad microbiana.

El suelo interviene en un rol elemental en la filtración y purificación del agua caída por lluvia y la deposita en acuíferos subterráneos, proporcionando así depósitos de reserva de agua. De manera que los principales servicios provistos por el suelo se pueden enumerar de la siguiente manera (Daily et al., 1997):

- Amortiguador y moderador del ciclo hidrológico.

- Soporte físico para las plantas.

- Retención y liberador de nutrientes para las plantas.

- Descomposición de desechos y de materia orgánica.

- Regeneración de fertilidad del suelo.

- Regulación de los ciclos de los principales elementos químicos.

Las áreas sensibles deberían contribuir a proteger la calidad de las aguas. Las zonas riparias son conocidas por ser especialmente efectivas en la protección de superficies de agua por parte de la escorrentía de nutrientes y se define como la vegetación que se extiende en la tierra, hacia los lados de un cuerpo de agua y provee algún grado de protección o mejoramiento a la misma.

La zona riparia, normalmente tiene buen acceso al movimiento de agua proveniente de las partes altas de la cuenca y muchos estudios demuestran que estas situaciones ubican a la vegetación como áreas buffer de los cuerpos de agua desde 
fuentes difusas o no puntuales de nutrientes. Además de actuar como zonas buffer estas zonas proveen otras funciones muy importantes como (Naiman et al., 2005):

- Crear sombra para reducir la temperatura de las aguas y mejorar el hábitat acuático.

- Proveer una fuente de material necesario para la salud y desarrollo de organismos acuáticos y vida silvestre.

- Servir de amortiguador para filtrar sedimentos, materia orgánica, fertilizantes, plaguicidas y otros materiales contaminantes.

- Actuar como trampas de sedimentos provenientes de la escorrentía y erosión.

- Facilitar el movimiento de ciertas especies a lo largo de la red hidrográfica.

- Reducir los daños por inundaciones.

- Crear una dinámica predecible del cauce y la planicie de inundación.

Las áreas más sensibles deberían encontrarse alejadas de los centros urbanos, caminos y barrios residenciales. los efectos asociados a la urbanización afectan directamente la salud de los ecosistemas. La urbanización implica el avance de la frontera urbana sobre las áreas naturales de la cuenca.

Como consecuencia, se produce deforestación para la construcción de viviendas, aumento de residuos sólidos, efluentes cloacales y pluviales, así como también aumento de la demanda de agua potable y servicios.

Este proceso produce la degradación del paisaje y deterioro de la calidad de las aguas (Miltner et al., 2004).

Muchos autores (Brabyn, 2005) utilizan las variables de distancias a centros urbanos, áreas residenciales, vías de comunicación, etc., además de las características biofísicas para estimar cuán natural es el paisaje. Las zonas alejadas de ciudades, pueblos y vías de comunicación dificultan el acceso y también encarecen la construcción de viviendas y los servicios.

\section{Materiales y métodos}

Luego de definido el modelo conceptual, se debieron seleccionar los criterios o factores que integrarán el análisis multicriterio. Para ello se eligieron las variables de: presencia de bosque y vegetación riparia, distancias a centros urbanos, caminos y barrios residenciales y el índice de inestabilidad del suelo. Todos ellos fueron trabajados en formato raster; en los párrafos siguientes se detalla la construcción de cada uno. 
Una vez definidos los criterios se utilizó la fórmula de WOWA para su combinación. Esta fórmula se encuentra como una rutina del modulo MCE, sin embargo previamente a la agregación, los criterios fueron estandarizados con el modulo FUZZY, asignado los pesos de importancia con el modulo WEIGTH-AHP y seleccionados los pesos de orden, todo con el programa Idrisi 3.2.

\section{Construcción de las variables: presencia de bosque y vegetación riparia}

Para determinar estas condiciones primero se elaboró un mapa de coberturas de las subcuencas de los arroyos Trabunco-Quitrahue, esto se llevó a cabo a través de un proceso llamado clasificación (Para mayor detalle ver el ANEXO II). Clasificar digitalmente una imagen implica categorizar una imagen multibanda. Esto significa reducir la escala de medida, de una variable continua (los valores originalmente obtenidos por el sensor) a una escala nominal o categórica (Chuvieco, 1996).

Existen dos tipos principales de clasificación: la clasificación no supervisada, donde el usuario fija el número inicial de clases que desea obtener y luego el software asigna los píxeles automáticamente a las distintas clases en base a operaciones estadísticas, y la clasificación supervisada, donde el conocimiento previo de la zona de estudio permite al usuario identificar áreas representativas de cada categoría (áreas de entrenamiento).

Para la clasificación se realizó una combinación de los dos métodos a partir de la imagen satelital Lansat 7 ETM+ de enero del 2007.

1. Se realizó una clasificación no supervisada de la imagen, en la cual se generaron cien clases espectrales, que luego se identificaron y se reagruparon para definir clases temáticas.

2. A su vez se realizó una clasificación supervisada de la imagen original, utilizando la combinación de bandas 5-4-3. Mediante esta técnica se pueden seleccionar píxeles de la imagen que representan patrones que se reconocen, o se pueden identificar con la ayuda de otras fuentes. Para la realización de esta técnica se debe tener un conocimiento previo de la zona de estudio.

3. Se realizó la selección de las muestras de entrenamiento (conjunto de píxeles que representan una clase potencial), mediante la definición de polígonos en la imagen. Así, el área de los polígonos se usó para crear una firma. Una vez creadas las firmas que en este caso fueron 38, se aplicó la regla de decisión de mínima distancia con la cual se llevó a cabo la clasificación. El resultado fue una capa temática y un archivo de firmas.

4. Se llevó a cabo una nueva clasificación utilizando los archivos de firmas de la clasificación no supervisada y la clasificación supervisada. De la imagen 
clasificada final con un total de 138 clases se reagruparon a través de la manipulación del archivo de firmas y quedaron definidas las siguientes clases preliminares: bosque de coníferas, bosque nativo, bosque mixto, suelo desnudo, pastizal, roca expuesta y nieve.

Para la incorporación de la clase vegetación riparia (zonas de transición semiterrestres a áreas influenciadas por el agua dulce, normalmente extendiéndose desde los bordes de los cuerpos de agua hasta los bordes de las comunidades litorales; (Naiman et al., 2005) se procedió de la siguiente manera:

Se determinó el ancho de los arroyos, con lo cual se contaba con la siguiente información: 28 perfiles transversales de la zona de la desembocadura del arroyo Trabunco (Damiáni, 1999). Para esta zona y al momento de tomar la medición el valor promedio del cauce del arroyo con agua, arrojó un valor de 9,20 metros de ancho, siendo el valor mínimo 4,19 y el máximo 25,28 metros. Tomando los márgenes del arroyo los valores fueron de 3, 96 la media; 6,47 y 34,65 metros los valores mínimos y máximos. Si bien estos valores fueron tomados en un momento dado, bajo un régimen específico y en una porción muy pequeña de toda la longitud del arroyo Trabunco, nos da una idea de las dimensiones del mismo.

Existen normativas internacionales que protegen la vegetación de los márgenes de los cuerpos de agua; para el caso de la provincia de Neuquén (la cual compete a nuestra área de estudio) no se ha encontrado ninguna referencia de las mismas, pero sí en el caso de otras provincias como Misiones y Tierra del Fuego.

Debido a que los ecosistemas de la zona de estudio y de Tierra del Fuego corresponden a la ecorregión de los bosques andino patagónicos se tomaron los valores expresados en el anexo 1 del decreto 852/95 de la ley Provincial 145 que establece la prohibición de todo tipo de aprovechamiento en masas forestales ubicadas a una distancia menor a: 100 metros de las orillas de lagos, lagunas, costa marítima y rutas nacionales; 50 metros de rutas provinciales, ríos, arroyos, vegas y turbales; y en bosques localizados en terrenos con pendientes superiores a 25 grados. Por lo tanto, se estableció para los arroyos de la cuenca el valor de 10 metros de ancho de cauce con agua, y el de 50 metros desde el cauce, para limitar la extensión de la vegetación ribereña. Se elaboró un buffer de 60 metros sobre los arroyos, luego con la función mask del programa ERDAS IMAGINE 8.5 se extrajo de la imagen ya clasificada. Esta nueva imagen fue exportada al programa ArcView 3.2 y transformada a un archivo grid.

A su vez se elaboraron las coberturas de bosque ripario y vegetación riparia a partir del archivo buffer y la imagen clasificada que contenía las clases parciales de bosque nativo, bosque mixto, bosque en sombra y pastizal. De esta manera se generó un archivo grid conteniendo las coberturas mencionadas que se ubican a una distancia de 60 metros a partir de los arroyos. Esto fue realizado con las funciones clip y reclassify del módulo de análisis espacial del 
programa ArcView 3.2. Finalmente se creó un mosaico entre los archivos que contenían las coberturas parciales y las coberturas de bosque y vegetación riparia.

A partir del mapa de tipo de coberturas final se extrajeron dos capas temáticas: "Bosque" (a través de la reclasificación de las clases bosque nativo, bosque mixto y bosque coníferas) y la capa "Vegetación Riparia" (Figura 28).

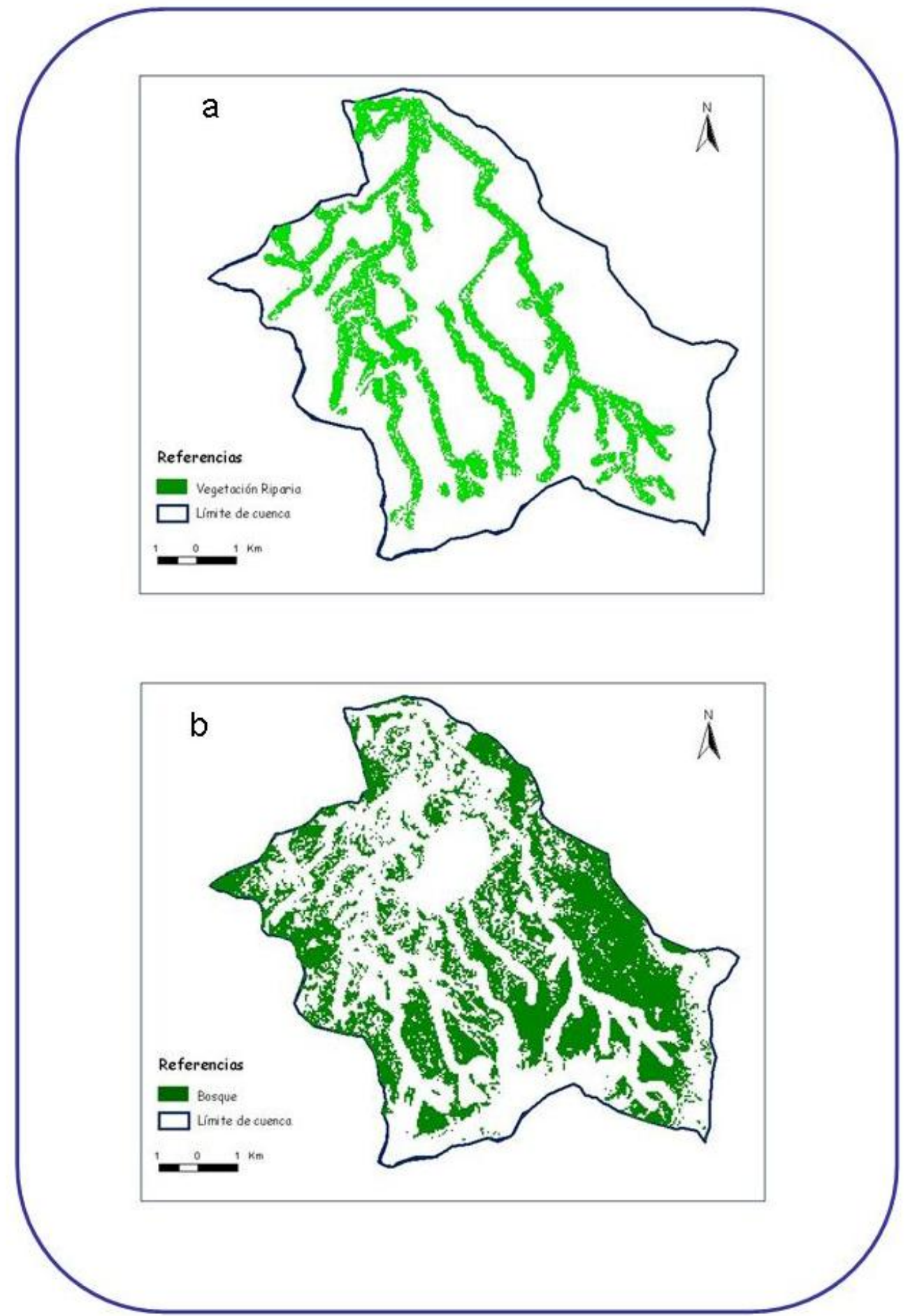

Figura 28: Capas temáticas de vegetación riparia (a) y bosque (b). 
En cuanto al suelo, debido a las características nombradas en el modelo conceptual y a las condiciones detectadas en el análisis ambiental (como sustrato geológico inestable y riesgo de erosión), se optó por implementar un índice que refleje estas circunstancias.

De esta manera, se elaboró el índice de inestabilidad del suelo que representa la fragilidad del suelo frente a los procesos de erosión y deslizamiento de tierra. Se expresa mediante un valor que va de 0 a 250. Donde 0 significa un suelo estable y 250 que el suelo es muy inestable.

Este índice esta formado por tres variables: el grado de fracturación y erosión de las rocas; la profundidad del suelo y la pendiente del terreno. A continuación se describen las mismas.

1. Grado de fracturación y erosión de las rocas (GFyE): esta variable indica las áreas más vulnerables en cuanto al deslizamiento de tierra y derrumbes. Se obtuvo del mapa geológico de zonas críticas, y se expresa en: grado I, II y III siendo rocas con bajo, moderado y alto grado de fractura y erosión respectivamente.

2. Pendiente del terreno ( $P$ ): es sabido que cuanto mayor es el ángulo de la pendiente, mayor será la erosión del suelo, es decir un aumento del ángulo de la misma causa un aumento de la velocidad de escorrentía, con incremento de la energía cinética del agua y una mayor fuerza erosiva. Por lo tanto a mayor pendiente aumenta la probabilidad de erosión del suelo. La variable se obtuvo a partir de la derivación del modelo digital de elevaciones y esta expresada en grados.

3. Profundidad del suelo (PS): la variable se obtuvo a partir del mapa de suelos de las subcuencas de los arroyos Trabunco-Quitrahue (Ver Tabla 5), y se expresa de manera cualitativa en ocho categorías que resumen el grado de profundidad y la pendiente media. En la categoría 1 la profundidad es mayor a 200 centímetros y en la 8 el suelo ha desaparecido quedando expuesta la roca madre. 
Tabla 5: Tipo de suelo, profundidad y pendiente media de las subcuencas de los arroyos Trabunco-Quitrahue

\begin{tabular}{|c|c|c|}
$\begin{array}{c}\text { Categoria } \\
\text { de suelo }\end{array}$ & $\begin{array}{c}\text { Profundidad } \\
\text { del suelo }(\mathrm{cm})\end{array}$ & $\begin{array}{c}\text { Pendiente } \\
\text { media (\%) }\end{array}$ \\
\hline 1 & $>200$ & $1-6$ \\
\hline 2 & $100-200$ & $0-3$ \\
\hline 3 & $100-200$ & $10-15$ \\
\hline 4 & $100-200$ & $15-40$ \\
\hline 5 & $100-200$ & $20-40$ \\
\hline 6 & $<100$ & $>40$ \\
\hline 7 & $\begin{array}{c}\text { Horizonte A } \\
\text { ausente }\end{array}$ & $>40$ \\
\hline 8 & Roca expuesta & $>70$ \\
\hline
\end{tabular}

A su vez, a cada una de estas variables se le asignó un peso de acuerdo a su importancia relativa, el cual resulta de la consulta bibliográfica.

De esta manera el índice de inestabilidad del suelo queda expresado:

$$
\text { IIS }=0,20 \times G F Y E+0,40 \times P+0,40 \times P S
$$

Posteriormente fue espacializado, de modo que cada una de las variables que lo conforman fueron rasterizadas. A continuación se estandarizaron las variables mediante funciones de tipo lineal y sigmoidal respectivamente y se tomaron puntos de control como se indica en la tabla 6. Para este procedimiento se utilizó la rutina de WLC del modulo MCE del programa Idrisi 3.2.

Tabla 6: Estandarización de variables para la elaboración del IIS

\begin{tabular}{|c|c|c|c|c|c|c|}
\hline \multirow[t]{2}{*}{ Variable } & \multirow{2}{*}{$\begin{array}{l}\text { Función de } \\
\text { Estandarización }\end{array}$} & \multicolumn{4}{|c|}{ Puntos de control } & \multirow{2}{*}{$\begin{array}{l}\text { Peso } \\
\text { (w) }\end{array}$} \\
\hline & & $A$ & $B$ & C & $D$ & \\
\hline Profundidad del suelo & Lineal simétrica & 0 & 7 & 7 & 8 & $40 \%$ \\
\hline Grado de fracturación y erosión & Sigmoidal creciente & 0 & 0 & 0 & 3 & $20 \%$ \\
\hline Pendiente del terreno & Sigmoidal creciente & 2 & 2 & 2 & 30 & $40 \%$ \\
\hline
\end{tabular}

Como resultado, el mapa del IIS (Figura 29) expresa diferentes áreas de la cuenca valoradas de 0 a 250 de acuerdo a su grado de inestabilidad. Siendo los valores más altos las áreas de mayor inestabilidad del suelo. 


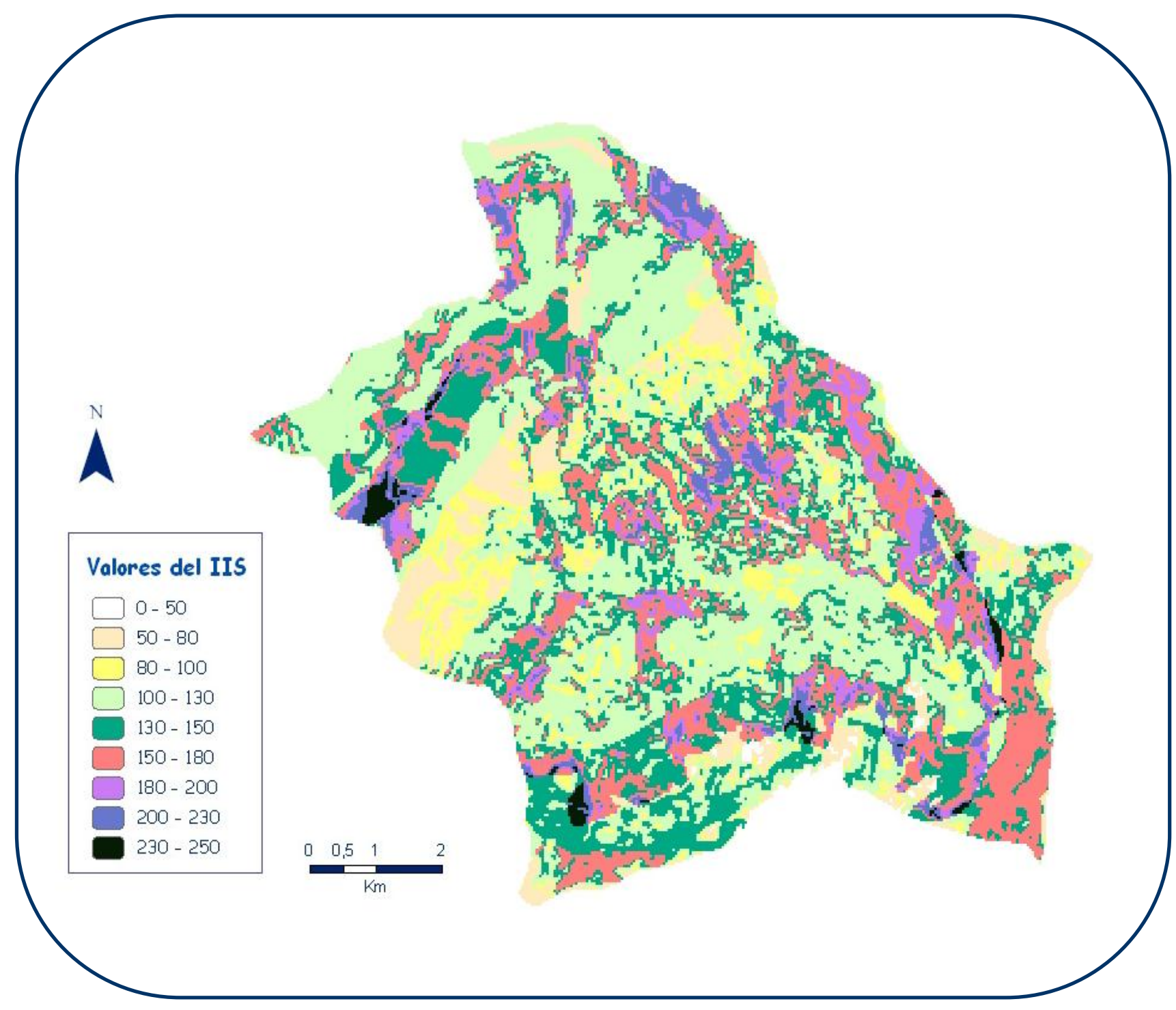

Figura 29: Mapa del índice de inestabilidad del suelo. 
Construcción de las variables de distancia al centro urbano, caminos y barrios residenciales:

Como se mencionó anteriormente, se digitalizaron los caminos de la cuenca pertenecientes a un tramo de la ruta nacional 234 y ruta provincial 19, los polígonos que corresponden a la ciudad San Martín de los Andes y la zona del barrio Covisal y también se tomaron los puntos de ubicación de los barrios residenciales Los Techos y las Pendientes ubicados en la parte alta de la cuenca.

Estos archivos vectoriales se transformaron a archivos raster para poder calcular las distancias a los píxeles involucrados, mediante el módulo find Distance del programa ArcView 3.2. En la figura 30 se observan las variables resultantes, expresadas en metros. 


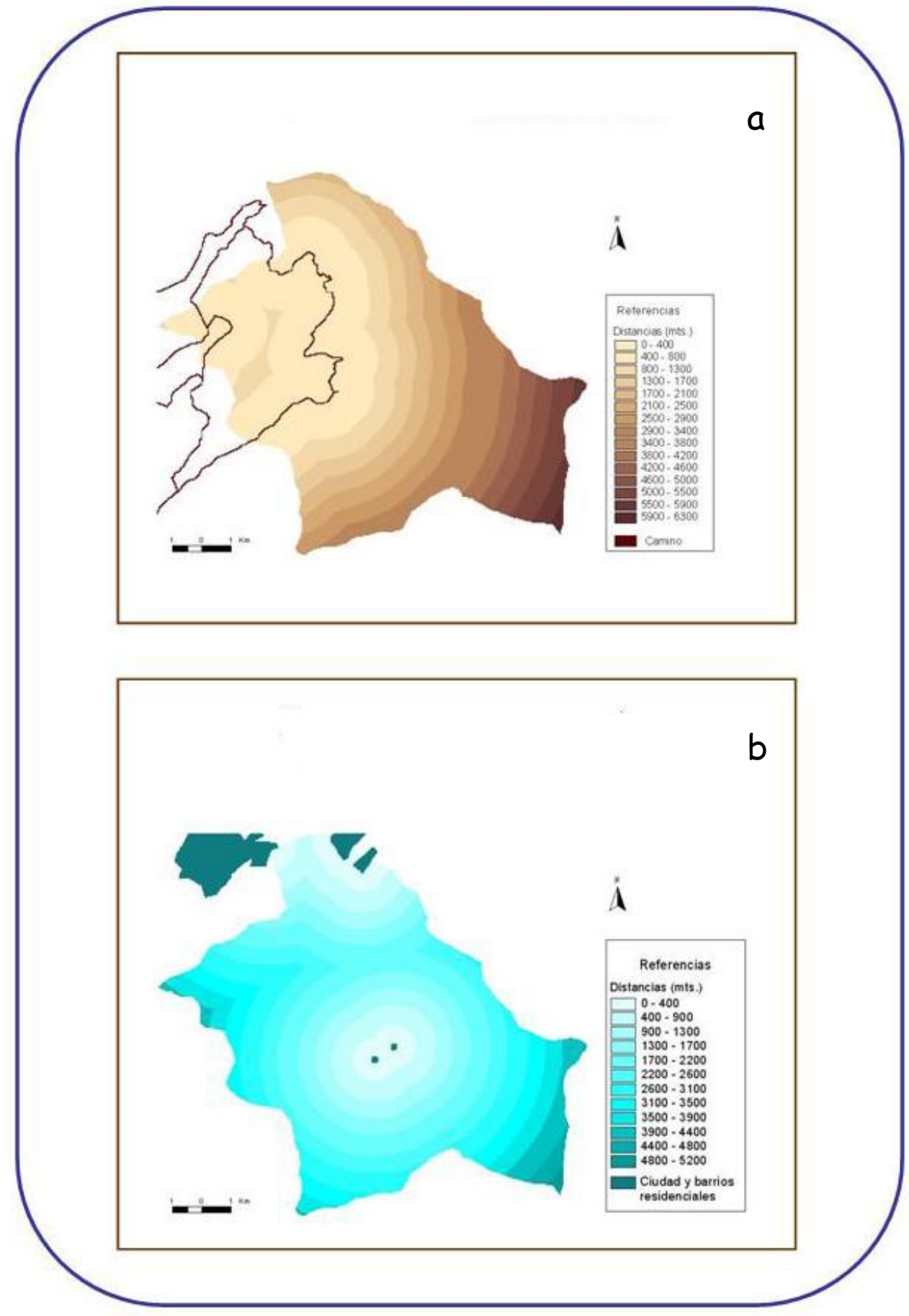

Figura 30: Mapas de las variables distancia a caminos (a) y distancia a ciudad y barrios residenciales $(b)$. 
Como se indicó en párrafos anteriores, se estandarizaron los criterios utilizando el módulo Fuzzy del programa Idrisi 3.2. Se aplicó la función lineal decreciente para el criterio índice de inestabilidad del suelo y la función sigmoidal creciente para los criterios distancia a los caminos y distancias a la ciudad y barrios residenciales como se muestran en las figuras 31,32 y 33 .

Como resultado, los criterios quedaron expresados en valores continuos de 0 (mínima aptitud) y 255 (valor máximo de aptitud) según su grado de pertenencia al grupo difuso. También se debió transformar el criterio de bosque y vegetación riparia en un mapa tipo booleano (Figura 34) para poder ser incorporado al análisis multicriterio como una restricción.

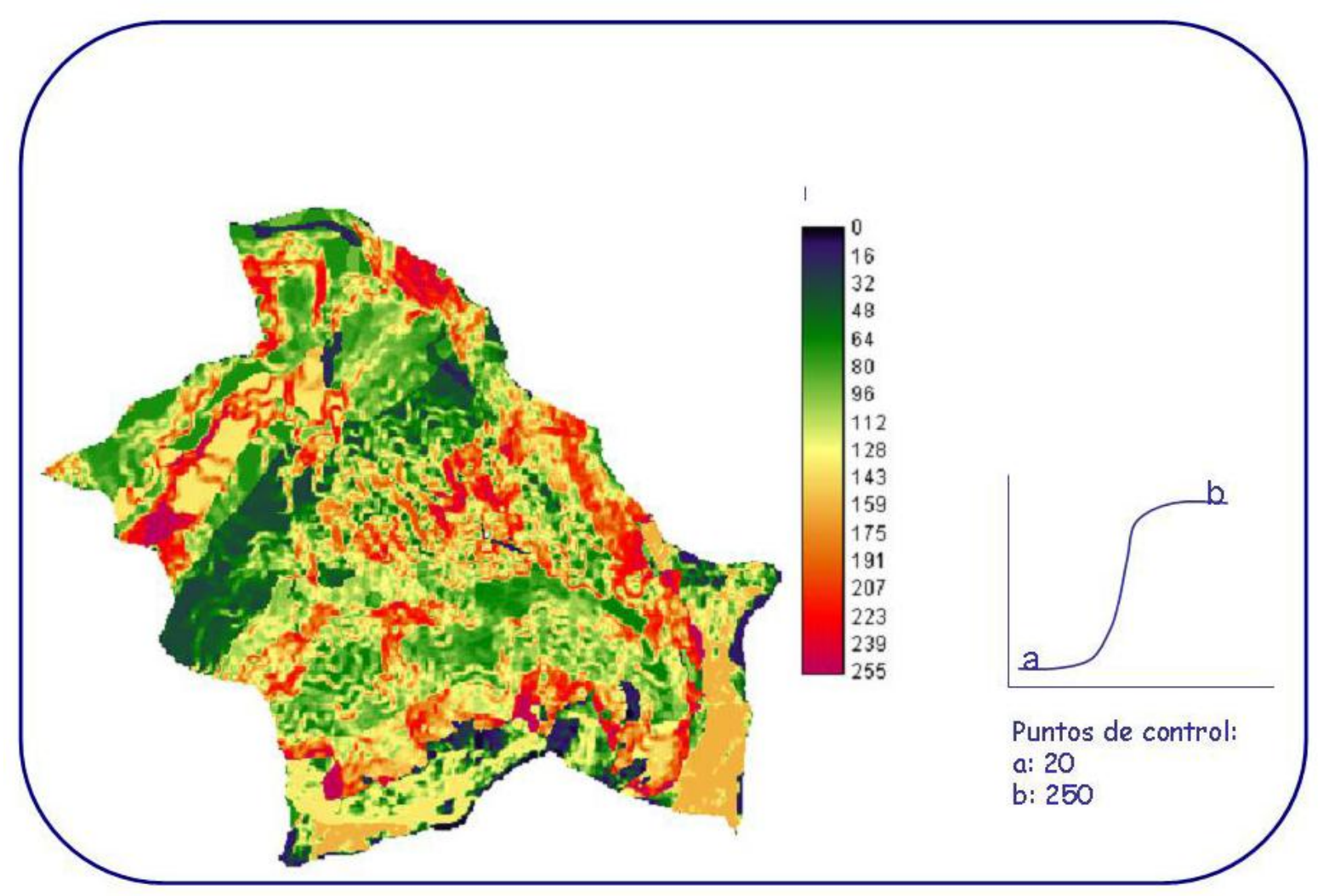

Figura 31: Estandarización del criterio IIS y puntos de control. 


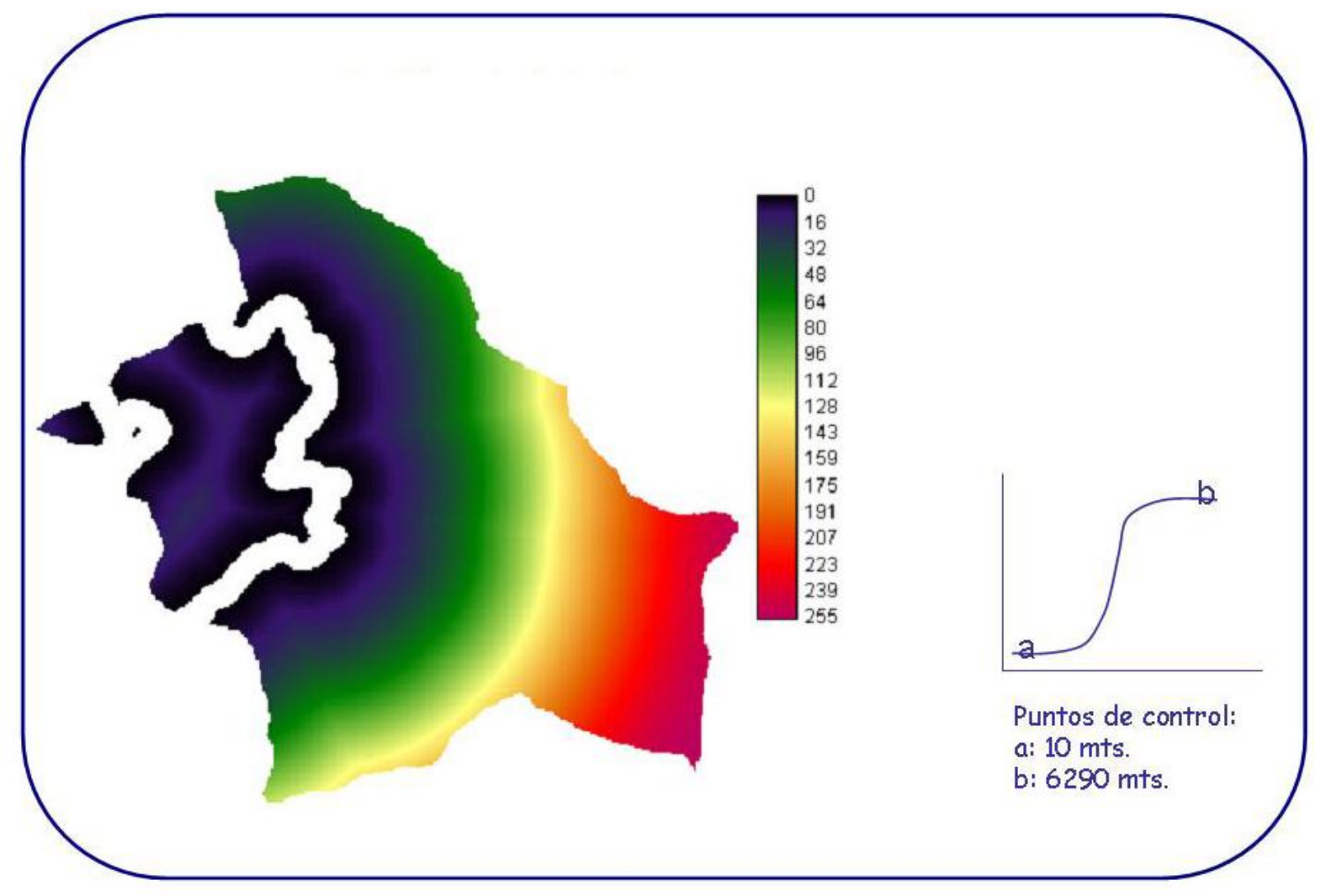

Figura 32: Estandarización del criterio distancia a caminos y puntos de control.

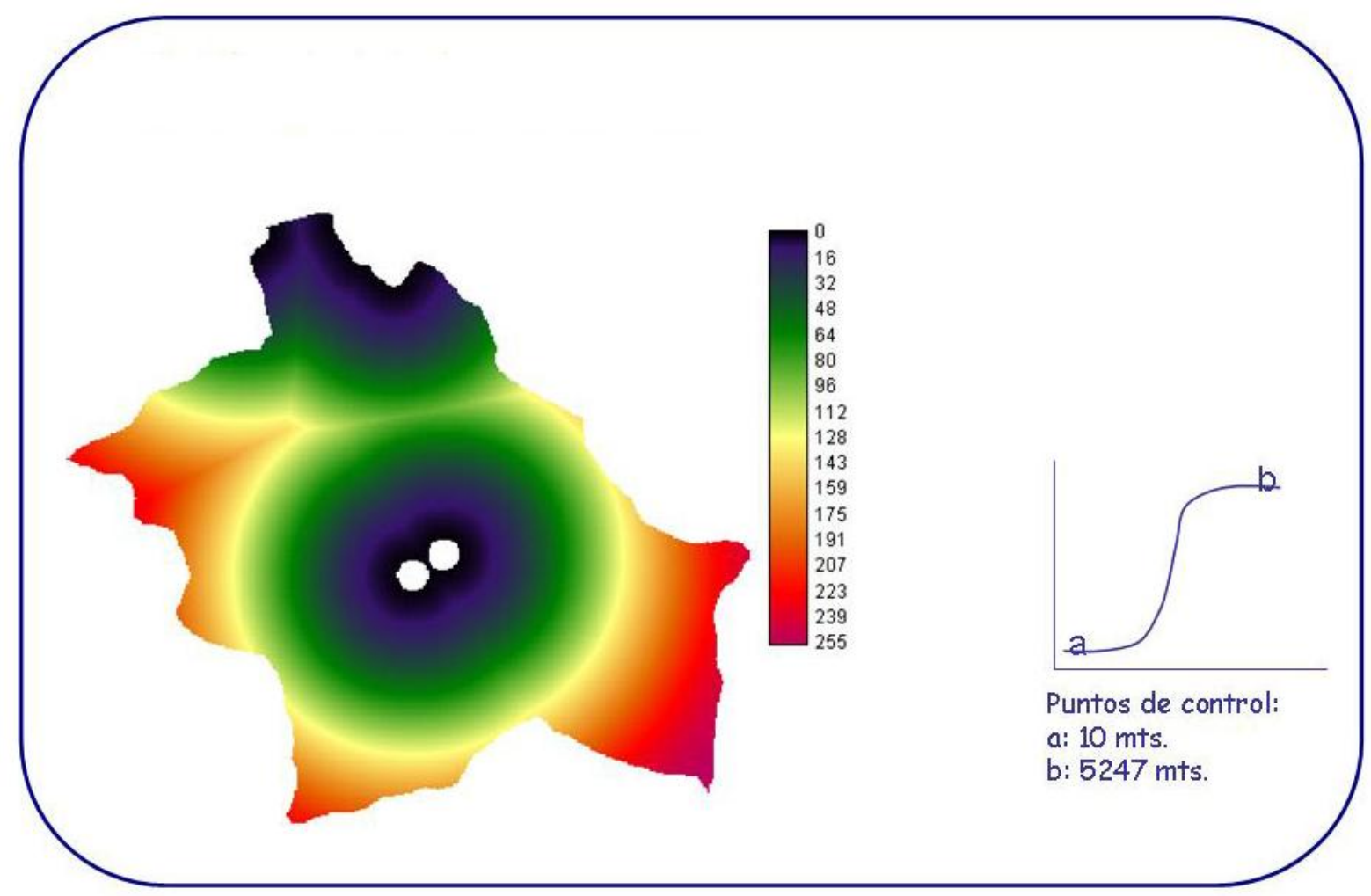

Figura 33: Estandarización del criterio distancia a ciudad y barrios residenciales y puntos de control. 


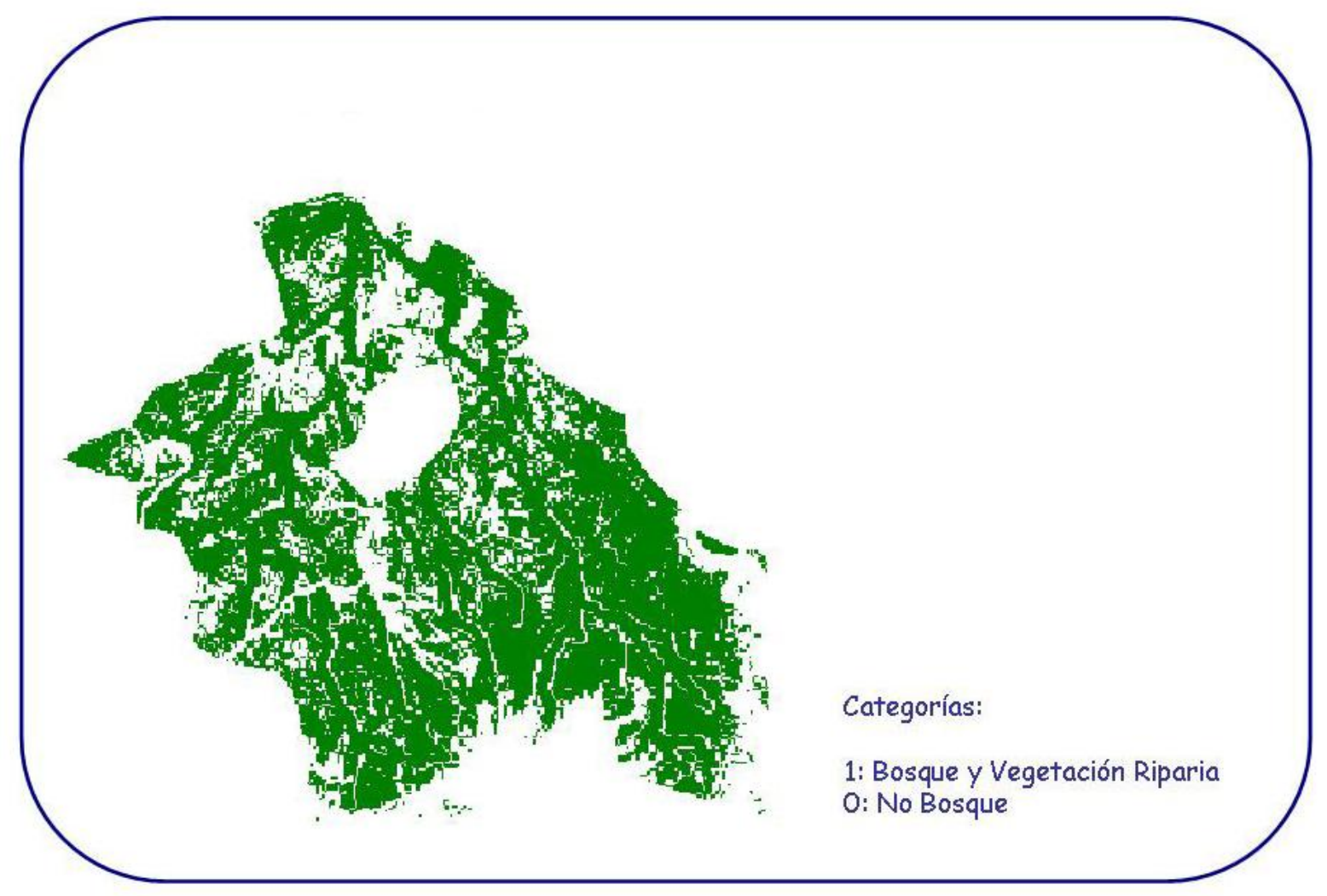

Figura 34: Mapa booleano del criterio bosque y vegetación riparia.

\section{Aplicación de los pesos de importancia}

Para asignar los pesos de importancia a cada factor, se implementó la metodología de comparación por pares de Saaty, explicada anteriormente. Para ello se desarrolló una matriz en la que se presentaron los factores y se les asignó un valor de acuerdo al ranking de importancia de comparación por pares (Tabla 7). Luego se obtuvo el peso de los factores (Tabla 8) a través del cálculo del valor del vector propio principal, esto se calculó con el módulo "WEIGTH- AHP" del programa Idrisi 3.2.

Tabla 7: Matriz de comparación por pares para evaluar la importancia relativa de los 3 factores

\begin{tabular}{|l|l|l|l|}
\hline & $\begin{array}{l}\text { Índice de inestabilidad } \\
\text { del suelo (IIE) }\end{array}$ & $\begin{array}{l}\text { Distancias a } \\
\text { caminos }\end{array}$ & $\begin{array}{l}\text { Distancia a la ciudad } \\
\text { y barrios residenciales }\end{array}$ \\
\hline $\begin{array}{l}\text { Índice de inestabilidad del } \\
\text { suelo (IIE) }\end{array}$ & 1 & 1 & \\
\hline $\begin{array}{l}\text { Distancias a caminos } \\
\text { Distancia a la ciudad y } \\
\text { barrios residenciales }\end{array}$ & $1 / 7$ & 3 & 1 \\
\hline
\end{tabular}


Debido a que la matriz completa de comparación por pares contiene múltiples rutas por las cuales puede evaluarse la importancia relativa de los criterios, es posible también determinar el grado de consistencia usado para desarrollar los puntajes. La tasa de consistencia (CR) indica la probabilidad de que los puntajes de la matriz se generen de manera aleatoria (esto también se calcula con el módulo de Idrisi 3.2). Saaty señala que las matrices con puntajes $C R$ mayores que 0,10 deben ser re-evaluados.

Tabla 8: Factores y pesos de importancia

\begin{tabular}{|l|l|}
\hline Factores & Pesos \\
\hline Índice de inestabilidad del suelo (IIE) & 0.7324 \\
\hline Distancias a caminos & 0.0801 \\
\hline Distancia a la ciudad y barrios residenciales & 0.1876 \\
\hline
\end{tabular}

Valor de $C R=0.05$

Aplicación de los pesos de orden

Para la aplicación de los pesos de orden se construyó una tabla (Ver tabla 9) conteniendo diferentes combinaciones de pesos, cada una de estas asociaciones dará origen a un escenario, a partir de la ecuación WOWA aplicada con el módulo MCE del programa Idrisi 3.2; para concretarse finalmente en mapas de áreas sensibles o de aptitud.

Tabla 9: Pesos de orden para la generación de los escenarios

\begin{tabular}{|c|l|l|l|}
\hline \multirow{2}{*}{ Escenarios } & \multicolumn{3}{|c|}{ Pesos de orden } \\
\cline { 2 - 4 } & Peso 1 & Peso 2 & Peso 3 \\
\hline 1 & 1.00 & 0.00 & 0.00 \\
\hline 2 & 0.70 & 0.20 & 0.10 \\
\hline 3 & 0.50 & 0.30 & 0.20 \\
\hline 4 & 0.33 & 0.33 & 0.33 \\
\hline 5 & 0.20 & 0.30 & 0.50 \\
\hline 6 & 0.00 & 0.00 & 1.00 \\
\hline
\end{tabular}

Se generaron entonces, seis escenarios diferentes con esta metodología: el primer escenario es el más conservador, el segundo combina un poco de riesgo, en el tercero el riesgo es mayor, en el cuarto escenario el intercambio es completo (todos los factores tienen el mismo peso de orden), en el quinto el riego es mayor y 
la compensación disminuye y en el sexto escenario el riesgo es máximo y no hay compensación (Figura 35).

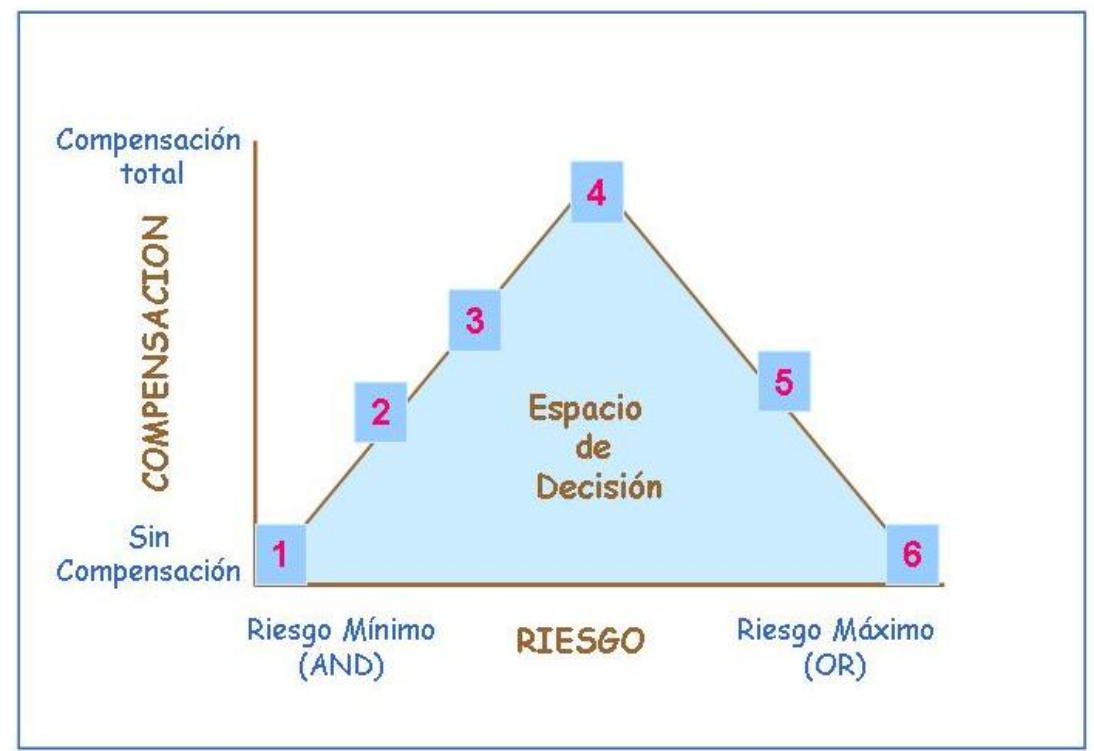

Figura 35: Ubicación de los seis escenarios en el espacio de decisión. 


\section{Resultados}

Como resultado de la aplicación de la metodología y los parámetros establecidos, se obtuvieron seis escenarios que muestran distintas alternativas dentro del espacio de decisión, es decir se observan áreas con diferente grado de sensibilidad o aptitud producto del orden de agregación y peso de los criterios.

Las figuras 36 a 41 muestran en valores de aptitud, las áreas con diferentes grados de sensibilidad de la cuenca. La gama de colores de los azules- turquesas representa las áreas de menor aptitud (o menos sensibles) para la protección de los recursos y la gama de colores amarillo a rojo muestran valores de aptitud más altos (o más sensibles). También se muestra el histograma y una tabla resumen con los estadísticos para cada escenario.

Como se puede apreciar en los histogramas, para cada escenario el rango de valores de aptitud es variable, y también lo es para la porción del espectro total que comprenden (de 0 a 255).

El escenario 1 el más conservador, la amplitud del rango es de 227 y varia de 1 a 228 , en los escenarios 2, 3, 5 y 6 la amplitud es similar (de 235 a 239) pero varían en cuanto a la porción del espectro que ocupan. Por ejemplo el escenario 6 abarca la porción que va desde valores de 20 a 255, en cambio el escenario 2 va de valores de 2 hasta el 236.

A su vez el escenario 4 (el cual se ubica en la posición de intercambio completo entre los criterios) es el que presenta la mayor amplitud en el rango de aptitud de valores (de 4 a 248).

Estas variaciones en los escenarios no son otra cosa que la cantidad de píxeles involucrados en la toma de decisión y su valoración en cuanto a la aptitud para pertenecer al grupo. En este caso el grupo de pertenencia, según nuestro objetivo, son las áreas de mayor sensibilidad y por lo tanto que mayor prioridad representan para ser protegidas o conservadas de acuerdo a los criterios y condicionantes establecidos en el modelo conceptual.

Por otro lado, cada escenario muestra un gradiente continuo que va desde una aptitud baja comenzando con valores de 0 , hasta una aptitud alta con valores de 255. 

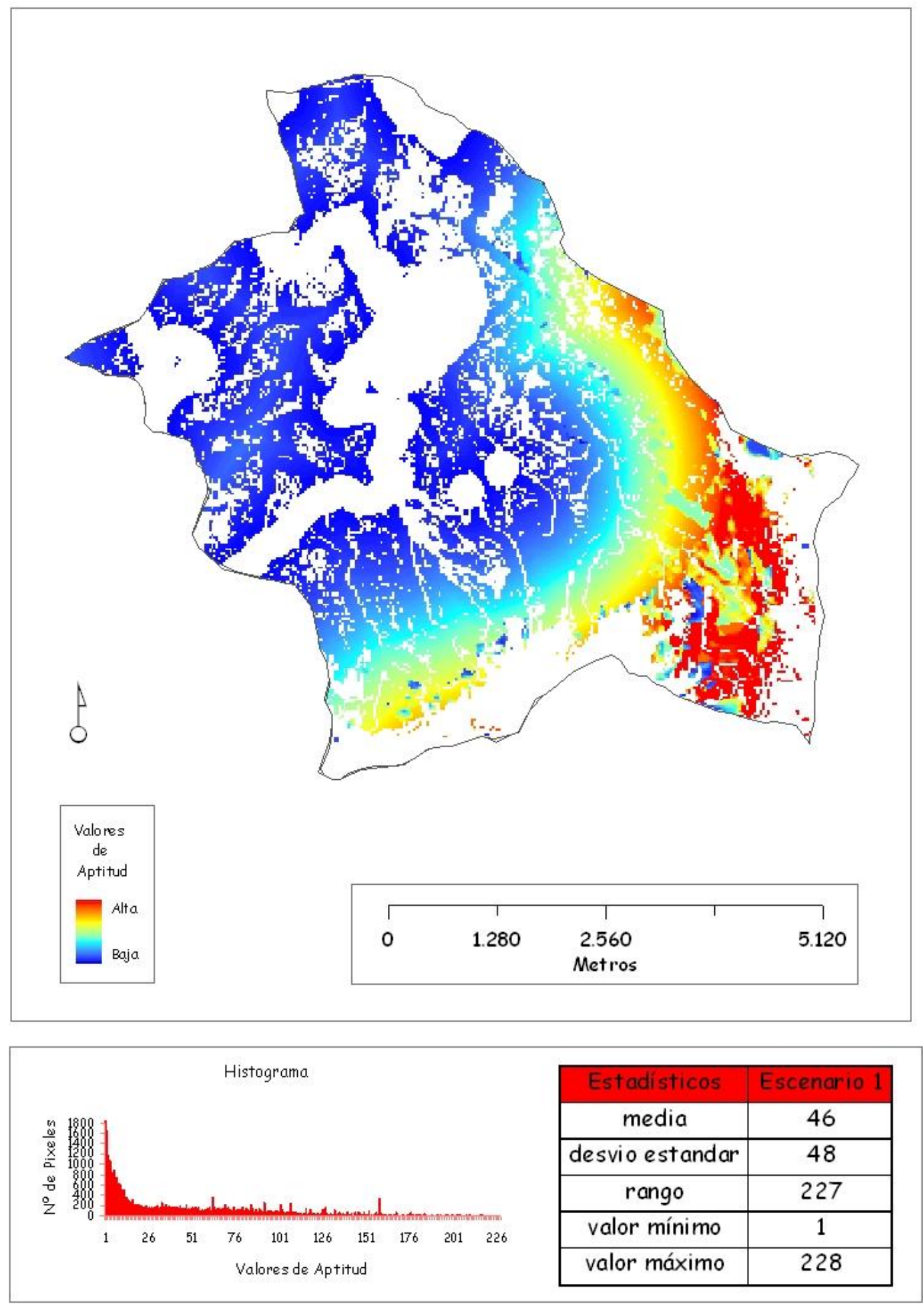

Figura 36: Valores de aptitud, histograma y estadísticos para el Escenario 1. 

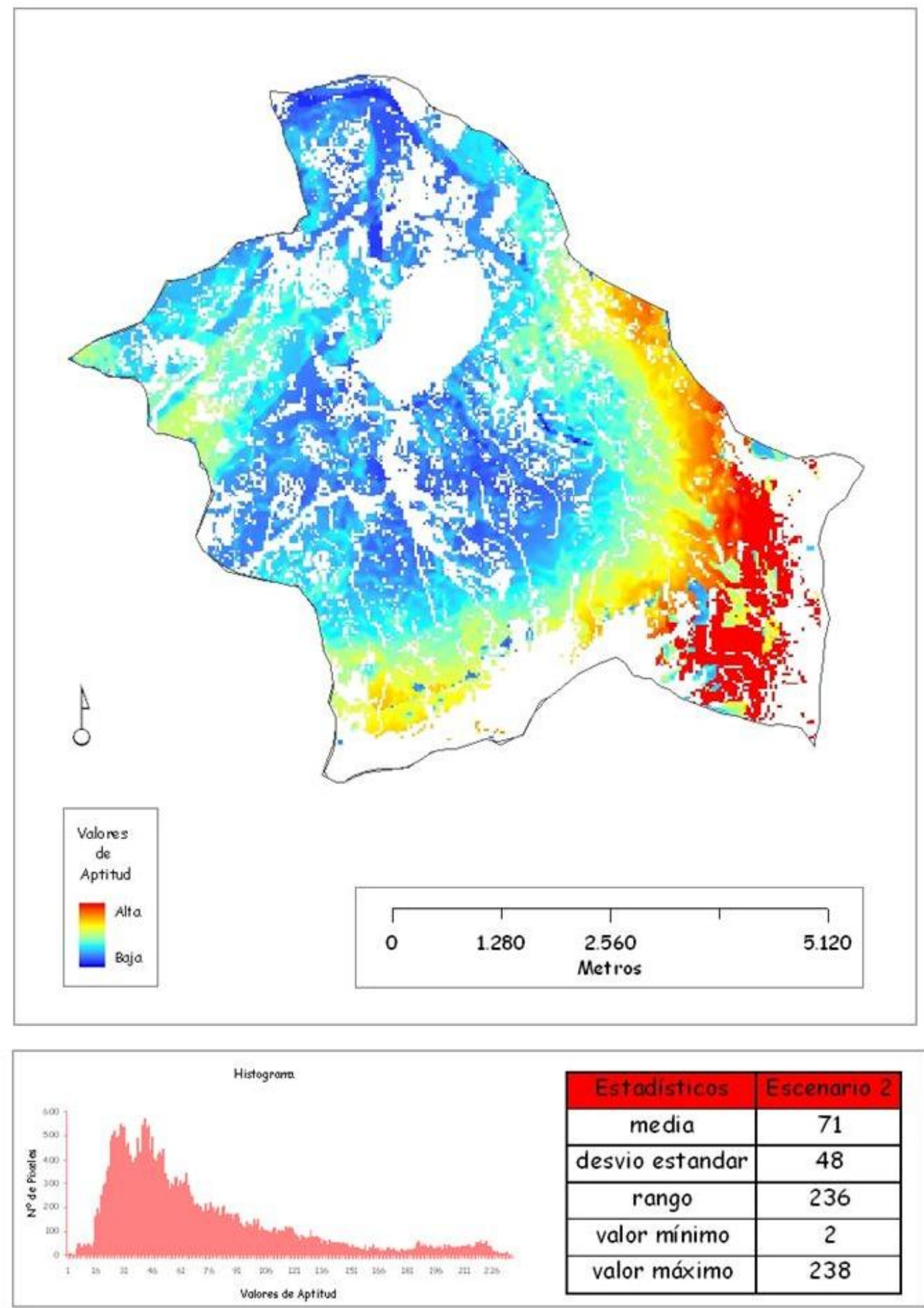

Figura 37: Valores de aptitud, histograma y estadísticos para el Escenario 2. 

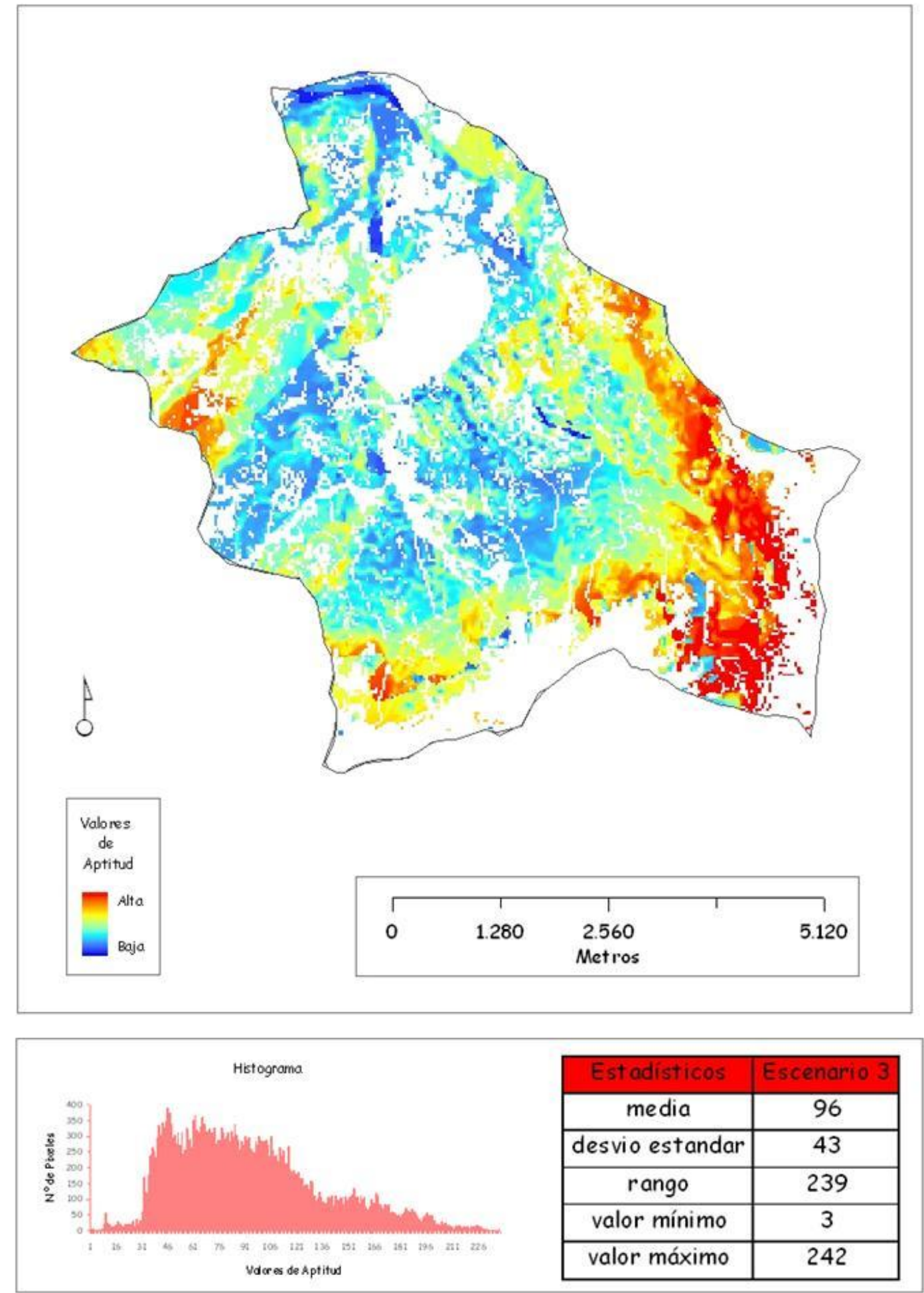

Figura 38: Valores de aptitud, histograma y estadísticos para el Escenario 3. 

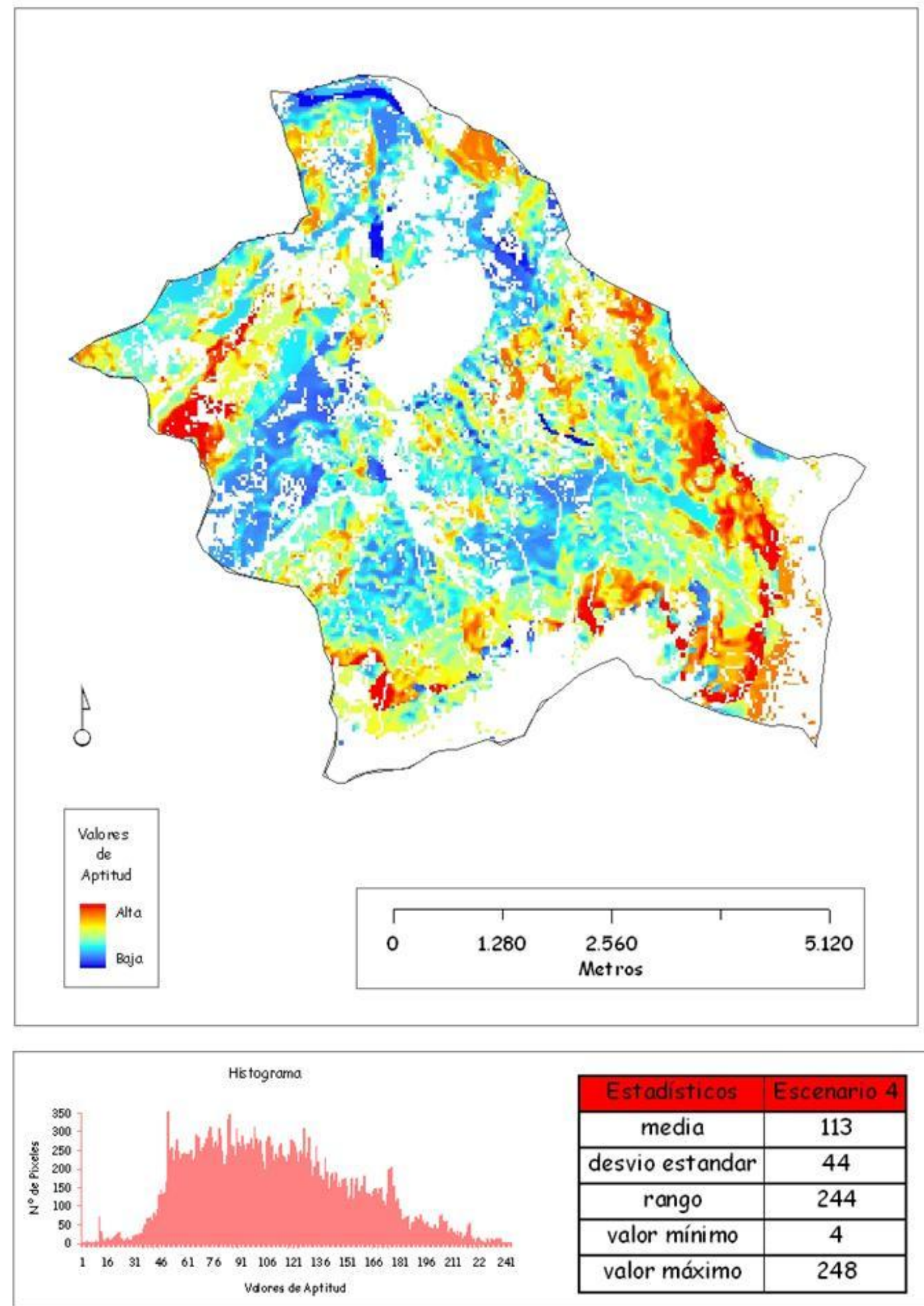

Figura 39: Valores de aptitud, histograma y estadísticos para el Escenario 4. 

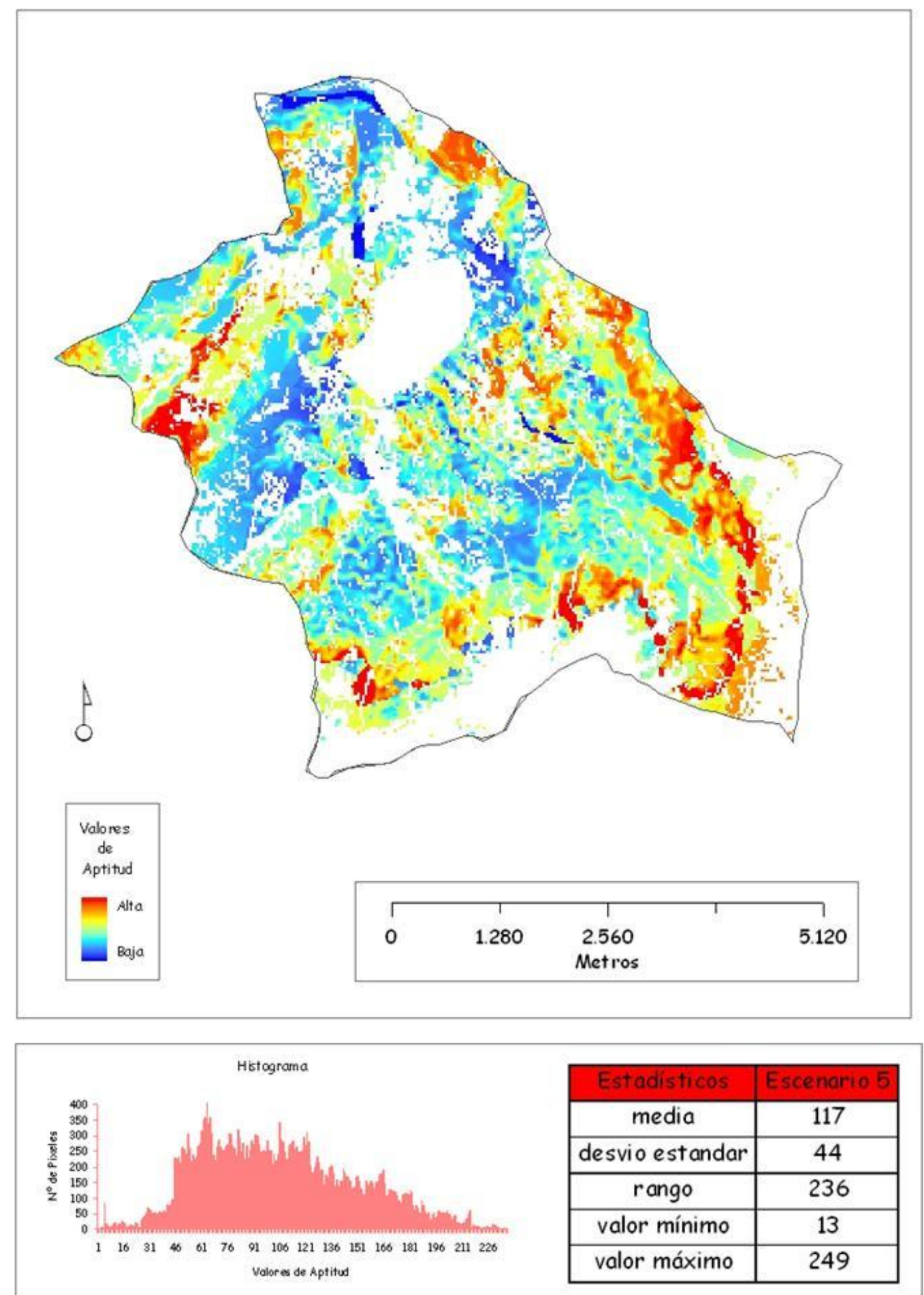

Figura 40: Valores de aptitud, histograma y estadísticos para el Escenario 5. 

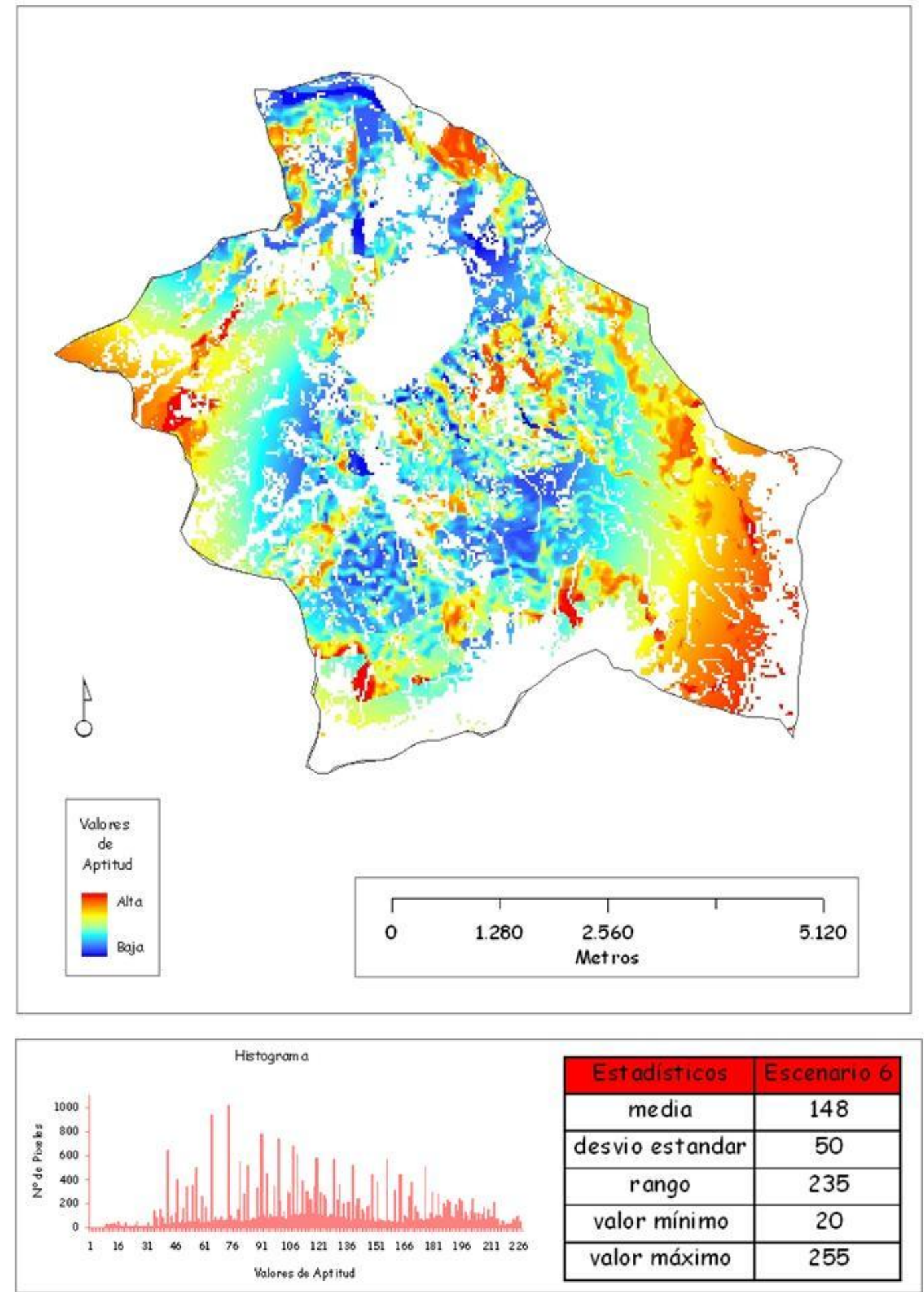

Figura 41: Valores de aptitud, histograma y estadísticos para el Escenario 6. 
Para facilitar el análisis de los resultados, se realizó una reclasificación de los valores de manera de agruparlos en tres categorías: prioridad de protección de los recursos naturales baja, media y alta. Así, los seis escenarios quedaron espacializados como muestra la figura 42, también fueron calculadas las superficies (en hectáreas) que ocupan cada una de las categorías.

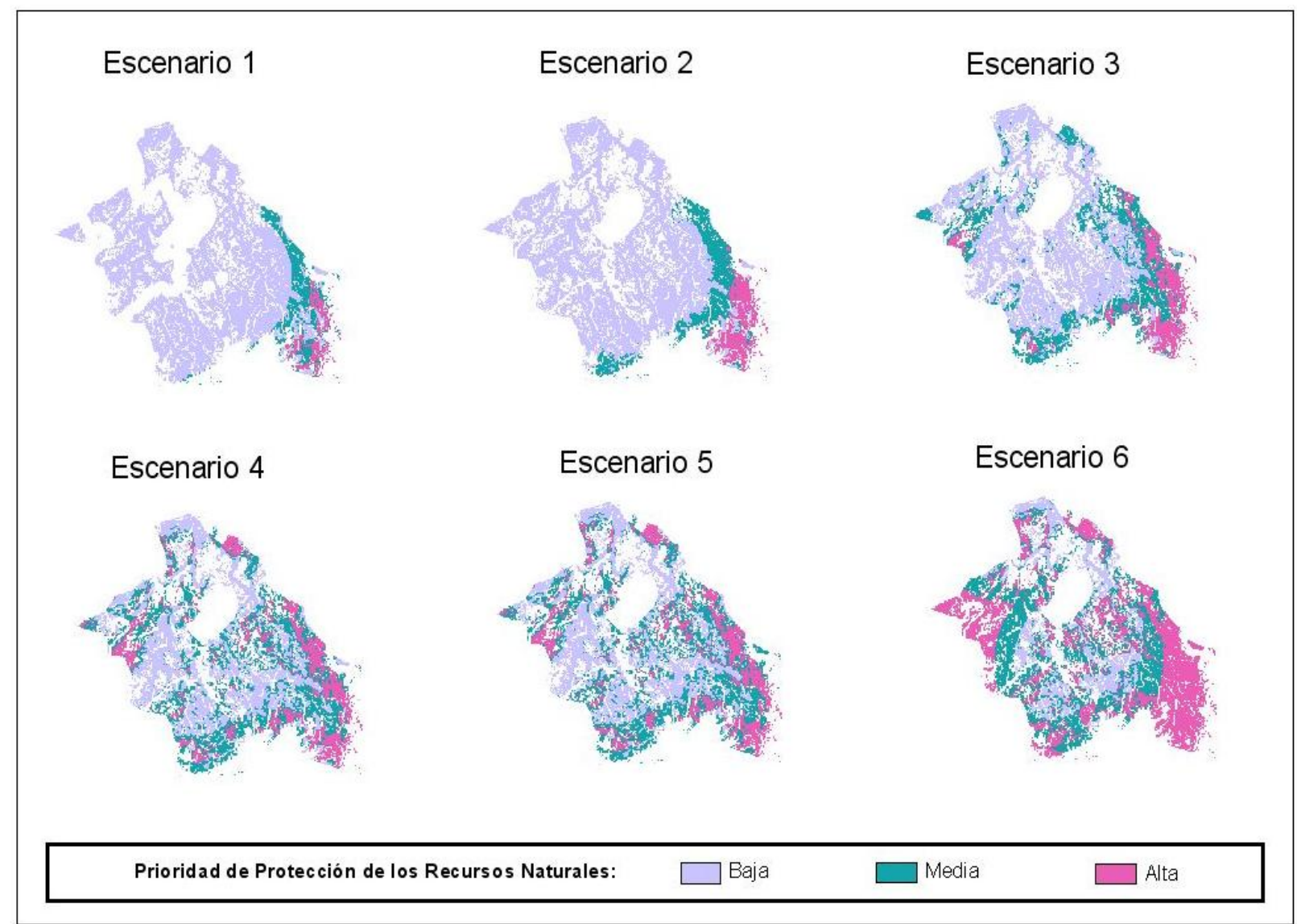

Figura 42: Prioridad de protección de los distintos escenarios de las subcuencas Trabunco-Quitrahue.

El escenario 1 (el más conservador) solo selecciona 112,5 hectáreas con prioridad de protección alta, siendo solo el 2,3\% de la cuenca, esto es debido a que solo los píxeles que tuvieron los valores más altos en todos los criterios fueron seleccionados para pertenecer a esta categoría.

En el extremo contrario se encuentra el escenario 6, que atribuye 1.292 hectáreas a una alta prioridad de protección, las que corresponden al $27,2 \%$ de la cuenca. En este caso cualquier píxel que tenía un valor alto en alguno de los criterios era seleccionado para pertenecer a esta categoría. 
Por ello el mapa del escenario 6 muestra zonas con valores bajos en alguno de los criterios (por ejemplo, las zonas cercanas a la ciudad) pero con un valor alto en otro criterio (por ejemplo, el índice de inestabilidad del suelo).

En los escenarios 4 y 5 la situación es muy similar ya que cada uno asigna el $12 \%$ y el 13,2\% respectivamente, de la superficie de la cuenca con una prioridad alta de protección de los recursos naturales. En el escenario 4 el intercambio en los criterios es máximo ya que todos reciben el mismo peso.

En el escenario 2, con un poco más de compensación entre los factores y un riesgo mínimamente superior al escenario 1, selecciona solo 227 hectáreas de las 4.927 que conforman las subcuencas; y el escenario 3 optando por un riesgo y compensación mayor selecciona 367 hectáreas. En la figura 43 se muestran las hectáreas asignadas a cada categoría. 


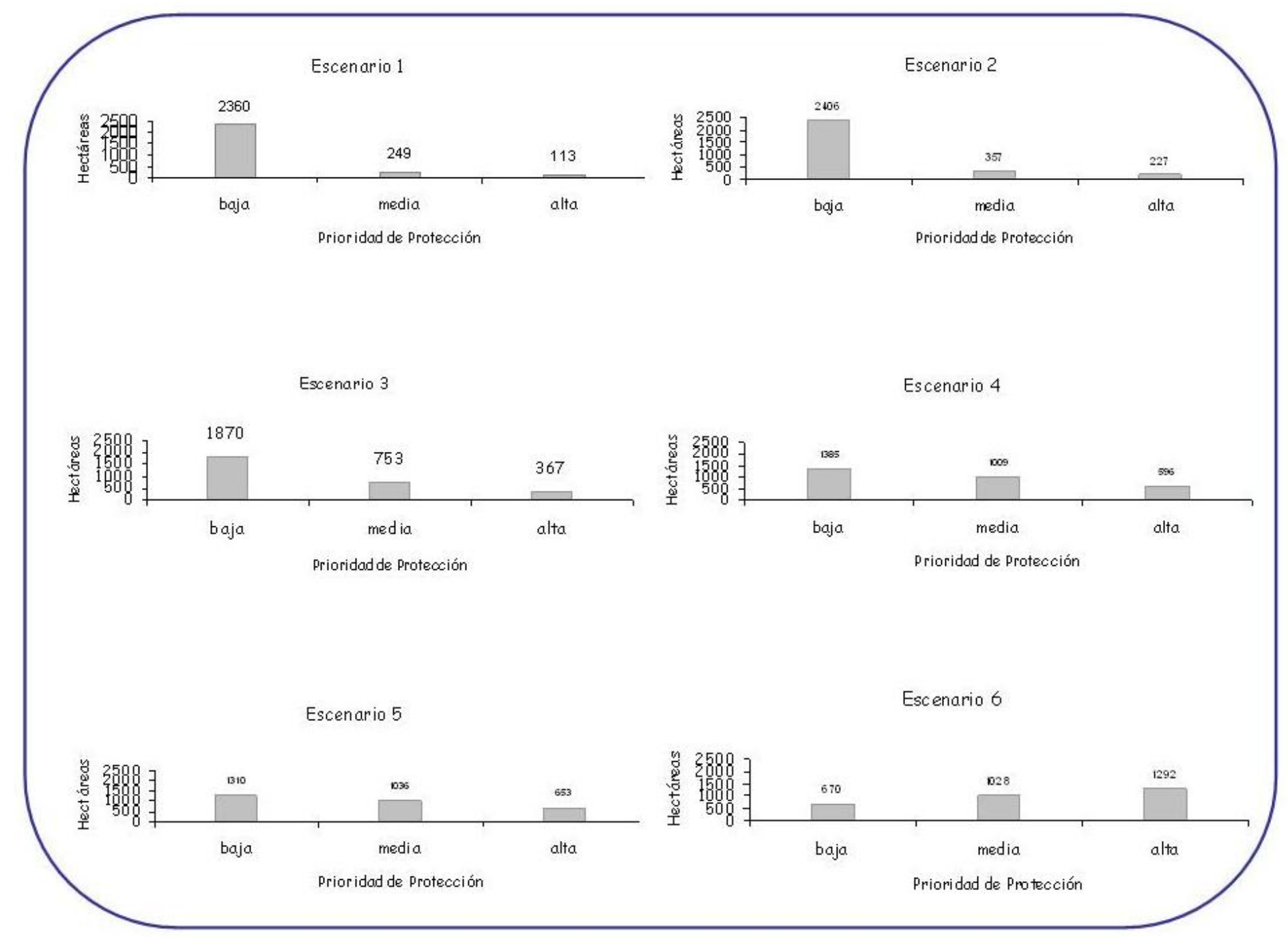

Figura 43: Superficie (en hectáreas) por categoría de prioridad de protección de los seis escenarios. 
Identificación y mapeo de las áreas prioritarias para la protección de los recursos naturales de las subcuencas de los arroyos Trabunco-Quitrahue.

Tomando en cuenta los seis escenarios, la ubicación espacial de las áreas con prioridad alta para la protección de los recursos naturales, en general difiere de un escenario a otro. Sin embargo existen algunas zonas que son seleccionadas en todos los casos y otras que son seleccionadas por la mayoría de los escenarios.

Para la generación del mapa final de áreas prioritarias de protección de los recursos naturales se procedió de la siguiente manera: se realizó una agregación de todos los escenarios con el módulo MCDM del programa ArcView 3.2, en el cual se estandarizaron los valores con la función lineal creciente (los puntos de control fueron $a=1$ y $b=3)$, luego se les asignó a todos los escenarios el mismo peso $(0,20)$, y se corrió el modelo que dio de manera preliminar un mapa con valores de sensibilidad de 0 a 100, posteriormente se reclasificó el mapa quedando tres categorías, que agrupan los valores de sensibilidad de 65 a 100. Así, quedaron identificadas cuatro zonas como se observan en la figura 44.

La zona $A$, presenta los valores de mayor sensibilidad (entre 90 y 100) y es seleccionada en todos los escenarios, tiene una superficie de 384,4 hectáreas, esta ubicada en la subcuenca del arroyo Trabunco con una orientación longitudinal norte -sur. Abarca desde la cota 1.400 hasta la de 2.000 metros.

En esta zona el índice de inestabilidad del suelo tiene valores de medio a muy alto (de 120 hasta 250), representa pendientes muy pronunciadas, suelos poco profundos y el grado de facturación y erosión es variable. Se encuentra a más de 3.000 metros de distancia de los caminos y zonas urbanas y la vegetación dominante esta representada por un bosque de Lenga maduro.

Por estas características, este sitio es seleccionado como una de las zonas con mayor prioridad para su protección, lo que alentaría en este caso a la regeneración del bosque y el suelo, y junto con ellos los servicios ecosistémicos que proveen.

La zona $B$, presenta valores de sensibilidad entre 80 y 90 , es seleccionada por cuatro escenarios, este sector tiene una superficie de 82 hectáreas, se ubica sobre la parte media de la subcuenca Trabunco. Los valores del IIS son medios a altos, se encuentra a más de 2.500 metros de los caminos y áreas residenciales, la pendiente promedio supera el $20 \%$, y el bosque comprende especies de Lenga y Ñire.

La justificación de protección para este sector, es que además de ser una área más vulnerable frente a muchas otras, se encuentra contigua a la zona $A$, con lo cual se amplia la superficie total de protección de estos ecosistemas y con ello todo los beneficios que aportan para la zona de estudio. 
La zona $C$ presenta valores de sensibilidad de 70 a 80 . Está ubicada en la cabecera de las subcuencas y ocupa 317 hectáreas. Presenta valores medios a altos del IIS, alejada de los barrios residenciales y caminos. La vegetación dominante es el bosque de Lenga achaparrado, propio de estas alturas.

La característica más sobresaliente, además de las propiedades ya nombradas, es el hecho de que en esta zona se encuentran las nacientes de muchos cuerpos de aguas temporarias e intermitentes que en su posterior trayecto formarán los arroyos Trabunco y Quitrahue.

La zona de cabecera constituye el área donde se inician los cursos de agua. Esta función se logra cuando los suelos, generalmente bajo cubierta forestal, se saturan de agua fomentando el escurrimiento ante la infiltración. La función de esta zona es vital para el funcionamiento de toda la cuenca y dada las condiciones que requiere su funcionamiento, su fragilidad es elevada (Cotler et al., 2004).

Existe abundante bibliografía acerca del valor que tiene conservar la cabecera de las cuencas, sobretodo si presenta una cubierta vegetal boscosa. La cabecera de una cuenca cumple una importante función reguladora, ya que influye en la cantidad, calidad y temporalidad del flujo de agua, protege a los suelos de ser erosionados y de la consiguiente sedimentación, previene la degradación de los arroyos y la afectación en general de los distintos ecosistemas a lo largo de una cuenca (Sánchez, 2003).

A su vez, en ambas subcuencas existe una gran diversidad de usos de este recurso, que como se mostró en la EAR, su calidad no es tan buena en algunos sectores. Por la tanto, la protección de esta zona aportaría un plus importante en la generación y mantenimiento del recurso hídrico.

La zona D presenta valores de sensibilidad entre 65 y 70 , es seleccionada por cuatro escenarios, y abarca dos áreas. La más pequeña ocupa 27 hectáreas, se encuentra en la parte baja de la subcuenca Trabunco, lindante al barrio Covisal. Este sector tiene el grado más alto de fracturación y erosión, pendientes pronunciadas, y por lo tanto valores elevados del IIS.

La protección de este sector toma sentido por el hecho de su cercanía con el área urbana, advirtiendo un posible avance antrópico sobre esta zona tan frágil, en cuanto al componente edáfico.

La otra área tiene una superficie de apenas 68,5 hectáreas, esta ubicada en la subcuenca del arroyo Quitrahue entre los 1000 y 1.300 metros s.n.m. También representa valores muy altos del IIS, con grandes pendientes, suelos con profundidad media a baja y un grado de erosión moderada. Si bien es un área alejada del área urbana, no ocurre lo mismo con los caminos ya que presenta 
valores cercanos a 60 metros de ellos. Aquí la vegetación dominante es un bosque mixto. Esta zona seria interesante de proteger con el fin de evitar que futuros emprendimientos en el área aumenten la inestabilidad del suelo, que de por sí es elevada. De esta manera se podría implementar un plan de manejo con el fin de mantener la fertilidad y estructura del suelo para permitir el buen funcionamiento del ecosistema en su conjunto.

Tomando en cuenta estas cuatro zonas de alta sensibilidad e identificadas como prioritarias para la protección y conservación de los recursos naturales, cubren una superficie de 879 hectáreas, las cuales representan el 18\% de las subcuencas de los arroyos Trabunco-Quitrahue. 


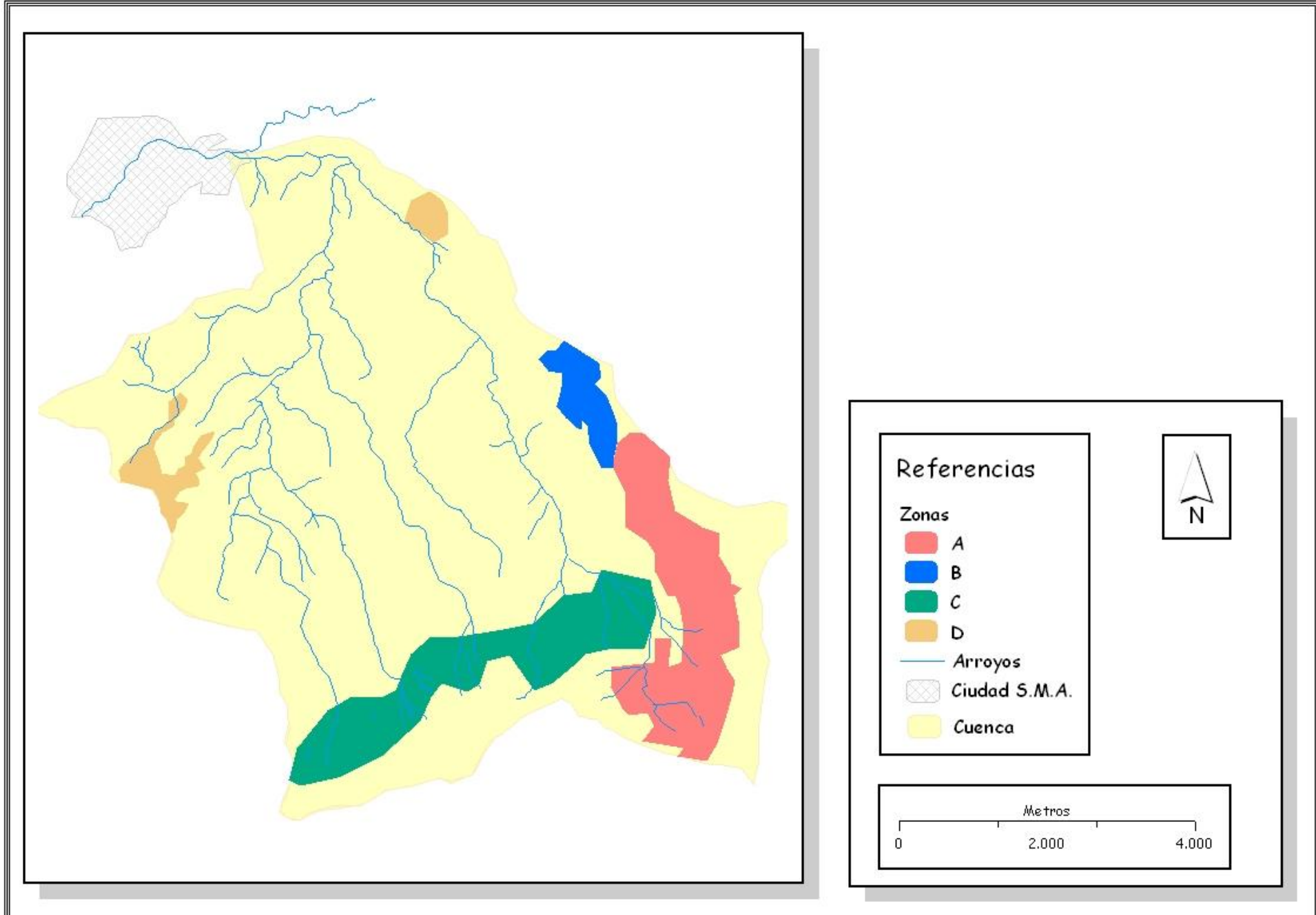

Figura 44: Mapa de zonas prioritarias para la protección de los recursos naturales de las subcuencas de los arroyos Trabunco-Quitrahue. 


\section{Discusión}

El mapa final de protección de los recursos naturales, arroja cinco sectores agrupados en cuatro zonas las cuales tres representan menos de 100 hectáreas de superficie, si bien el área de estudio son subcuencas pequeñas, existen varias experiencias que apoyan la conservación de este tipo de áreas.

En el mundo de la conservación de áreas, las acciones más efectivas pueden ser la protección de las grandes superficies continuas de bosques y otros ambientes que protegen especies de flora y fauna amenazadas. Sin embargo, numerosos fragmentos de hábitat más pequeños y alterados, también pueden cumplir una función de conservación importante en la medida que sea un hábitat temporal o permanente para la alimentación, refugio o reproducción de especies nativas (http:// www.parquesparachile.cl).

En este sentido cobra importancia el concepto de "objeto de conservación". Los objetos de conservación son un número limitado de especies, comunidades naturales o sistemas ecológicos que representan la biodiversidad de un paisaje a ser conservado o de un área protegida y que por lo tanto pueden ser utilizados en la medición de la efectividad de las medidas de conservación. Estos objetos de conservación sirven de filtro grueso o "sombrilla", los cuales una vez identificados y conservados, aseguran la persistencia del resto de los componentes en el espacio y el tiempo (Parrish et al., 2003).

Por ejemplo, en un predio podemos encontrar la presencia de especies catalogadas en estados de amenaza. Otras que son endémicas de territorio pequeño, por lo que únicamente pueden encontrarse allí. Incluso un bosque adulto relicto de lo que fue una formación boscosa anterior, una cabecera de cuenca, ciertos bosques ribereños o algunos humedales que regulan el ciclo hidrológico pueden ser calificados como objetos de conservación (Tacón Clavaín, 2004).

Por lo tanto, las zonas identificadas en las subcuencas de los arroyos TrabuncoQuitrahue encajan perfectamente dentro de este concepto.

La zona $A$ contiene un bosque de Lenga maduro, con muchos individuos deteriorados y un pequeño mallín (humedal). La conservación de la zona ayudaría a la recuperación del bosque y la biota asociada, ya que una de las maneras más eficaces de controlar la dinámica de la biota es a través de la regulación de los procesos hidrológicos: por ejemplo, mediante el aumento de la retención de agua a través de la reforestación (Petts, 1984). También la protección y restauración del mallín contribuiría a mejorar el flujo de agua y nutrientes, amplificando los ciclos biogeoquímicos (Mitsch et al., 1995) y a la disminución de exportación de sedimentos (Vought et al., 1994; Raisin, 1996; Zalewski et al., 1997) 
La protección de la zona $D$, estaría enfocada en la recuperación del suelo y disminución de la erosión, la zona B sería complementaria a la zona $A$.

Por último, la zona $C$ como se dijo anteriormente constituye la cabecera de una cuenca boscosa y de montaña. Según la FAO se admite por regla general que las cuencas hidrográficas boscosas constituyen sistemas hidrológicos excepcionalmente estables. Si se comparan con otros usos de las tierras, los bosques sanos:

? influyen considerablemente en la cantidad de agua obtenida de las cuencas hidrográficas;

2, descargan aguas de la mejor calidad;

? descargan, por unidad de precipitación lluviosa, caudales máximos y volúmenes de crecida más bajos;

? atenúan la variación en los caudales, entre los flujos altos y bajos, a lo largo del año;

- proporcionan una estabilidad de los suelos mucho mayor y reducen al mínimo el desplazamiento de la masa de los suelos, así como la erosión en cárcavas y en la superficie:

? arrojan un mínimo de sedimentos aguas abajo.

Por lo tanto, los beneficios de conservar este sector son mundialmente promovidos y reconocidos.

Es importante destacar, que si bien no se indica en el mapa de áreas prioritarias para la protección de los recursos naturales, se propone, como se mencionó en el modelo conceptual, tomar en cuenta la conservación de las áreas de ecotonos y vegetación riparia.

Diversos autores destacan la importancia de estas zonas en las cuencas hidrográficas, Pusey y Arthington (2003) resaltan esta zona como significativa en la protección de los recursos acuáticos, Zalewski (2000) lo hace como la herramienta principal para reducir la transferencia de nutrientes hacia los cuerpos de agua, y Naiman y Decamps, (1990) sostienen que mediante el restablecimiento del ecotono agua-tierra mejoran la regulación de los procesos hidrológicos.

Según FAO (2003) recomienda que los bosques ribereños deben ser objeto de una ordenación encaminada a proteger la calidad del agua, lo cual puede a su vez incrementar la capacidad de producción de los ecosistemas acuáticos y mejorar la salud y el bienestar de las poblaciones locales.

Por lo tanto, se recomienda el establecimiento de manera complementaria a las zonas propuestas, la asignación de áreas de amortiguación entre el ecotono tierraagua, habitualmente llamadas zona de vegetación o bosque ribereño. 
En cuanto a la estrategia metodológica utilizada, se optó por una serie de pasos que logró organizar, complementar y analizar la información de manera eficaz a través de las EAR y la base SIG. El análisis multicriterio usando el método del promedio ponderado ordenado con la incorporación de los pesos de importancia, dentro de un entorno SIG, logró que los resultados se encontraran espacializados.

Este método se aplicó a la identificación de áreas sensibles, prioritarias para la protección de los recursos naturales, del cual se obtuvieron seis escenarios, que variaron en cuanto al grado de riesgo y compensación en que los criterios fueron agregados en el análisis.

Por otro lado, al estar las variables espacializadas, es posible utilizar otras funciones, modificar los pesos, incorporar nuevas variables de manera rápida y eficiente, ya sea para obtener nuevos resultados, o para utilizar la base de datos en otros objetivos.

La estrategia metodológica empleada fue muy conveniente para los objetivos del trabajo, y resultó ser una herramienta útil que puede ser utilizada en otras localidades para resolver objetivos similares. 


\section{Capitulo V}

\section{Conclusiones}

El trabajo de tesis aborda una problemática regional que ocurre en muchas localidades de la ecorregión de los bosques andino patagónico. Estas localidades presentan un modelo de crecimiento urbano, que no incluye al componente ambiental, de manera que su desarrollo repercute explícitamente sobre los bienes y servicios que proveen los ecosistemas, afectando directamente la actividad principal que es el turismo, basado en los atractivos paisajes naturales de la zona.

Tomando como marco de referencia este patrón, se utilizaron como ejemplo las subcuencas de los arroyos Trabunco-Quitrahue en las que se implementó una estrategia metodológica para mitigar y prevenir la degradación de los ecosistemas (contaminación de cuerpos de agua, pérdida de hábitat, etc.) basada principalmente en un análisis multicriterio espacializado, con el fin de detectar áreas sensibles, prioritarias para la protección de los recursos naturales.

De manera general, aquí se han tomado estas subcuencas, en las cuales se realizó un diagnóstico ambiental y se detectaron los problemas locales, se conformó una base de datos espacial y se identificaron las áreas de mayor sensibilidad de acuerdo a un conjunto de criterios preestablecidos para luego convertirse en los sitios prioritarios para ser conservados.

Esta serie de pasos metodológicos puede ser aplicada para cualquier cuenca de la ecorregión, ya que presentan características ambientales y naturales muy parecidas, las problemáticas locales se asemejan bastantes y en general el ambiente responde de manera similar.

Volviendo específicamente al ejemplo planteado; el mapa de áreas prioritarias para la protección de los recursos naturales de la cuenca es la síntesis resultante de la aplicación del modelo conceptual, producto de la evaluación ambiental regional y de la aplicación de una metodología novedosa, la que incluyó la selección de criterios, la asignación de pesos y la forma de agregación de los mismos.

Por otro lado para complementar la propuesta de las zonas prioritarias y las áreas de bosque y vegetación ribereña, desde esta perspectiva, se elaboraron una serie medidas preventivas y mitigadoras que debieran de implementarse de manera conjunta con las zonas propuestas, con el fin de mejorar el funcionamiento integral del área estudiada. A continuación se listan las mismas: 
- Recuperar la cobertura vegetal arbórea nativa en los sectores de la cuenca alta, por medio de mecanismos que favorezcan el establecimiento de renovales de Lenga.

- Implementar medidas para minimizar la erosión en sectores de esquí en consenso con responsables del emprendimiento y establecer patrones de uso sustentable del suelo en aceptación con la comunidad mapuche.

- Definir densidades urbanas en relación al grado de inestabilidad del suelo y cercanía a los cursos de agua en consenso con las autoridades locales de SMA, empresarios inmobiliarios y autoridades del Parque Nacional Lanín.

- Instaurar una asignación de caudales para los distintos usos en la cuenca y organizar una entidad (asociación de usuarios) de diálogo destinado al manejo del recurso hídrico de la cuenca.

- Establecer un programa de monitoreo de caudales, sedimentos, contaminantes y carga orgánica. Ya que en toda la cuenca no existe un registro continúo de los mismos.

- Efectuar un manejo adecuado en los diferentes rodales de bosque, con el fin de aumentar la producción de madera y leña para autoconsumo o para la venta, de manera de incrementar su cantidad y calidad.

Finalmente, mas allá del trabajo de tesis, sería importante la implementación de estas zonas prioritarias y su posterior monitoreo, de manera de evaluar si el ambiente responde positivamente a estos sitios de conservación, y de ser así sería más interesante aún, la aplicación de esta metodología a otras pequeñas cuencas de la región. 


\section{Capítulo VI}

\section{Referencias Bibliográficas}

1. APN (Administración de Parques Nacionales). 2004. Plan Operativo Bianual 2003-2004. Parque Nacional Lanín. 41 pp.

2. Ascough, J. H. Rector, D. Hoag, G. Mc Master,B.Vendenberg, M. Shaffer y L. Ahjua. 2002. Multicriteria Spatial Decision Support Systems: Overview, Applications and Future Research Directions. Integrated Assessment and Decision Support, Proceedings of the First Biennial Meeting of the International Environmental Modeling and Software Society, Volume 3, pp. 175 - 180. IEMSS.

3. Banco Mundial. 1991. Libro de consulta de evaluación ambiental. Vol. I y II. Departamento de Medio Ambiente, Trabajo Técnico No. 139.

4. Bereciartua, P. 2003. Modelos de Simulación, Sistemas Expertos y Sistemas Soportes de Decisión (SSD). En: Apuntes del Curso Internacional de Postgrado: Gestión Integrada de los Recursos Hídricos. 21 pp.

5. Bosque, J. 1992. Sistemas de Información Geográfica. Ed. Rialp, Madrid. 452 pp.

6. Brabyn, L. 2005. Solutions for characterizing natural landscape in New Zealand using Geographical informations systems. Journal of Environmental Management: 1-12.

7. Broquel P. M. Frugoni y G. Falbo. 1995. Mapa de Suelos: Cuenca Trabunco- Quitrahue. Convenio Municipalidad de San Martín de los Andes- Universidad Nacional del Comahue. 21 pp.

8. Brunstein, F. y R. Sarandón. 2004. Evaluación Ambiental Programática del Corredor de los Lagos y del de las Misiones Jesuíticas. Informe Final. Programa de mejora de la competitividad del sector turismo en la Argentina. Sectur-Bid (AR-L 1004). 70 pp.

9. Burkart, R., N. Bárbaro, R. Sánchez y D. Gómez.1999. "Ecorregiones de la Argentina". Administración de Parques Nacionales. Buenos Aires, Argentina.

10. Cabrera, A. 1971. Fitogeografía de la Republica Argentina. Boletín de la Sociedad Argentina de Botánica, Vol. XIV, No 1-2.

11. Calcagno, A. 2003. Gestión del uso sectorial y de la oferta. En: Apuntes del Curso Internacional de Posgrado: Gestión Integrada de los Recursos Hídricos. 16 pp.

12. Carver, S.J. 1991. Integrating Multi-Criteria Evaluation with Geographical Information Systems. International Journal of Geographical Information Systems. 5(3): 321-339. 
13. CEPAL/ILPES/PNUMA. 1986. La dimensión ambiental en la planificación del desarrollo. Tomo 1. Grupo editor latinoamericano, Buenos Aires.

14. Cotler H., A. Priego, C. Rodríguez y C. Guadarrama. 2004. Determinación de Zonas Prioritarias para la Eco-rehabilitación de la Cuenca Lerma-Chapala. Gaceta Ecológica No 71. Instituto Nacional de Ecología, DF México: 79-92.

15. Chuvieco, E. 1996. Fundamentos de teledetección espacial. 3th Edición. Editorial Rialp. SA. Madrid. 567 pp.

16. Convenio DGRH-UNLP (Dirección Nacional de Gestión de los Recursos Hídricos- Laboratorio de Hidrología U.N.L.P).1996. Estudio y Caracterización de los Recursos Hídricos Compartidos con la Republica de Chile. Actividades en Cuencas Prioritarias.119 pp.

17. Convenio DNRRHH-SMA (Dirección Nacional de Recursos Hídricos, Secretaria de Obras Públicas y Comunicaciones de la Nación Municipalidad de San Martín de los Andes). 1994. Plan de Ordenación de la Cuenca Trabunco- Quitrahue. Diagnostico Preliminar. 22 pp.

18. Convenio Secretaria de Obras Públicas y Comunicaciones de la Nación- Dirección Nacional de Recursos Hídricos y Municipalidad de San Martín de los Andes .1995. Plan de Sistematización de los Arroyos Trabunco-Quitrahue. San Martín de los Andes, Provincia de Neuquén. 28 pp.

19. Daily, G. C. 1997. Introduction: What Are The Ecosystem Services. En: Nature's Services: Societal Dependence on Natural Ecosystems. Island Press. Gretchen C: 1-10.

20. Daily, G. C., P. Matson y P. Vitousek. 1997. Ecosystem Services supplied by Soil. En: Nature's Services: Societal Dependence on Natural Ecosystems. Island Press. Gretchen C: 113-132.

21. Daily, H. y Jr. Cobb. 1989. For the Common Good: Redirecting the Economy Toward Community, the Environment, and a Sustainable Future. Beacon Press, Boston.

22. Damiáni J. A. 1999. "Relevamiento Topográfico de los Arroyos Pocahullo, Trabunco y Calbuco", Plan de sistematización de la cuenca Lacar-Río Hua Húm, Dirección de Gestión Ambiental. Municipalidad de San Martín de los Andes. 21pp.

23. Deza, M., A. Giusiano y E. R. García. 1995. Geología de la Subcuenca del Río Pocahullo. Departamento Lacar. Informe de Avance. Ministerio de Producción y Turismo, Dirección Provincial de Minería y Servicio Geológico Neuquino. 7 pp.

24. Dirección General de Estadística y Censos de la Provincia de Neuquén. Provincial de Catastro e Información Territorial.

25. Eastman, J.R. y H. Jiang. 1996. Fuzzy Measures in Multi-Criteria Evaluation, Proceedings, Second International Symposium on Spatial Accuracy Assessment. En: Natural Resources and Environmental Studies. Fort Collins, Colorado. 527-534. 
26. Eastman, J.R., P.A. Kyem, J. Toledano. y W. Jin. 1993. GIS and Decision Making, Explorations. En: Geographic Information System Technology, 4, UNITAR, Génova.

27. Eastman, J. R. 1999. IDRISI 32 Guide to Gis and Image processing. Vol.2. Clark Univrsity

28. Eastman, J. R. 2001. IDRISI 32 Guide to Gis and Image processing. Vol.2. Clark Univrsity.

29. Eastman, J R. 2003. Idrisi Kilimanjaro. Guide to Gis and Processing. Clark University.

30.EPA. Environmental Protection Agency . 1980. Water Quality Criteria Documents. Part V . Availability Federal Register 45 (231), 79318 - 79379.

31. F.A.O. 2003. Los Bosques y el agua dulce: cuestiones y opciones. Comité de Montes. Roma. COFO-2003/3. En: www.fao.org/DOCREP/MEETING/005/Y8212S.HTM\#P19_575

32. Gabellone, N. A, R. Sarandón y C. Claps. 2003. Caracterización y zonificación ecológica de la cuenca del río Salado. En: Inundaciones en el área pampeana. Editorial de la Universidad de La Plata. (5): 36pp.

33. Gámir Orueta, Ruiz Pérez y Seguí Pons .1994. Practicas de análisis espacial. Ed Oikos-tau. Barcelona. 384 pp.

34. Gaviño Novillo, J. M. y R. Sarandón. 2002. Evaluación de Impactos Ambientales. En: Curso a distancia organizado por AIDIS (Asociación de Ingeniería Sanitaria y Ambiental) y Eductrade.

35. Guerrero Borges, V., R. Sarandón y G. Placci. 2005. Implementación de sistemas de información y sistemas soportes de decisiones en el ordenamiento territorial de áreas críticas para la conservación de la naturaleza. III Seminario Internacional: La Interdisciplina y el Ordenamiento Territorial. Formato digital.

36. Guerrero Borges, V., R. Sarandón y M. A. Giraut. 1999. El uso de los sistemas de información geográfica como herramienta para la evaluación y monitoreo de los recursos bióticos. Jornadas regionales sobre estrategias de conservación de fauna y flora amenazada. La Plata, Argentina.

37. Hernández, L. 2003. Percepciones sociales sobre los servicios ecosistémicos en dos comunidades aledañas a la reserva de la biosfera Chamela-Cuixmala, Jalisco. Tesis de grado. Universidad Michoacana de San Nicolás de Hidalgo. Facultad de Biología. 173 pp.

38. Klir, G.J. y B. Yuan. 1995. Fuzzy Sets and Fuzzy Logic: Theory and Application. Prentice-Hall, New Jersey.

39. Malczewski, J. 1999. GIS and Multicriteria Decision Analysis. Wiley, New York. 392 pp.

40. Massam, B. 1988. Multi-criteria decision making techniques in planning. Progress in Planning 30 (1): 1-84.

41. MEA. Millennium Ecosystem Assessment. 2005. Ecosystems and Human Well-being: Synthesis. Island Press. Washington, DC. 137 pp. 
42. Miltner, R., D. White y C. Yoder. 2004. The biotic integrity of streams in urban and suburbanizing landscape. Landscape and urban plannig. (69): 87-100.

43. Mitsch, W.J., J.K. Cronk, X. Wu y R.W Nairn. 1995. Phosphorus retention in constructed freshwater riparian marshes. Ecologycal Applications. (5): 830-845.

44. Monjeau, A., S. Anchorena, V. Montóni, J. Márquez, D. Alcalde, A. D iorio, H. Galván, C. Delholm, A. Di Vicenio y F. Gonzáles. 2005. Perfíl de Área Protegida, Argentina, Parque Nacional Lanín. Parks Watch, Fortaleciendo las áreas protegidas para conservar la biodiversidad. 65 pp.

45. Mui Hou, P. Y M. Minoura. 2004. A GIS- based multicriteria decisión making approach to forest conservations planning at a landscape scale: a case study in the Kinabalu Area, Sabah, Malasya. Landscape and Urban Planning (71): 207-222.

46. Naiman, R. y H Decamps. 1990. The Ecology and Management of Aquatic-Terrestrial Ecotones. UNESCO MAB, Parthenon, Paris.

47. Naiman, R, H Decamps y M. McClain M. 2005. Riparia: Ecology, Conservation, and Management of Streamside Communities (Aquatic Ecology) (Aquatic Ecology) (Hardcover). Elsevier. 413 pp.

48. Otero, A. y E. Gallego. 2008. Evolución del uso de la tierra privada en los Parque Nacionales. Estudio de caso: El Parque Nacional Lanín. Revista Digital Mundo Urbano. (29). En: http://www.mundourbano.unq.edu.ar

49. Parrish, J.D, D. Braun y R. Unnasch. 2003. Are We Conserving What We Say We Are? Measuring Ecological Integrity within Protected Areas. BioScience 851 (53): 9.

50. Pedrozo, F., N. Pérez, R. Rapacioli y H. Botta H. 1993. Informe Plan de Muestreo de la Cuenca del Arroyo Pocahullo y Lago Lacar $2 \mathrm{da}$. Etapa. Provincia del Neuquén Comité Consultivo Técnico para el Saneamiento del Lago Lacar. 30 pp.

51. Petts, G. E. 1984. Impounded Rivers: Perspectives for Ecological Management. Wiley, Chichester.

52. Pusey, B. J. y A. H. Arthington. 2003. Importance of the riparian zone to the conservation and management of freshwater fish: $A$ review. Marine and Freshwater Research (54):1-16.

53. Raisin, G.W. 1996. The role of small wetlands in catchment management: their effect on diffuse agriculture pollutants. Int. Rev. Ges. Hydrobiol. (81): 213-222.

54. Ross, T. 1995. Fuzzy Logic With Engineering Applications. McGrawHill, New York.

55. Saaty, T.L. 1977. A Scaling Method for Priorities in Hierarchical Structures. Math. Psychology. (15): 234-281.

56. Sánchez, O. 2003. Conservación de ecosistemas templados de Montaña en México. Instituto Nacional de Ecología. 315 pp. 
57. Sarandón, R., J. M. Gaviño Novillo y M. A. Giraut. 1997. El uso de indicadores en evaluaciones de impacto ambiental. Jornadas de Comunicaciones Científicas de la FCNyM - UNLP. La Plata, Argentina.

58. Sarandón, R. J. M. Gaviño N y M. A. Giraut. 1999. Indicadores ambientales aplicados a la evaluación del impacto ambiental de proyectos regionales. XIX Reunión Argentina de Ecología. S. M. de Tucumán, Argentina.

59. Sarandón, R., J. M. Gaviño N. y P. C. Pereyra. 2002. Using Indicators for Environmental Impact Assessment and Management. Proceedings of the IAIA' 01. Cartagena, Colombia. 10 pp.

60. Sarandón, R., P. Kent, I. Albarracín, C. L. Arias, M. Denadei, O. Dethier, C. Fiorini, A. M. Gomez, P. Losano, M. Mahy, M.E. Sendin y Y. Tochetti. .2003. Modelo de gerenciamiento de la Reserva Natural de Punta Tombo (Chubut, Argentina). Anuario 2003. Facultad de Ciencias Económicas de la Universidad Nacional de la Patagonia San Juan Bosco.

61. Sarandón, R. 1997. Evaluación ambiental regional de la normativa de usos para los valles de Tierra Mayor y Río Olivia. Análisis de los aspectos de la fragilidad ecológica (Provincia de Tierra del Fuego A). Consejo Federal de Inversiones (CFI). Secretaría de Planeamiento y Desarrollo Pcia. de Tierra del Fuego. AIAS. Informe Final.

62. Sarandón, R. 2000. Fundamentos y estrategias para el análisis del ambiente en los estudios de impacto ambiental. Curso de Postgrado en Evaluación del Impacto Ambiental, Maestría en Gestión Ambiental, Universidad Nacional del Litoral. 17 pp.

63. Suarez, S. y G. Olivares. 2006. Política y gestión del desarrollo del turismo en la Ciudad de Neuquén. Trabajos Turiciencia. En: www.turismoymercado.com

64. Tacón Clavaín, A. 2004. Conceptos generales para la conservación de la biodiversidad. Programa de Fomento para la Conservación de Tierras Privadas de la Décima Región. Proyecto CIPMA-FMAM. En: www.parquesparachile.cl/index.php?option=com_docman\&task=cat_vi ew\&gid $=14 \&$ Itemid $=122$

65. Temporetti, P., G. Baffico, P. Pedrozo, M. Guido y M. Diaz M. 2006. Análisis del agua de los arroyos Quitrahue y Trabunco. San Martín de Los Andes-Pcia. Neuquén. ler Informe. 9 pp.

66. Thomas, R.H. y R.J. Huggert. 1980. Modelling in Geography: A Mathematical Approach. Harper \& Row, London.

67. Vitousek, P.M., P.R. Ehrlich y A.H. Matson. 1986. Human appropriation of the products of photosynthesis. BioScience 34 (6): 368-373.

68. Voogd, H. 1983. Multicriteria Evaluation for Urban and Regional Planning. Pion, Ltd., Londres.

69. Vought, L., B. Dahl, J.C.L. Pedersen, J.O. Lacoursiere. 1994. Nutrient retention in riparian ecotones. AMBIO (23): 342-351. 
70. Walther, P. 1986. The meaning of zoning in the management of natural resource lands. Journal of Environmental Management. (22): 331-344.

71. Wetzel, R.G. 1975.Limnology. W.B. Saunders Company. 743 pp.

72. Yager, R.R. 1988. On ordered weighted averaging aggregation operators in multicriteria decision-making. IEEE Transactions on Systems, Man and Cybernetics 18 (1): 183-190.

73. Zalewski, M., G.A. Janauer y G. Jolankai. 1997. Ecohydrology. A new paradigm for the sustainable use of aquatic resources. Technical Documents in Hydrology. UNESCO-IHP, Paris. No.7.

74. Zalewski, M. 2000. Ecohidrology- the scientific background to use ecosystems properties as management tools towoard sustainability of water resources. Ecological Engineering (16): 1-8.

Paginas de Internet consultadas:

http://www.aidisar.org

$h+t p: / / w w w . c h a p e l c o . c o m$

http://esa.sdsc.edu/daily.htm

http://www.fao.org/DOCREP/MEETING/005/Y8212S.HTM

$h+t p: / / w w w . h i d r i c o s a r g e n t i n a . g o v . a r / I n d i c e-L a c a r$

http://www.inforesources.ch/publications_s.htm.

$h+t p: / / w w w . m e d i o a m b i e n t e . g o v . a r$

$h+t p: / / w w w . m u n d o u r b a n o . u n q . e d u . a r$

$h+t p: / /$ www.parquenacionallanin.gov.ar

$h+t p: / / w w w . p a r q u e s p a r a c h i l e . c l$

http://www.turismoymercado.com

$\mathrm{ftp}: / / f t p . g l c f . u m i a c s . u m d . e d u$ 
ANEXO I

\section{Evolución y características de los Sistemas de Información Geográfica}

Para la geografía, la geología, la topografía, la biología y demás ciencias que hacen uso de la información geográfica los Sistemas de Información Geográfica (SIG) han constituido una verdadera revolución para el conocimiento de los elementos y fenómenos que tienen lugar en la superficie terrestre.

En su evolución histórica está mayoritariamente aceptada la existencia de unos periodos más o menos claros y definidos que engloban las distintas fases por las que ha transcurrido la evolución de los Sistemas de Información Geográfica desde su aparición hace casi cuarenta años.

Son los años sesenta la década en la que se inicia la carrera tecnológica de los SIG. En Canadá se desarrolló por primera vez un sistema informático que trabajaba con datos geográficos. Paralelamente, en esta misma década se desarrollaron otros proyectos parecidos en Estados Unidos, como fueron: LUNR and Resource Information System (Bosque, 1992).

Es Estados Unidos donde los SIG van a tener el campo de experimentación adecuado, tanto entre las instituciones públicas como en las privadas, y por ello va a ser en este país donde se desarrollen las aplicaciones de mayor envergadura $e$ importancia.

En Europa, es el Reino Unido donde aparecen algunas de las iniciativas más interesantes. Tal circunstancia ocurre de forma casi paralela en el tiempo a los desarrollados en EE.UU. Luego la Unión Europea también participaría del interés por desarrollar los SIG.

En los años setenta el desarrollo está caracterizado, en general, por una disminución de las iniciativas individuales y un aumento de los intereses a nivel corporativo, especialmente por parte de las instancias gubernamentales y de la administración.

Es en los ochenta cuando ocurre el despegue definitivo y de mayor apogeo de la nueva tecnología. Se da la llamada fase comercial. En este periodo el interés de grandes industrias relacionadas con los SIG crece sobremanera. En la década de los noventa, es cuando los Sistemas de Información Geográfica empezaron a 
difundirse al nivel del usuario doméstico debido a la generalización de las computadoras personales.

Es a partir del año 2000 que el rendimiento de las computadoras aumenta debido a los avances tecnológicos y se consolida la necesidad de paquetes informáticos de información geográfica. Así, se establece una nueva etapa en la evolución de los SIG, sobre todo con la generalización del uso de Internet, que permite la distribución a nivel mundial de la cartografía.

El año 1987 constituye una fecha clave para el análisis del comienzo de esta temática en nuestro país cuando se llevó a cabo la I Conferencia Latinoamericana sobre Sistemas de Información Geográfica en San José de Costa Rica y varios profesionales argentinos asistieron a ella tomando contacto con esta moderna tecnología. La primera reunión nacional de importancia sobre la temática SIG fue realizada por el Instituto Geográfico Militar (IGM) en el año 1990.

Ya en la actualidad el uso de esta herramienta se ha diversificado ampliamente a través de organismos públicos: como el Instituto Nacional de Estadísticas y Censos (INDEC), el Instituto Nacional de Tecnología Agropecuaria (INTA) y la Dirección de Aplicación de Imágenes Satelitarias (DAIS); a nivel municipal, empresarial y por supuesto las universidades públicas y privadas de nuestro país.

La base de datos es central para el sistema: una colección de mapas e información relacionada en formato digital. Debido a que la base de datos se ocupa de las características de la superficie terrestre, puede interpretarse que consiste en dos elementos: una base de datos espaciales que describe la geografía (forma y posición) de las características de la superficie terrestre, y una base de datos de atributos que describe las peculiaridades o cualidades de estas características. Entonces, se puede tener una parcela de propiedad definida en la base de datos espacial y cualidades como su uso de la tierra, dueño, valor de la propiedad, y demás, en la base de datos de atributos.

Debido a la diversidad y complejidad de las variables geográficas, para interpretar los fenómenos espaciales debe comprenderse la naturaleza de los objetos geográficos. En ellos se distinguen tres componentes: un componente espacial que describe la posición de los objetos geográficos respecto a un sistema de coordenadas conocido y las relaciones locacionales entre los objetos; un componente temporal en el cual se asigna un determinado estado posicional y temático para un objeto en un determinado instante, y un componente temático que hace referencia al tipo de atributo que definen a un objeto geográfico (color, tipo de ocupación, vegetación, etc.) (Gámir Orueta et al., 1994).

Los Sistemas de Información Geográfica se construyen sobre un modelo de la realidad espacial. Un SIG almacena dos tipos de datos que se encuentran en los mapas: las definiciones geográficas de las características de la superficie terrestre y los atributos o cualidades que esas características poseen. No todos 
los sistemas usan la misma lógica, sin embargo, usan una o la combinación de ambas técnicas fundamentales de representación cartográfica: vectorial y raster (Figura 1).

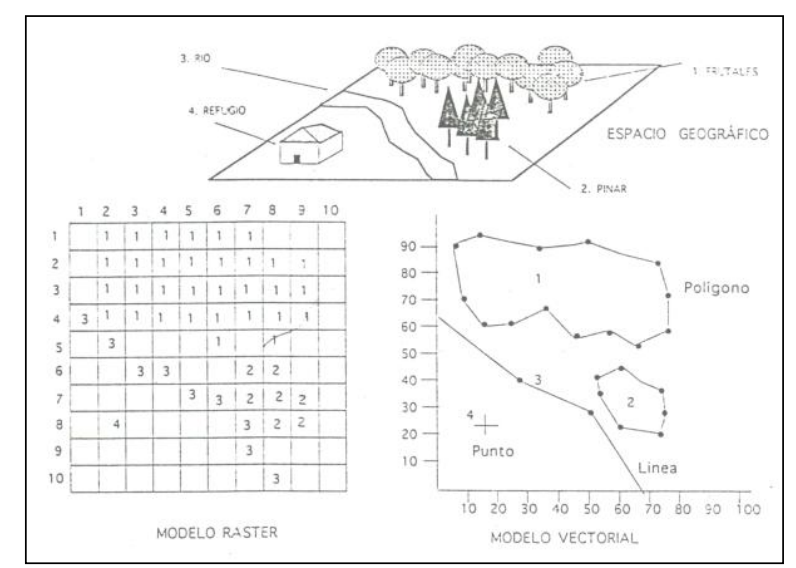

Figura 1: Ejemplos de formatos raster y vectorial. Fuente: Gámir Orueta et. al. 1994.

EL modelo vectorial considera que el espacio geográfico es continuo y distingue tres tipos de información: puntual, representada por un nodo con una localización geográfica $(x, y)$ y una serie de atributos; lineal: representada por un segmento $o$ arco que une dos nodos y una serie de atributos; y zonal: representada por un polígono que a su vez esta constituido por nodos y arcos y que posee un conjunto de atributos. Ejemplos de archivos vectoriales son los shapefiles y coberage.

El modelo raster se fundamenta en la división del espacio geográfico en el uso de una malla regular para definir un sistema de polígonos uniformes. La morfología de la malla es poligonal y homogénea y su forma generalmente es cuadrada (píxel). La referencia espacial de cada píxel se identifica por un par de coordenadas $x$ e $y$. Ejemplos de archivos rasters son los IMG, Tiff, Grids, JPG, etc.

Los sistemas raster son por lo general datos intensivos debido a que éstos deben guardar datos en cada ubicación de celda, sin importar si la información que tiene la celda es de interés o no.

Como resultado, los sistemas raster tienen más poder analítico que sus pares vectoriales en el análisis de espacio continuo y son idealmente apropiados para el estudio de datos que están en constante cambio sobre el espacio como el terreno, la biomasa vegetal, las lluvias, etc.

Como consecuencia, los sistemas raster tienden a ser muy rápidos en la evaluación de problemas que implican varias combinaciones matemáticas de los datos en capas múltiples. Además, debido a que las imágenes satelitales emplean una estructura 
raster, la mayoría de estos sistemas pueden incorporar con facilidad estos datos, y algunos brindan completas capacidades de procesamiento de imágenes.

Mientras los sistemas raster están predominantemente orientados al análisis, los sistemas vectoriales tienden a estar más orientados a la gestión de las bases de datos. Los sistemas vectoriales son bastante eficientes en su almacenamiento de datos cartográficos porque sólo guardan los límites de las características, y no aquello que se encuentra dentro de esos límites. 
ANEXO II

\section{Mapa de Tipos Cobertura de las subuencas de los arroyos Trabunco-Quitrahue}

\section{Introducción:}

El mapa de cobertura fue realizado a través de un proceso llamado clasificación. Clasificar digitalmente una imagen implica categorizar una imagen multibanda. Esto significa reducir la escala de medida, de una variable continua (los valores originalmente obtenidos por el sensor) a una escala nominal o categórica (Chuvieco 1996).

Clasificar es asignar los píxeles originales de una imagen a un conjunto de categorías. Dependiendo del número digital, ND, (el valor que captura el sensor) de ese píxel en cada una de las distintas bandas, será asignado a una u otra clase.

Existen dos tipos principales de clasificación: la clasificación no supervisada, donde el usuario fija el número inicial de clases que desea obtener y luego el software asigna los píxeles automáticamente a las distintas clases en base a operaciones estadísticas, y la clasificación supervisada, donde el conocimiento previo de la zona de estudio permite al usuario identificar áreas representativas de cada categoría (áreas de entrenamiento).

A partir de ahí, el software calcula las estadísticas elementales de cada categoría (media, rango, desvío estándar, etc.), a partir de los ND que definen a cada una de las clases, para luego asignar el resto de los píxeles de la imagen a una de esas categorías en función de sus ND. A continuación se detalla la metodología empleada para la elaboración del mapa de coberturas y los resultados de las mismas.

El área de estudio comprende las subcuencas de los Arroyos Trabunco-Quitrahue cuya superficie es de 4.927 hectáreas y es parte de una unidad mayor, la cuenca del Arroyo Pocahullo el cual atraviesa la ciudad de San Martín de los Andes y desemboca en el Lago Lacar (Pcia. de Neuquén, R. Argentina). 


\section{Materiales y métodos}

Para la elaboración del mapa de cobertura se utilizó el programa ERDAS IMAGINE 8.5 y el programa ArcView 3.2. Se utilizó la imagen satelital Lansat 7 ETM+ correspondiente a enero del 2007, la cual fue georreferenciada y reproyectada al sistema de coordenadas Gauss Krüger Faja1, datum Campo Inchauspe.

Se recortó la imagen delimitando la zona de estudio; se elaboró una máscara para eliminar las áreas y coberturas que generarán conflicto durante la clasificación. Para ello se eliminaron de la imagen las porciones correspondientes al área del lago Lacar, caminos; centros urbanos (ciudad de San Martín de los Andes y Barrio Covisal) y vivero forestal A.L.P.L.A (Figura 1).

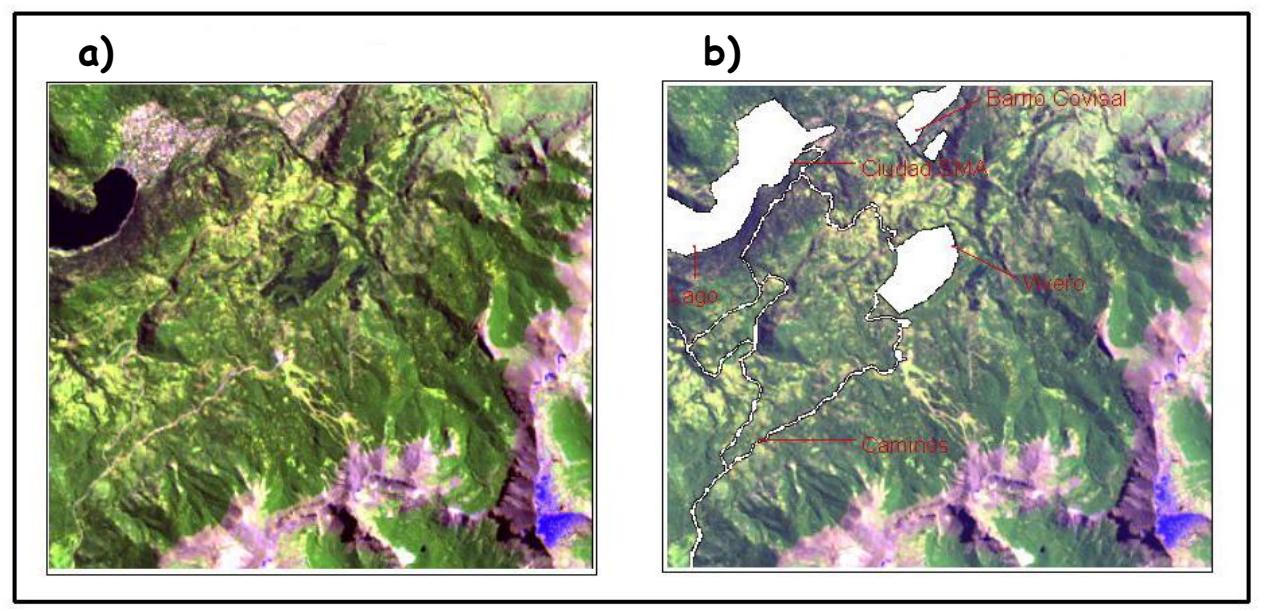

Figura 1: Imagen Landsat (a) y Máscara (b).

Para la clasificación se realizó una combinación del método supervisado y el método no supervisado ya que las firmas creadas en los dos entrenamientos pueden unirse y agregarse unas con otras.

Como primer paso se realizó una clasificación no supervisada de la imagen, el resultado del entrenamiento no supervisado es un conjunto de firmas que define a una muestra de entrenamiento o conglomerado. Cada firma corresponde a una clase y se usa con una regla de decisión para asignar los píxeles del archivo de la imagen a una clase.

Los conglomerados son definidos con un algoritmo de aglomeración que usa mucho de los píxeles de un archivo de datos de entrada para su análisis. La aglomeración se llevó a cabo a través del método ISODATA, el cual usa las distancias espectrales e interactivamente clasifica los píxeles, redefine el criterio para cada clase y clasifica nuevamente, hasta que los patrones de distancia espectral de los datos emergen gradualmente. 
El proceso comienza con un número especificado de conglomerados arbritarios, el número de conglomerados a ser considerados es la base para una clase y es el máximo valor de clases a formarse.

Para el caso del mapa de coberturas se generaron 100 clases por lo tanto el resultado de la clasificación fue una capa temática raster (Figura 2) y un archivo de firmas, que pueden ser posteriormente borradas, unidas o adicionadas a otro conjunto de firmas. Luego se identificaron las clases espectrales y se reagruparon para definir clases temáticas, con lo cual, se vio que ciertas clases temáticas como el pastizal se confundían con la clase suelo desnudo.

Como segundo paso, con el fin de poder discriminar mejor estas dos clases se realizó una clasificación supervisada de la imagen original, utilizando la combinación de bandas 5-4-3. Mediante esta técnica se pueden seleccionar píxeles de la imagen que representan patrones que reconoce, o puede identificar con la ayuda de otras fuentes. Para la realización de esta técnica se debe tener un conocimiento previo de la zona de estudio.

Se realizó la selección de las muestras de entrenamiento (conjunto de píxeles que representan una clase potencial), luego con los niveles digitales de éstos se calculan las estadísticas de los píxeles de la muestra para crear una firma paramétrica de la clase. Las muestras de entrenamiento se determinaron mediante la definición de polígonos en la imagen a partir de examinar la misma y dibujar los polígonos alrededor de los sitios de interés. Así, el área dentro de los polígonos se usará para crear una firma.

Una vez creadas las firmas que en este caso fueron 38, se aplicó la regla de decisión de mínima distancia con la cual se llevó a cabo la clasificación, el resultado fue una capa temática (Figura 2) y un archivo de firmas.

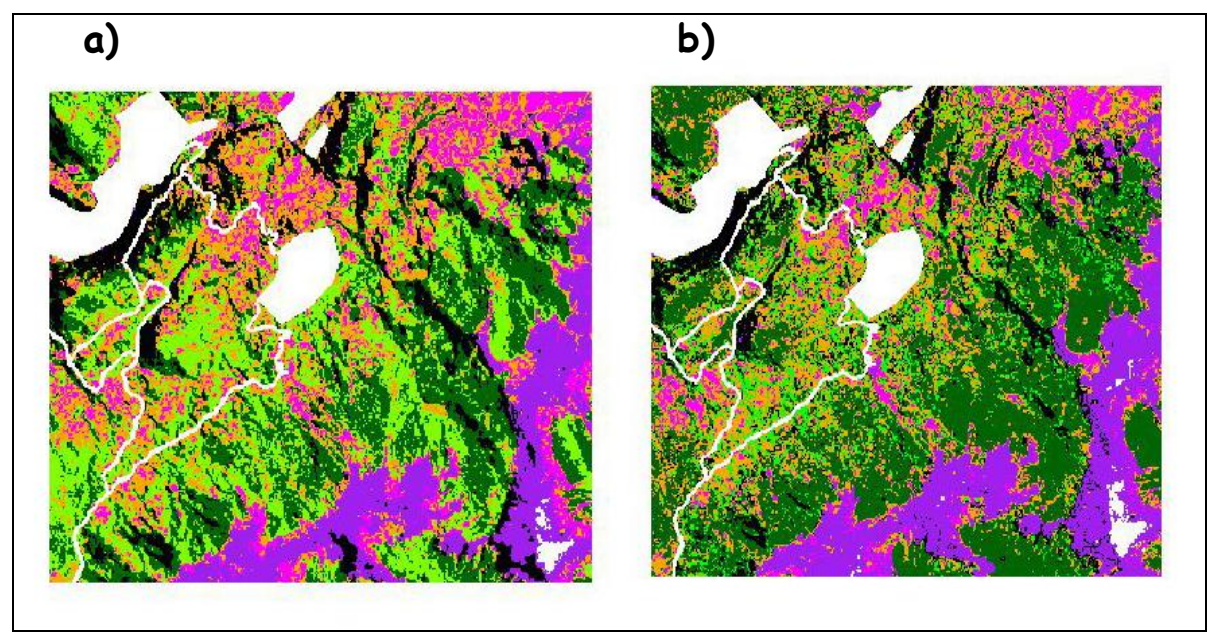

Figura 2: Imágenes clasificadas con el método supervisado (a) y no supervisado (b). 
En tercer lugar se llevó a cabo una nueva clasificación utilizando los archivos de firmas de la clasificación no supervisada y la clasificación supervisada, con el fin de poder definir mejor las clases pastizal y suelo desnudo.

De la imagen clasificada final con un total de 138 clases se reagruparon a través de la manipulación del archivo de firmas y quedaron definidas las siguientes clases preliminares: bosque en sombra, bosque de Lenga, bosque mixto, suelo desnudo, pastizal, roca expuesta y nieve.

- Incorporación de las clases bosque ripario y vegetación riparia.

La vegetación riparia o ribereña son zonas de transición semiterrestres a áreas influenciadas por el agua dulce, normalmente extendiéndose desde los bordes de los cuerpos de agua hasta los bordes de las comunidades litorales (Naiman et al., 2005). Para poder discriminar esta nueva clase e incorporarla al mapa de coberturas se procedió de la siguiente manera:

En primer lugar se debió determinar el ancho de los arroyos, con lo cual se contaba solo con la siguiente información: 28 perfiles transversales de la zona de la desembocadura del arroyo Trabunco (Damiáni, 1999). Para esta zona y al momento de tomar la medición, el valor promedio del cauce del arroyo con agua arrojó un valor de 9,20 metros de ancho, siendo el valor mínimo 4,19 y el máximo 25,28 metros. Tomando los márgenes del arroyo los valores fueron de 3, 96 la media; 6,47 y 34,65 metros los valores mínimos y máximos.

Si bien estos valores fueron tomados en un momento dado, bajo un régimen especifíco y en una porción muy pequeña de toda la longitud del arroyo Trabunco, nos da una idea de las dimensiones del mismo.

En segundo lugar, existen normativas internacionales que protegen la vegetación de los márgenes de los cuerpos de agua; para el caso de la provincia de Neuquén (la cual compete a nuestra área de estudio) no se ha encontrado ninguna referencia de las mismas, pero sí en el caso de otras provincias como Misiones y Tierra del Fuego.

Debido que los ecosistemas de las subcuencas Trabunco-Quitrahue y de Tierra del Fuego corresponden a la ecorregión de los bosques andino patagónicos, se tomaron los valores expresados en el anexo 1 del decreto 852/95 de la ley Provincial 145 que establece la prohibición de todo tipo de aprovechamiento en masas forestales ubicadas a una distancia menor a: 100 metros de las orillas de lagos, lagunas, costa marítima y rutas nacionales; 50 metros de rutas provinciales, ríos, arroyos, vegas y túrbales; $y$ en bosques localizados en terrenos con pendientes superiores a 25 grados. 
Por lo tanto, se estableció para los arroyos de la cuenca el valor de 10 metros de ancho de cauce con agua, y el de 50 metros desde el cauce, para limitar la extensión de la vegetación ribereña.

En tercer lugar, se elaboró un buffer de 60 metros sobre los arroyos, luego con la función mask del programa ERDAS IMAGINE 8.5 extrajo de la imagen ya clasificada. Esta nueva imagen fue exportada al programa ArcView y transformada a un archivo grid (Figura 3).

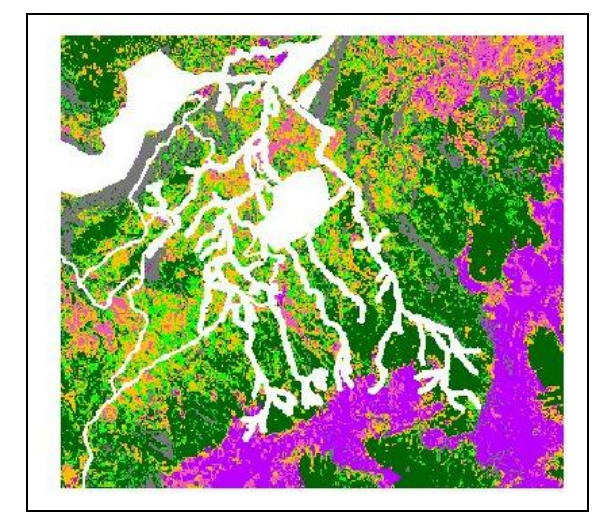

Figura 3: Imagen clasificada con la extracción de la zona buffer

A su vez, se elaboraron las coberturas de bosque ripario y vegetación riparia (Figura 4) a partir del archivo buffer y la imagen clasificada que contenía las clases parciales de bosque de lenga, bosque mixto, bosque en sombra y pastizal. De esta manera se generó un archivo grid conteniendo las coberturas mencionadas que se ubican a una distancia de 60 metros a partir de los arroyos. Esto fue realizado con las funciones clip, y reclassify del módulo de análisis espacial del programa ArcView.

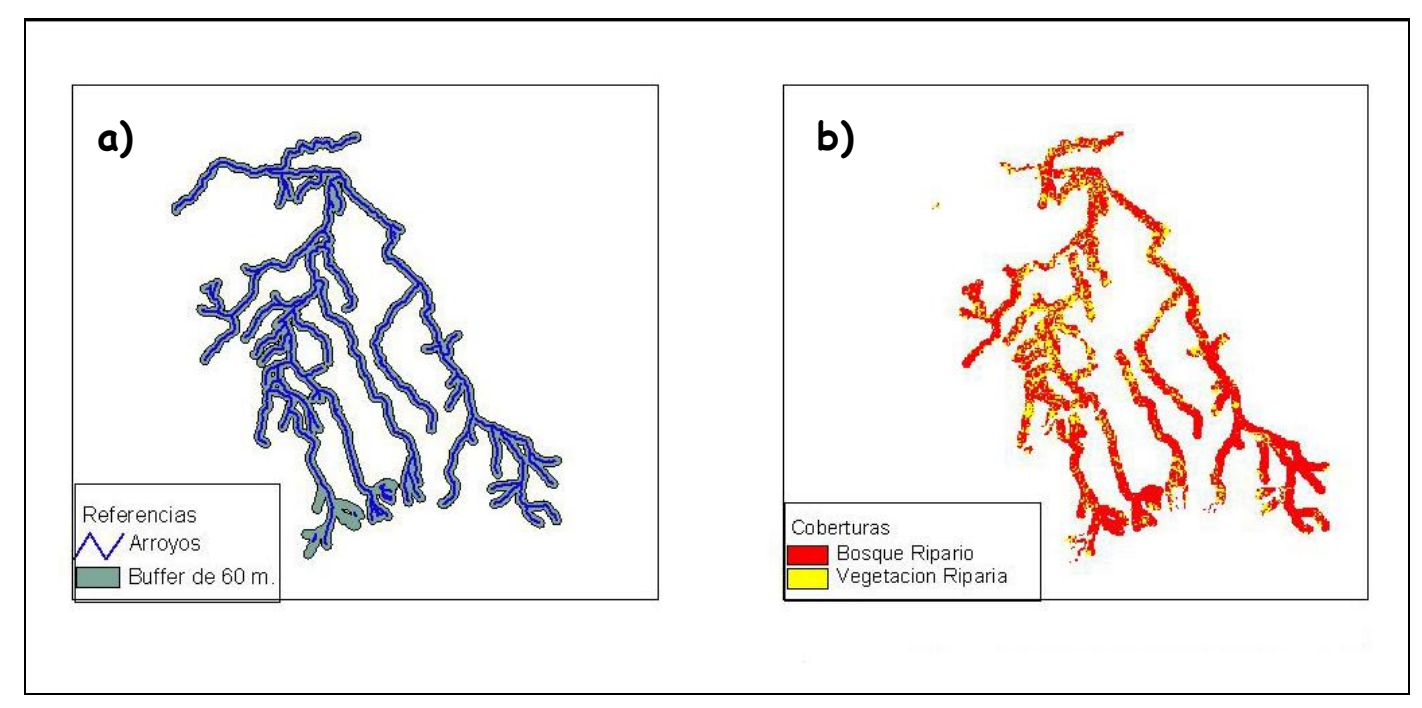

Figura 4: Cobertura de bosque ripario (a) y vegetación riparia (b) de los arroyos Trabunco y Quitrahue. 
Finalmente, se creó un mosaico entre los archivos que contenían las coberturas parciales y las coberturas de bosque y vegetación riparia.

\section{Resultados:}

Como resultado de todos los procedimientos anteriormente detallados, quedó conformado el mapa de coberturas de las subcuencas de los arroyos TrabuncoQuitrahue correspondiente a febrero del 2007 (Figura 5). El mismo contiene ocho tipos de coberturas:

Bosque de Lenga: Ecosistema natural dominado por Lenga.

Bosque Mixto: Ecosistema natural conformado por especies leñosas como Ñire, Lenga, Radal y cañaverales.

Bosque de Coníferas. Ecosistemas naturales e implantados, conformado por especien nativas y exóticas.

Bosque ripario: bosque ubicado a distancias de hasta 60 metros de los cuerpos de agua.

Pastizales: pequeñas fragmentos de vegetación herbácea.

Vegetación Riparia: vegetación herbácea ubicada a distancias de hasta 60 metros de los cuerpos de agua.

Suelo desnudo: Áreas desmontadas donde no se observa vegetación.

Roca/Nieve: Afloramientos de roca madre y nieve. 


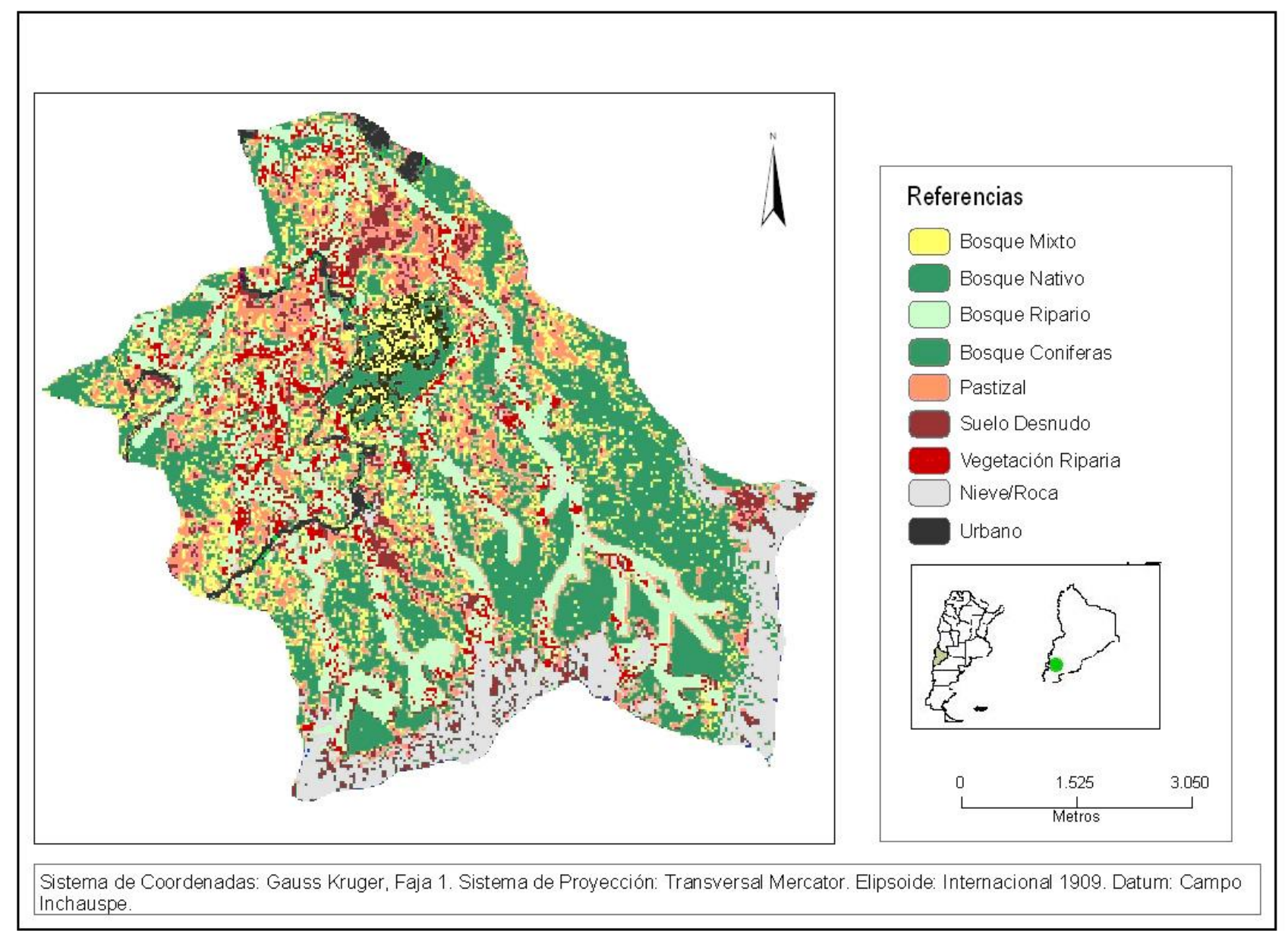

Figura 5: Mapa de coberturas de las subcuencas de los arroyos Trabunco-Quitrahue correspondiente a febrero del 2007. 
